\title{
Reactions of nitrilimines with heterocyclic amines and enamines. Convenient methodology for synthesis and annulation of heterocycles
}

\author{
Ahmad S. Shawali*a and Mastoura M. Edrees ${ }^{\mathrm{b}}$ \\ ${ }^{a}$ Department of Chemistry, Faculty of Science, University of Cairo, Giza, Egypt \\ ${ }^{b}$ National organization for drug control and research, dokki, Giza, Egypt \\ E-mail: $\underline{\text { as_shawali@yahoo.com }}$
}

\begin{abstract}
This review summarizes the reactions of nitrilimines, genearted in situ by base-catalyzed dehydrohalogenation of the respective hydrazonoyl halides, with aminoazoles, aminoazines and various types of enamines. It also presents the highlights of recent developments in the utility of such reactions for synthesis of a variety of heterocycles which are not obtainable by other synthetic means. Such reactions provide convenient strategies for synthesis and annulation of heterocycles. It covers the literature from 1985 to mid 2006.
\end{abstract}

Keywords: Aminoazoles, aminoazines, 1,3-dipolar cycloadditions, hydrazonoyl halides

\section{Contents}

1. Introduction

2. Reactions with aminoazoles

2.1 Aminopyrazoles

2.2 Aminoimidazoles

2.3 Amino isoxazoles

2.4 Aminothiazoles

2.5 Aminotriazoles

2.6 Aminotetrazoles

3. Reactions with aminoazines

3.1 Aminopyridines

3.2 Aminopyrimidines

3.3 Aminopyrazines

3.4 Aminotriazines

4. Reactions with enamines 
4.1 Acyclic enamines

4.2 Endocyclic enamines

4.3 Exocyclic enamines

4.4 Heterocyclic enamines

4.5 Ketene aminals

5. Conclusions

6. References

\section{Introduction}

Ever since the first identification of nitrilimines 2, their chemistry has developed dramatically during the past 40 years. Their ease of generation from different precursors coupled with the highly regio- and stereoselective nature of their cycloaddition reactions has resulted in extensive use as key synthons in many heterocyclic syntheses. Furthermore, hydrazonoyl halides $\mathbf{1}$ are the most commonly used precursors of nitrilimines due to their stability and their easy accessibility from different precursors. Conversion of $\mathbf{1}$ into $\mathbf{2}$ is usually accomplished by treatment of the former 1 with a suitable base such as triethylamine. The mechanism of such a conversion has been reported by Shawali et al. ${ }^{1-3}$ At present, a huge variety of hydrazonoyl halides have been described and several aspects of their chemistry have been reviewed by Shawali et al. ${ }^{4-9}$ In addition, enamines $\mathbf{3}$ have proved to be versatile synthetic precursors for synthesis of heterocycles and natural products. Several review articles covering their chemistry have appeared in literature. ${ }^{10-17}$ A survey of these reviews together with those dealing with the chemistry of nitrilimines and their hydrazonoyl halides precursors reveals that little focus, if any, has been made hitherto on reactions of nitrilimines with enamines and heterocyclic amines. Our intention in this review is to remedy this situation through presenting the highlights of such reactions that have been reported from our laboratory and from others within the period from 1985 to mid 2006 and contained in Chemical Abstracts. Reactions already reported before 1985 will not be included in this review unless required for the sake of congruity. Also, reactions of heterocyclic amines that lead to the formation of arylazoheterocycles will not be covered here as such reactions have been surveyed in a recent authorative review by Shawali et al in $2003 .{ }^{9}$ The usefulness of the reactions to be reviewed herein arises from their versatility and remarkable utility in annulation and ring transformations of various heterocycles (Scheme 1) . 


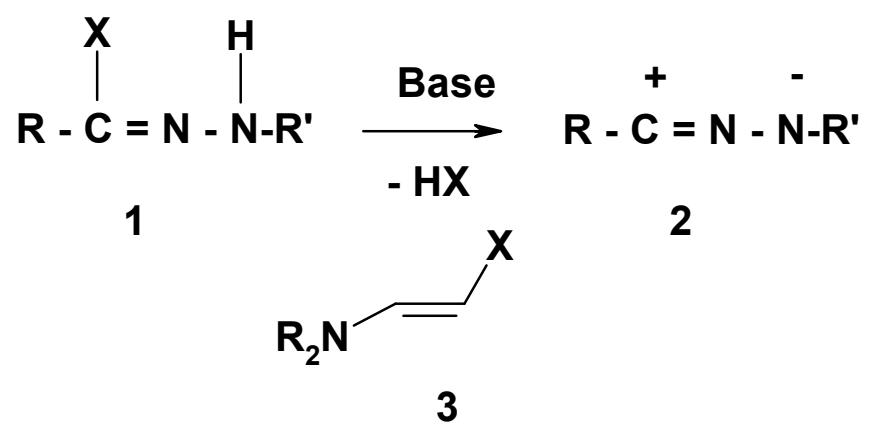

Scheme 1

\section{Reactions with aminoazoles}

\subsection{Aminopyrazoles}

Reactions of 3-aminopyrazole derivatives $\mathbf{4 A}^{18,19}$ and $\mathbf{4 B}^{20}$ with $C, N$-diarylnitrilimines were reported to give the respective pyrazolo[5,1-c][1,2,4]triazoles (5) in 24-50\% yield and (6) in 70 $85 \%$ yield. However, reaction of $\mathbf{4 A}$ with $N$-phenyl- $C$-acetylnitrilimine was reported to yield the phenylazo derivative 7 in $82 \%$ yield (Scheme 2 ). ${ }^{18}$
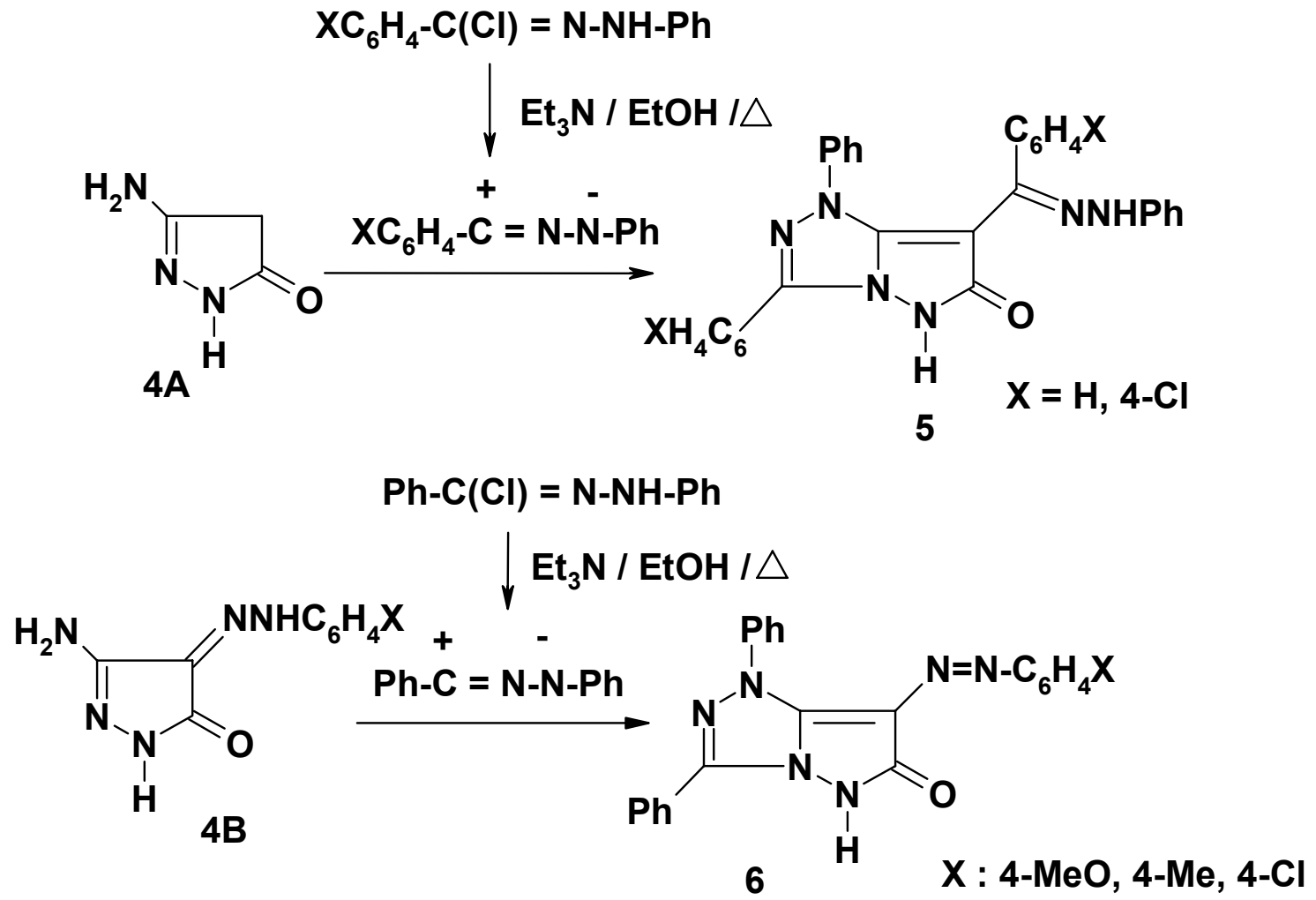


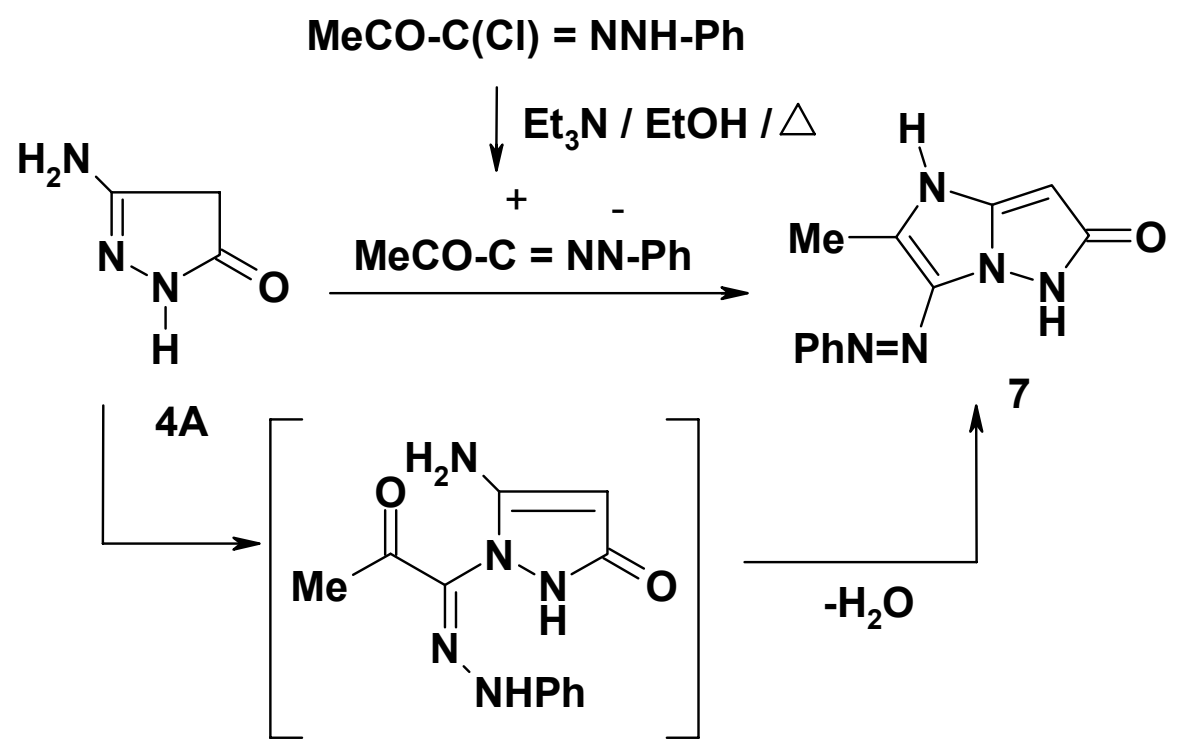

Scheme 2

Similar reaction of 4-amino-2,3-dimethyl-1-phenyl-5(2H)-pyrazolone 8 with each of $\mathrm{C}, \mathrm{N}$ diarylnitrilimines and $C$-acetyl- $N$-arylnitrilimines was reported to give the respective amidrazones 9 in 60-80\% yields (Scheme 3). ${ }^{19,21,22}$

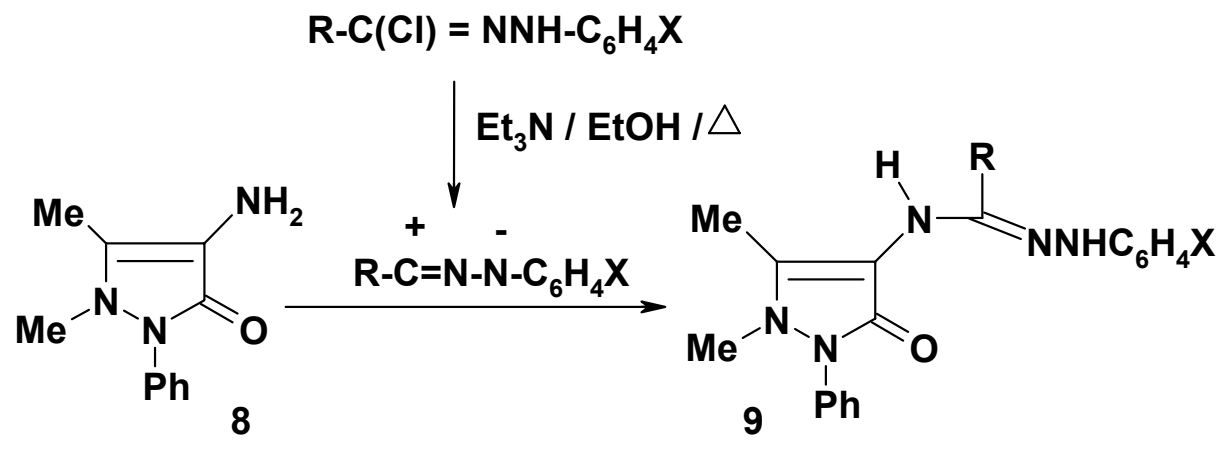

$\mathrm{R} / \mathrm{X}: \mathrm{Ph} / \mathrm{H}, 4-\mathrm{MeOC}_{6} \mathrm{H}_{4} / \mathrm{H}, \mathrm{MeCO} / \mathrm{H}, \mathrm{MeCO} / 4-\mathrm{Me}$,
$\mathrm{MeCO} / 4-\mathrm{Br}, \mathrm{MeCO}$ 4- $\mathrm{NO}_{2}, \mathrm{MeCO} / 4-\mathrm{MeO}$

\section{Scheme 3}

Reactions of $C, N$-diarylnitrilimines with 5-amino-3-substituted-pyrazoles $\mathbf{1 0}$ were reported to yield the pyrazolo[5,1-c][1,2,4]triazole derivatives 11 via elimination of ammonia from the initially formed amidrazone intermediate ${ }^{19,22}$ The latter products were also produced by the reaction of the same nitrilimines with the respective 3-substituted-4,5-dihydropyrazol-5-one 12 (Scheme 4). ${ }^{22}$ 


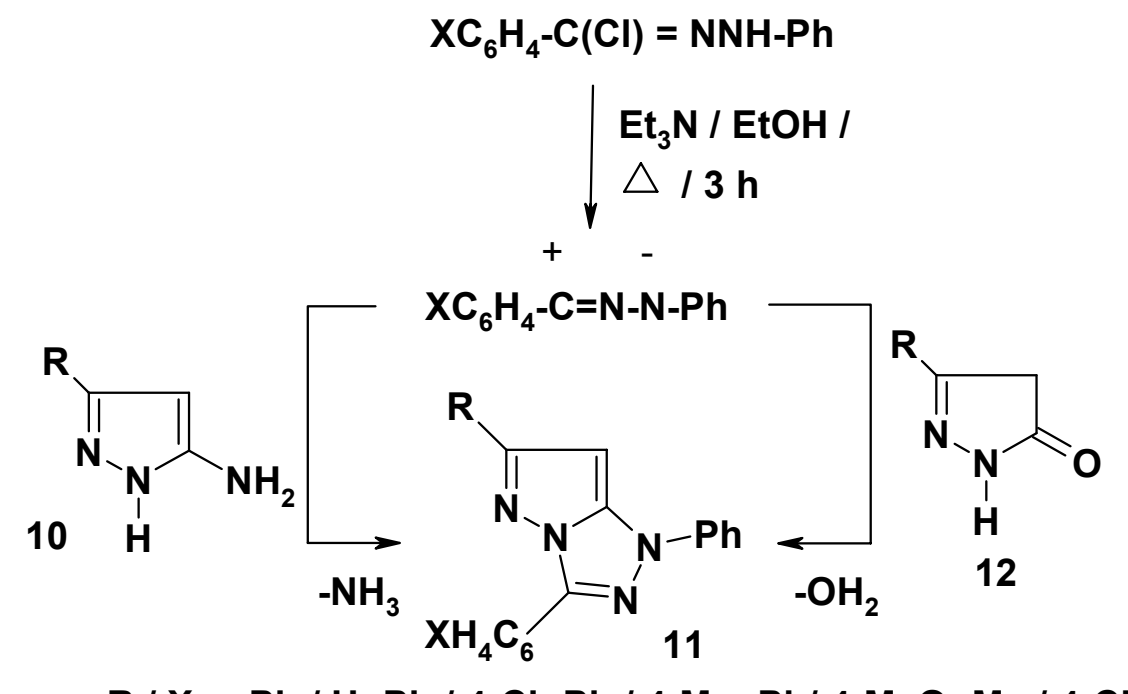

$\mathrm{R} / \mathrm{X}=\mathrm{Ph} / \mathrm{H} ; \mathrm{Ph} / 4-\mathrm{Cl} ; \mathrm{Ph} / 4-\mathrm{Me} ; \mathrm{Ph} / 4-\mathrm{MeO} ; \mathrm{Me} / 4-\mathrm{Cl}$

\section{Scheme 4}

Different results were reported for the reaction of 3-phenyl-5-aminopyrazole $(10 \mathrm{~A})$ with $C$ ethoxycarbonyl- $N$-arylnitrilimine. For example, in one report ${ }^{23}$ it was indicated that such a reaction yielded the pyrazolo[3,4-c]pyrazole derivative 13. In another report ${ }^{24}$ it was found that such a reaction yielded a product that was assigned the structure of imidazo[1,2- $b]$ pyrazole derivative 14 and not the isomeric structure 15, because the isolated product was recovered unchanged after being subjected to an oxidation treatment. ${ }^{24}$ Compounds of type $\mathbf{1 5}$ are expected to be oxidized readily to give the respective arylazo derivatives $\mathbf{1 6}$ ( Scheme 5). ${ }^{25-27}$ 


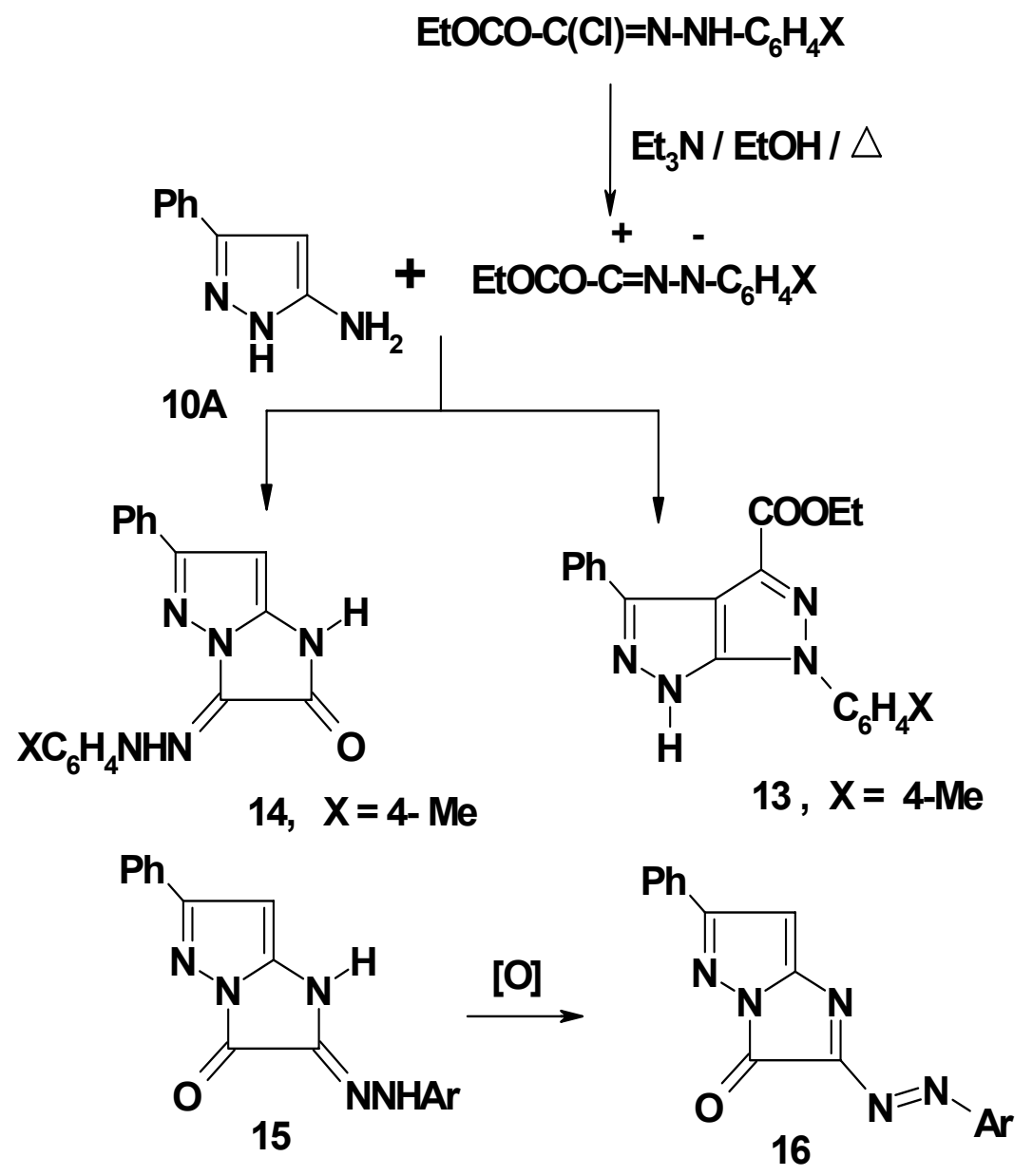

Scheme 5

Also, different results were reported for reactions of 3-phenyl-5-aminopyrazole 10A with $C$ acetyl- $N$-aryl-nitrilimines. Thus, in three reports $19,22,24$ it was indicated that such a reaction afforded the respective imidazo[1,2- $b]$ pyrazoles 17 . In another report ${ }^{28}$ this reaction was reported to yield the respective pyrazolo[3,4-c]pyazole derivatives 18 (Scheme 6). 


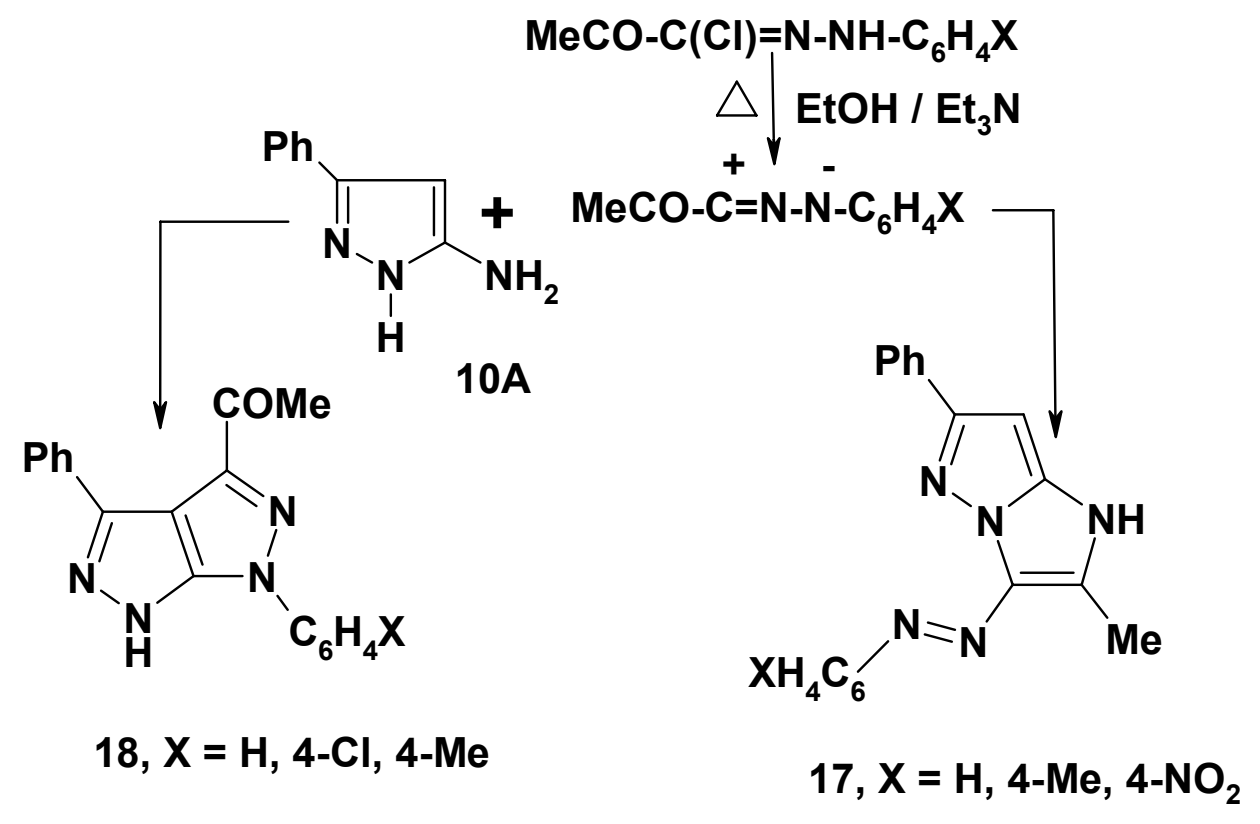

Scheme 6

Reaction of $C$-aroyl- $N$-phenylnitrilimine with 5-amino-3-methylpyrazole (10B) afforded a mixture of the 1,3-adducts 19 and $20{ }^{29}$ Heating 19 in ethanol in the presence of anhydrous sodium acetate afforded $\mathbf{2 1}$ in $52 \%$ yield (Scheme 7 ). ${ }^{29}$

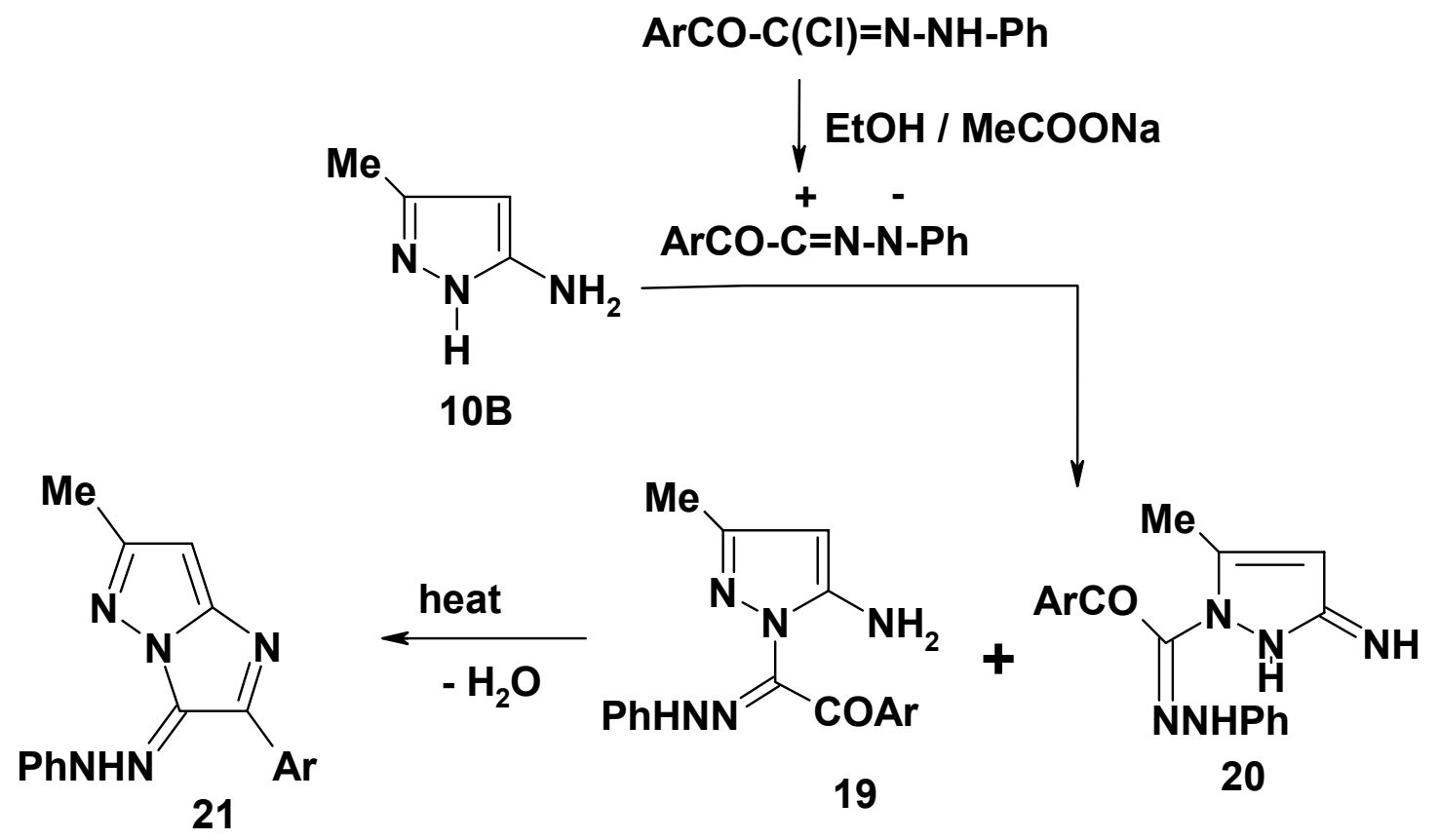

21, $\mathrm{Ar}: 2,4-\mathrm{Cl}_{2} \mathrm{C}_{6} \mathrm{H}_{3}$

Scheme 7 
Reactions of 5-amino-1,3-diphenylpyrazole (10C) with $C$-acyl- $N$-arylnitrilimines were reported to give the respective amidrazones 22 (Scheme 8). ${ }^{19,22,28}$

$\mathrm{RCO}-\mathrm{C}(\mathrm{Cl})=\mathrm{N}-\mathrm{NHC}_{6} \mathrm{H}_{4} \mathrm{X}$

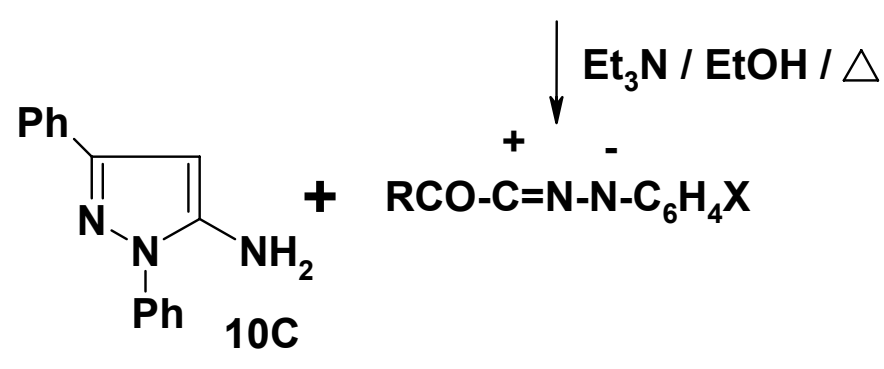

$\mathrm{R} / \mathrm{X}: \mathrm{Me} / 4-\mathrm{NO}_{2}, \mathrm{O}\left(\mathrm{CH}_{2}\right)_{4} \mathrm{~N} / \mathrm{H}$

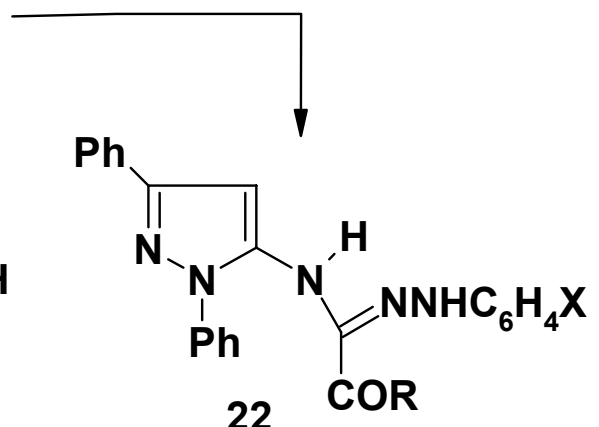

\section{Scheme 8}

Analogous reactions of 5-amino-3,4-disubstituted pyrazoles with nitrilimines gave products that depend on the type of the substituents present as well as the type of nitrilimine used. For example, $C$-acetyl- $\boldsymbol{N}$-arylnitrilimines ${ }^{18,21}$ were reported to react with 5 -amino-4bromo-3-phenylpyrazole $\mathbf{1 0 D}$ to give the respective amidrazones 23 as end products in 50$90 \%$ yields. ${ }^{18,21}$ Similar reaction of $\mathbf{1 0 D}$ with $C, N$-diarylnitrilimines afforded 24 in 28 $60 \%$ yields (Scheme 9). ${ }^{18,19}$

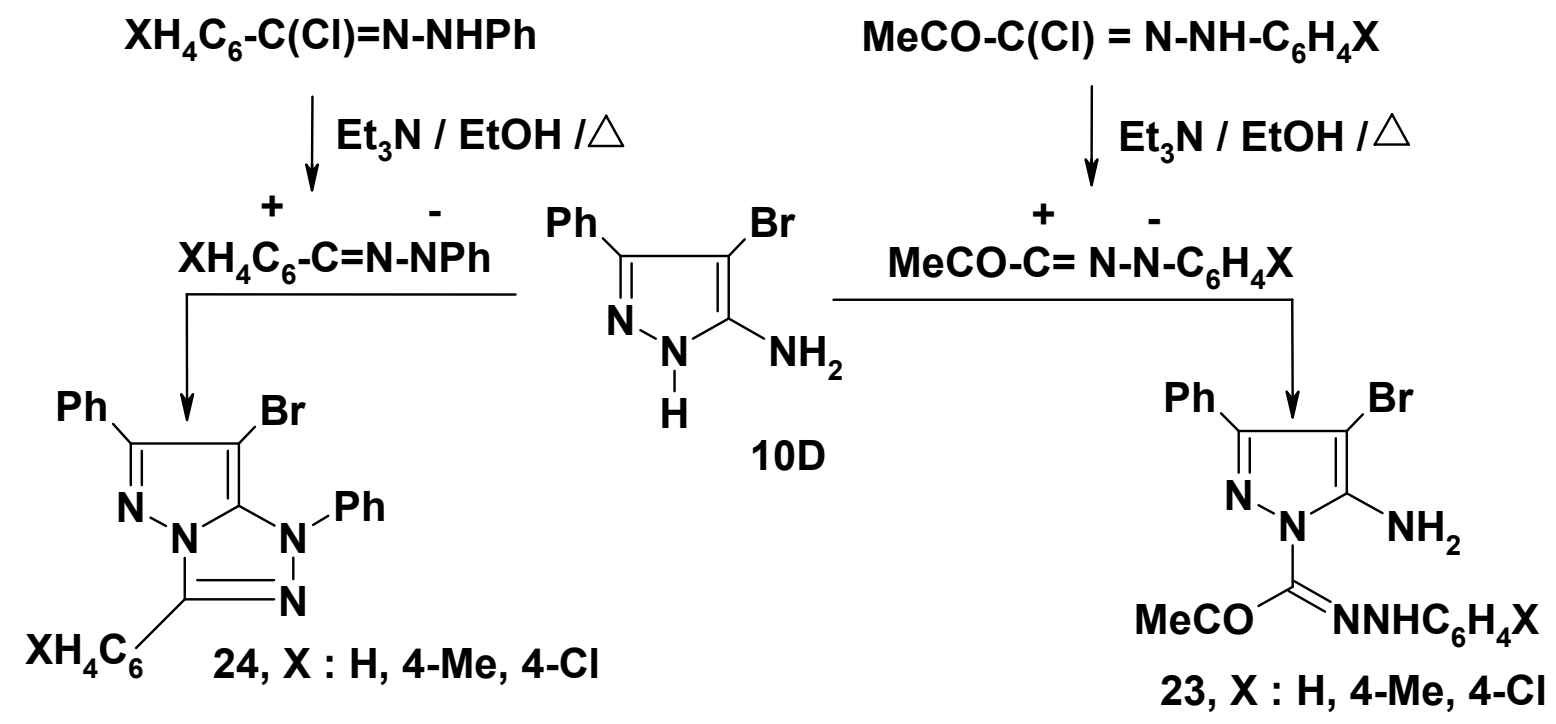

Scheme 9 
Also, the reactions of 5-amino-3-methyl-4-phenylpyrazole $10 \mathrm{E}$ with $C, N$-diaryl- and $C$-acetyl$\mathrm{N}$-phenylnitrilimines were reported to give the pyrazolo[1,5-c][1,2,4] triazoles 25 in $74-80 \%$ yield $^{18,19}$ and imidazo[1,5- $b$ ]pyrazole derivatives 26 in 90\% yield, respectively (Scheme 10). ${ }^{18}$

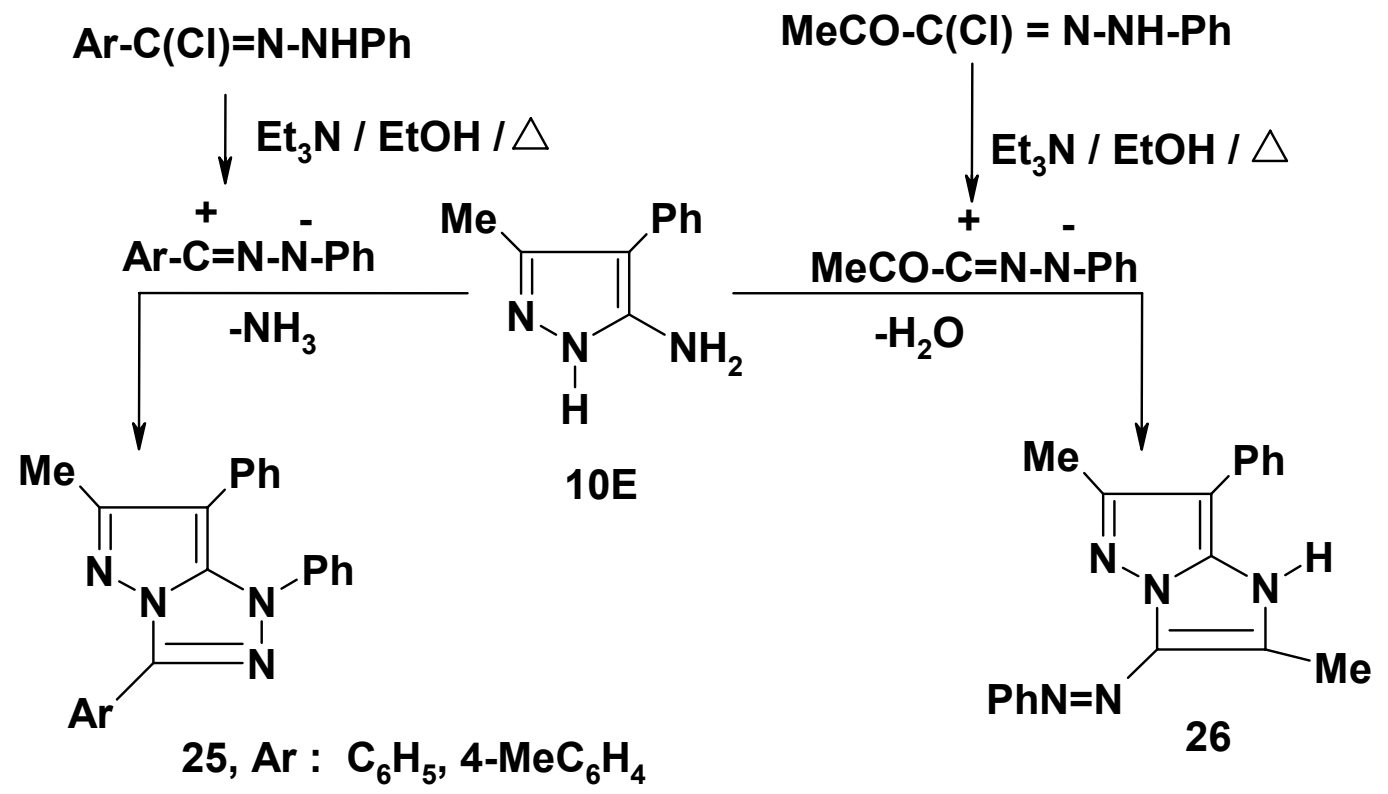

\section{Scheme 10}

However, reaction of 5-amino-4-cyano-3-phenylpyrazole $\mathbf{1 0 F}$ with both types of the foregoing nitrilimines yielded in both cases the respective 1,3-adducts namely the amidrazones 27 in $85-88 \%$ yield (Scheme 11). ${ }^{18}$

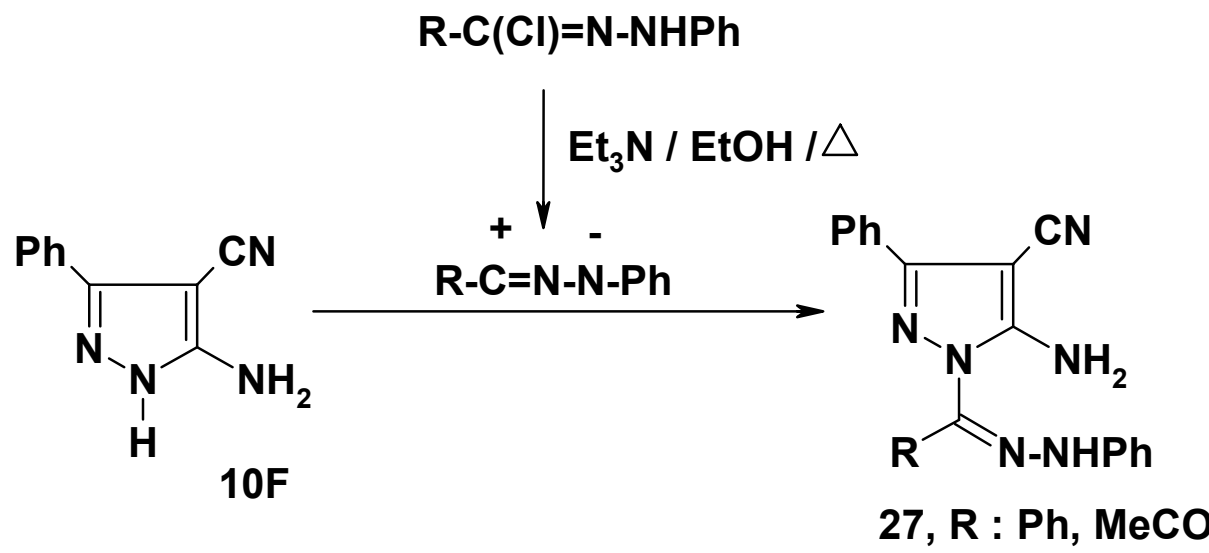

Scheme 11 
The reactions of $C$-aroyl- $N$-arylnitrilimines with 5-amino-3-phenyl-4-arylazopyrazoles 10G were reported to give 3,7-bis(arylazo)-2,6-diphenyl-1H-imidazo[1,2-b]pyrazole derivatives 28 in $70-90 \%$ yields. ${ }^{30}$ Although, four possible tautomeric structures A-D can be written for each of the compounds 28 (Figure 1), they were found to exist predominantly in the indicated tautomeric form 28A. This structural assignment was based on the similarity of their electronic absorption spectra with those reported for the azo chromophore ${ }^{31-33}$ and the results of the correlations of their acid dissociation constants with the Hammett equation (Scheme 12). ${ }^{30}$

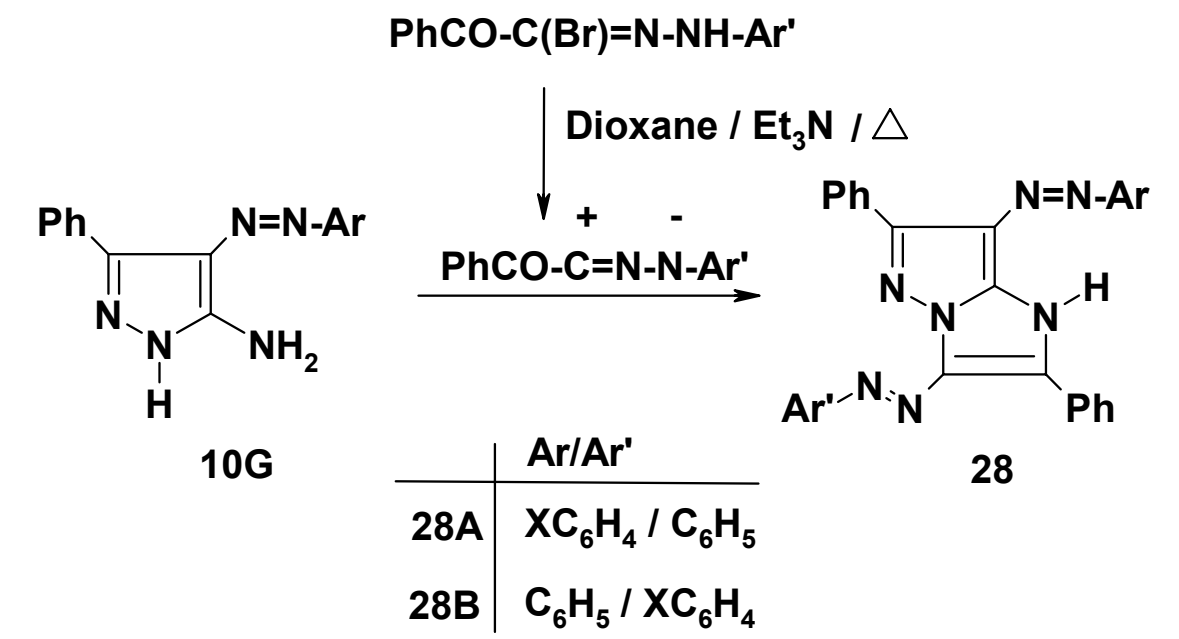

$\mathrm{X}$ : 4-MeO; 3-NO $\mathrm{N}_{2}$ 4-Me, $\mathrm{H}, 4-\mathrm{Cl}, 3-\mathrm{Cl}, 4-\mathrm{EtOCO}, 3-\mathrm{NO}_{2}, 4-\mathrm{NO}_{2}$

\section{Scheme 12}
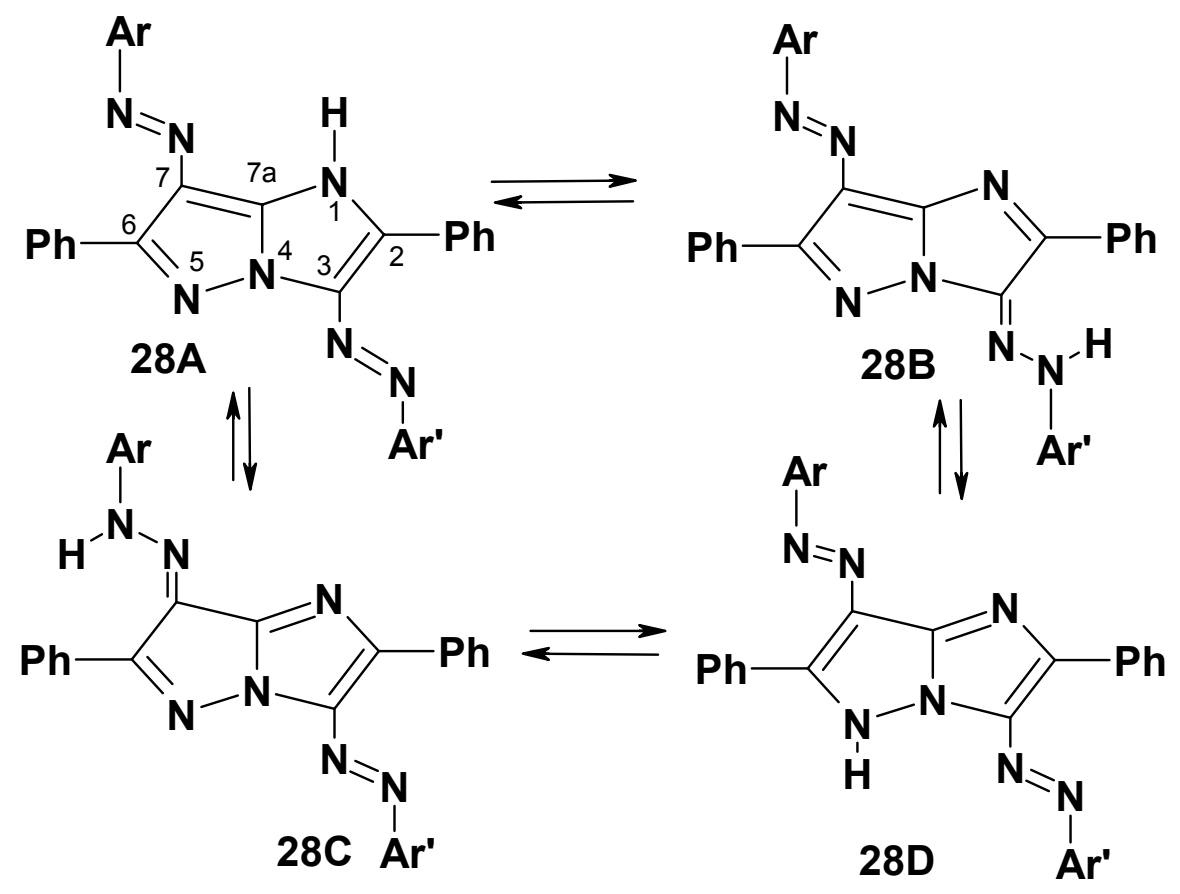

Figure 1 
Reaction of C,N-diphenylnitrilimine with 3,5-diamino-4-arylazopyrazoles 29 was reported to give the respective pyrazolo[1,5-c][1,2,4]triazoles 30 in 60-85\% yields.34 Similar reaction of 29 with C-acetyl-N-arylnitrilimines yielded the 1,3-adducts 31 in $80-92 \%$ yields (Scheme 13).18, $19,21,28$

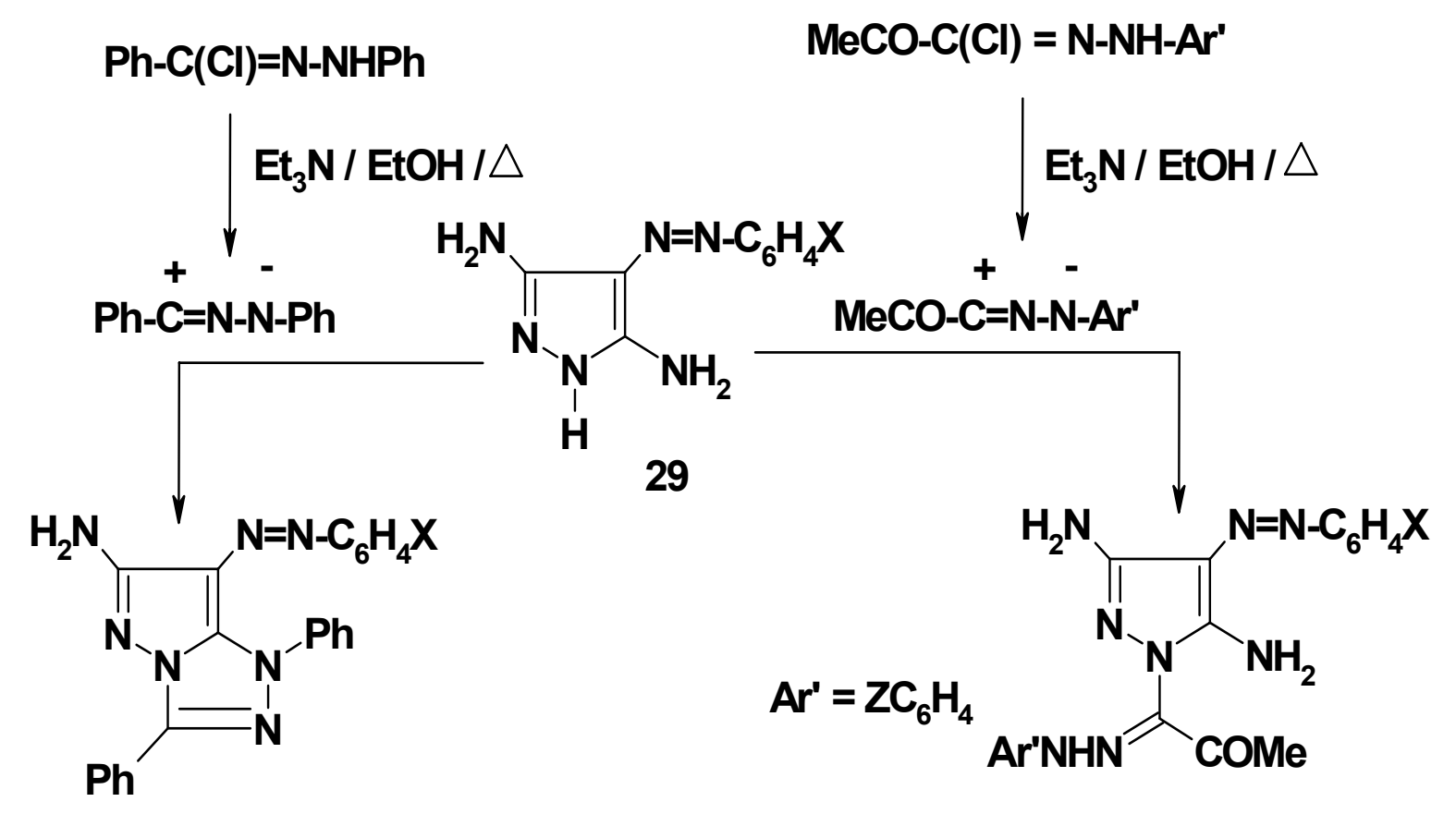

30, X : H, 4-Me, 4-MeO, 4-Cl

31, X/ Z : 4-Cl /4-MeO, 4-Cl / 4-Cl,

$\mathrm{H} /$ 4-Me, $\mathrm{H} / \mathrm{H}$

\section{Scheme 13}

\subsection{Aminoimidazoles}

Reaction of 2-aminobenzimidazole 32 with $C$-phenyl- and $C$-ethoxycarbonyl- $N$-arylnitrilimines yielded the respective amidrazones $\mathbf{3 3 a}, \mathbf{b}$ in $55 \%$ yields. ${ }^{22,}{ }^{23}$ The other possible isomeric structure $\mathbf{3 4}$ was discarded on the basis that if it were formed, it will be cyclized to give either $\mathbf{3 5}$ or $36 .{ }^{23}$ On the other hand, reaction of 2-aminobenzimidazole 32 with $C$-acetyl- $N$ phenylnitrilimine gave 1-phenyl-3-acetyl-1,2,4-triazolo[4,3-a]benzimidazole 37. ${ }^{22}$ Recently, it was reported, however, that reaction of $C$-acetyl- $N$-( $p$-chlorophenyl)nitrilimine with 2aminobenzimidazole yielded the amidrazone adduct $\mathbf{3 8}$ (Scheme 14). ${ }^{35}$ 


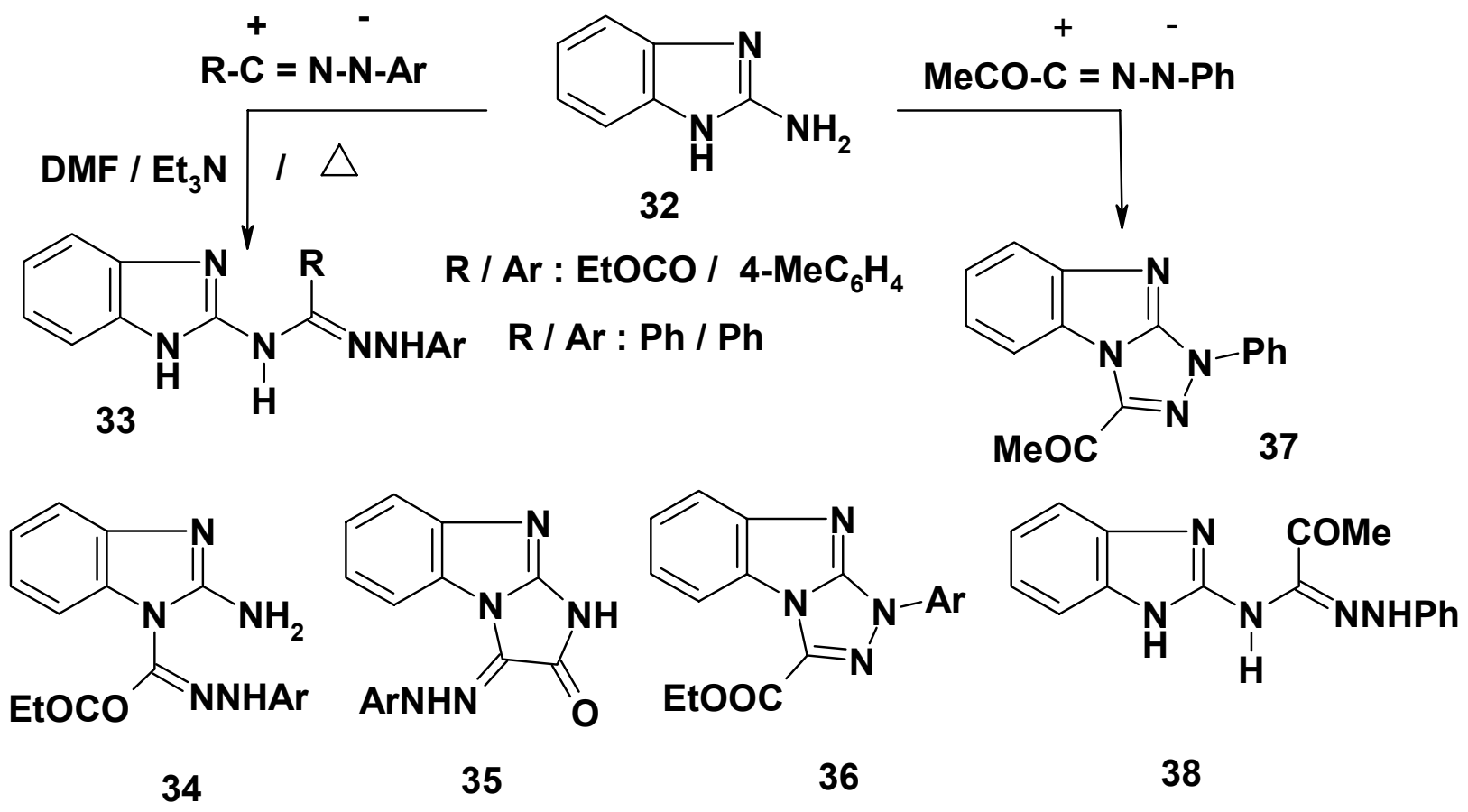

Scheme 14

\subsection{Aminoisoxazoles}

5-Amino-3-phenylisoxazole 39 was reported to react similarly with $C$-acetyl- $N$-arylnitrilimines to give the amidrazones 40 in $40-50 \%$ yields (Scheme 15). ${ }^{19,22}$

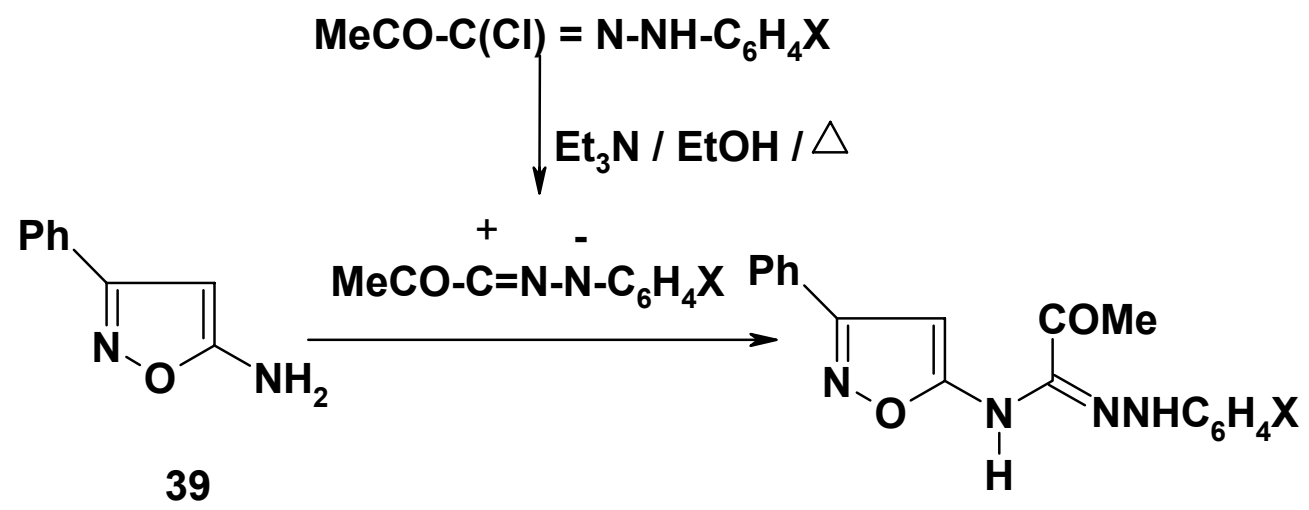

40, X: 4-Me, 4-NO

Scheme 15 


\subsection{Aminothiazoles}

$C$-Acyl- $N$-arylnitrilimines reacted with 2-amino-4-phenylthiazole (41A) and gave the respective imidazo[2,1-b]thiazole derivatives $\mathbf{4 3}$ in $80 \%$ yield. This reaction was supposed to proceed via initial formation of the amidrazones $\mathbf{4 2}$ followed by dehydrative cyclization of the latter to give 42 as end products (Scheme 16). ${ }^{24}$

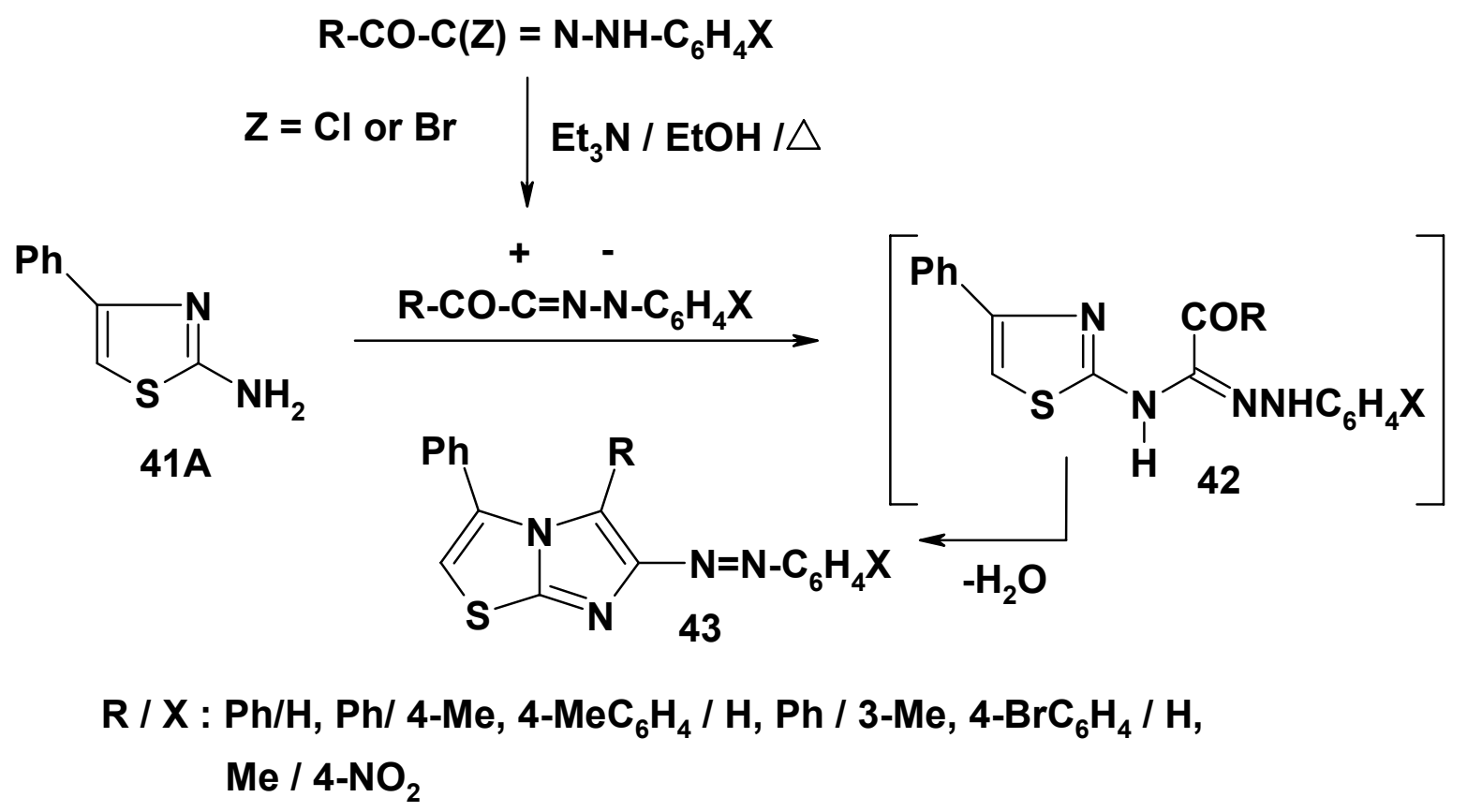

Scheme 16

Similarly, $C$-ethoxycarbonyl- $N$-phenylnitrilimine reacted with 2-amino-4-phenylthiazole 41A and yielded 6-arylhydrazono-5-oxo-3-phenylimidazo[2,1-b]thiazoles 44 (Scheme 17 ). ${ }^{24}$

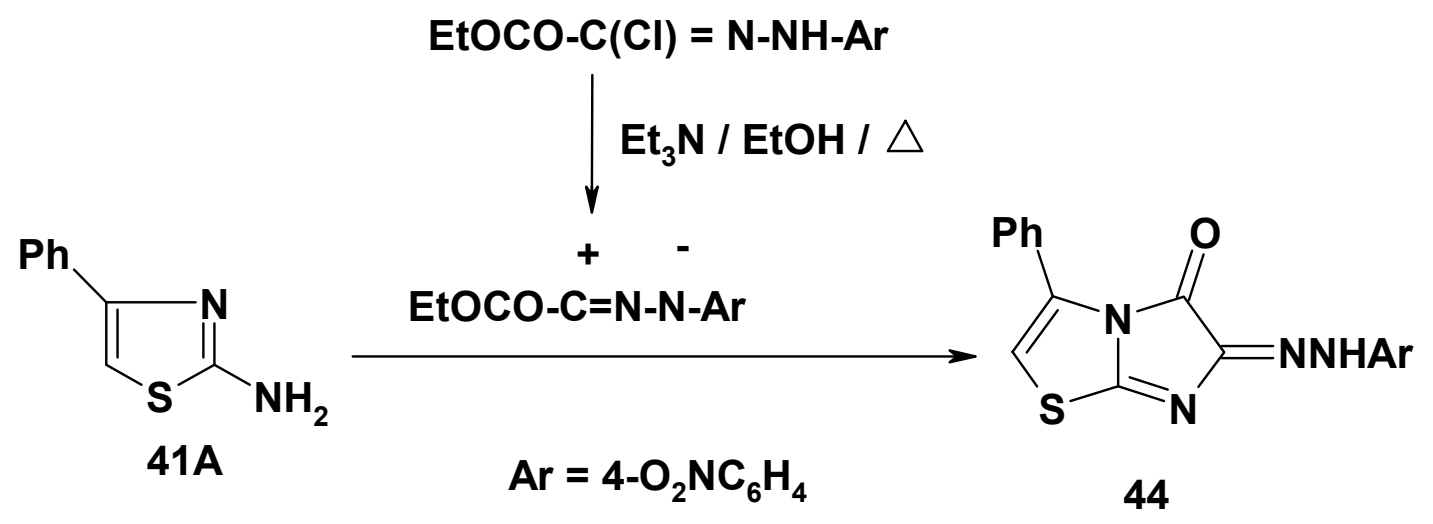

Scheme 17 
The amidrazones 46 were obtained in $88 \%$ yield from the reaction of 2-aminothiazole 41B with $C$-acetyl- $N$-phenylnitrilimine. ${ }^{21}$ Smilar reactions of 2-aminobenzothiazole 45 with $C, N$ diphenylnitrilimine and $C$-acetyl- $N$-phenylnitrilimine afforded the respective amidrazones 47 (Scheme 18). ${ }^{18,21}$

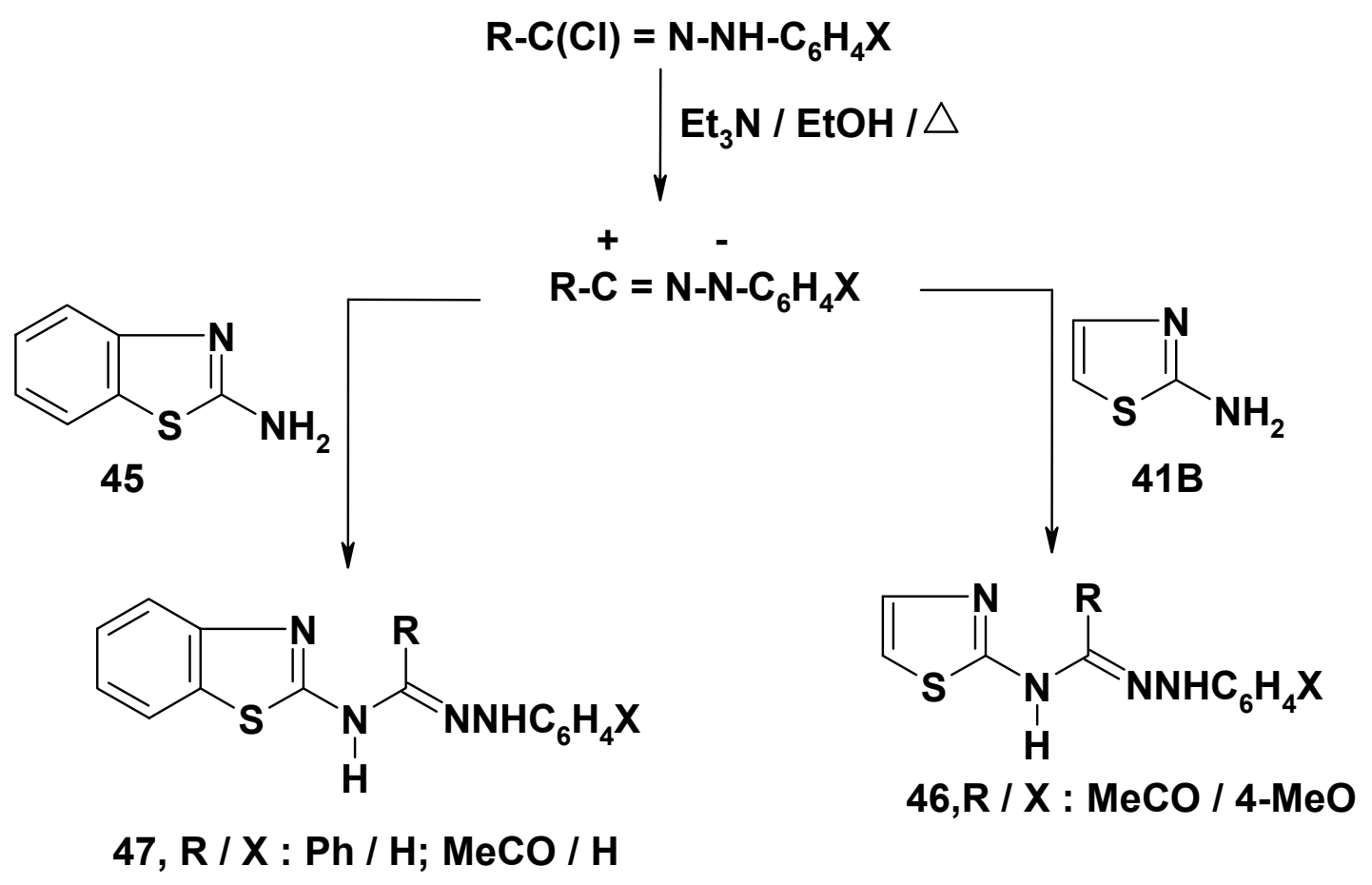

\section{Scheme 18}

\subsection{Amino-1,2,4-triazoles}

The reaction of 3-amino-1,2,4-triazole 48 with different $C$-acyl- $N$-arylnitrilimines afforded the respective 5-arylhydrazono-imidazo[1,2-b]]1,2,4]triazole derivatives $49 .{ }^{24}$ In another report, ${ }^{29}$ it was indicated that similar reaction of $\mathbf{4 8}$ with $C$-aroyl- $N$-arylnitrilimines yielded initially the amidrazones $\mathbf{5 0}$ in 39-57\% yields which underwent deaminative cyclization to give 1-aryl-3acyl-1,2,4-triazolo[3,4-c][1,2,4]triazoles 51 (Scheme 19). ${ }^{23,29}$ 


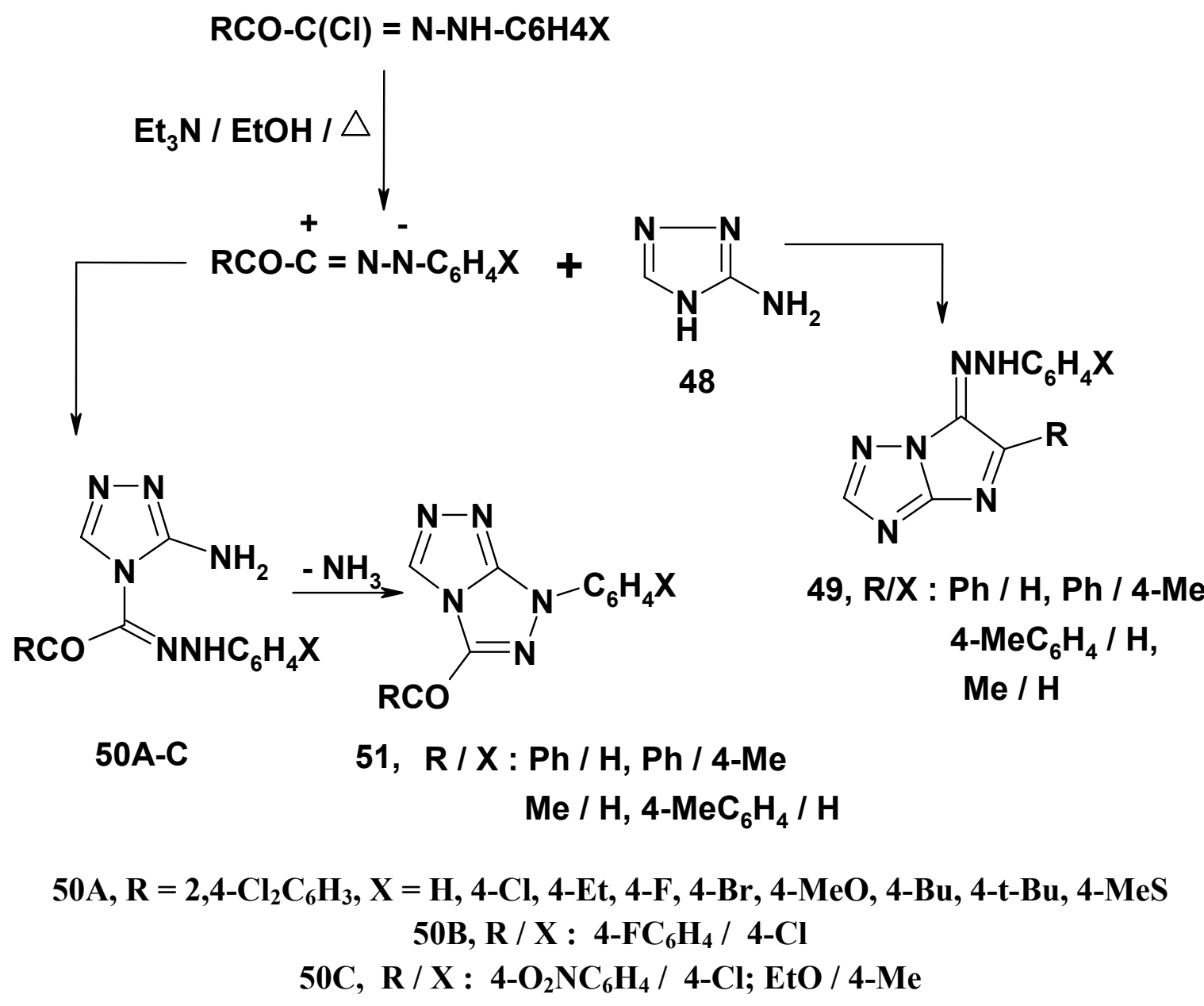

Scheme 19

Analogous reactions of $\mathbf{4 8}$ with each of $C, N$-diarylnitrilimines ${ }^{19}, 22$ and $C$-acetyl- $N$ arylnitrilimines ${ }^{19}$ were reported to be site selective and gave in both cases the respective 1,3adducts namely the amidrazones $\mathbf{5 2}$ in 40-60\% yields (Scheme 20). 


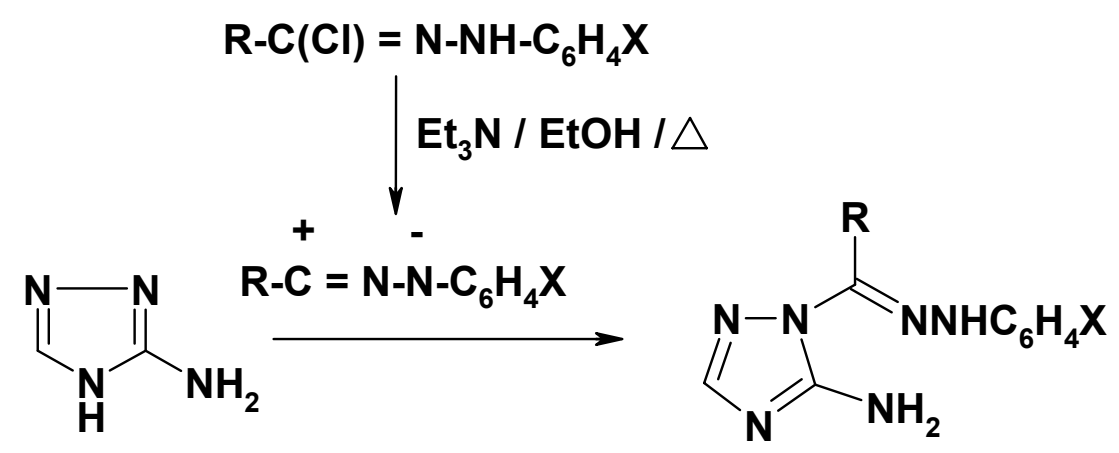

48

52, R / X : MeCO / H. MeCO / 4- $\mathrm{NO}_{2}$,

$\mathrm{Ph} / \mathrm{H}, 4-\mathrm{ClC}_{6} \mathrm{H}_{4} / \mathrm{H}$

Scheme 20

Contradictory results were reported for the reaction of 48 with $C$-ethoxycarbonyl- $N$ arylnitrilimines. In one report, it was indicated that such a reaction afforded 5-arylhydrazono-6oxo-7H-imidazo[5,1-b][1,2,4]triazole 53. ${ }^{24}$ In another report, it was indicated that it yielded 3ethoxycarbonyl-1-aryl-1,2,4-triazolo[5,1-c][1,2,4] triazole 54 in $70 \%$ yield. ${ }^{23}$ Further work is needed to clarify this contradiction (Scheme 21 ).

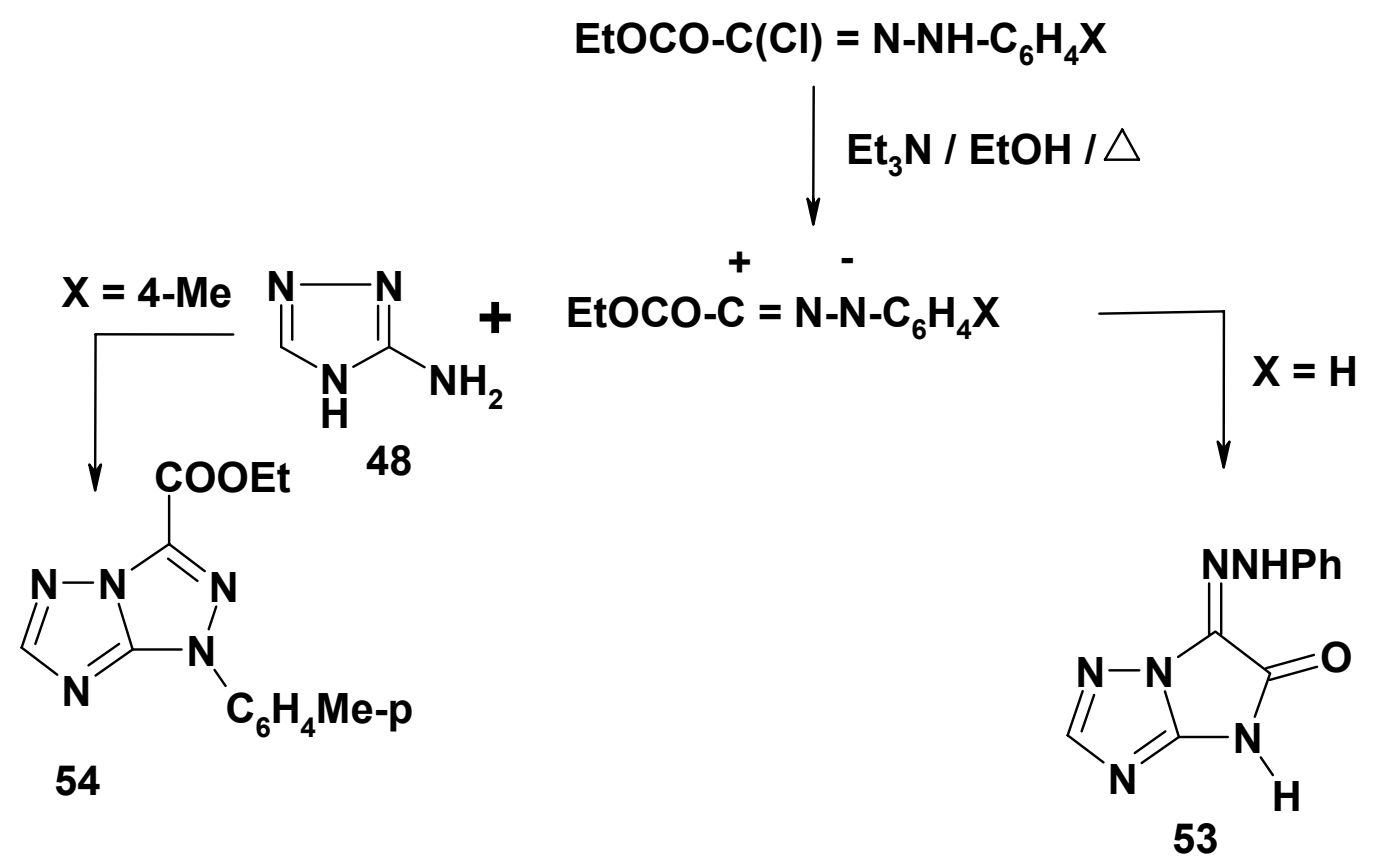

Scheme 21 
Reaction of 4-amino-5-phenyl-4H-1,2,4-triazole-3-thiol 55 with C-aroyl-N-arylnitrilimines afforded 7-arylhydrazono[1,2,4]triazolo[3,4-b][1,3,4]thiadiazines ${ }^{56.36}$ The acid dissociation constants $\mathrm{pK}$ and $\mathrm{pK}^{*}$, in the ground and excited states, respectively were correlated by Hammett equation. The $\mathrm{pK}$ data together with the spectral data indicate that the compounds $\mathbf{5 6}$ exist predominantly in the indicated hydrazone tautomeric form (Scheme 22). ${ }^{36}$

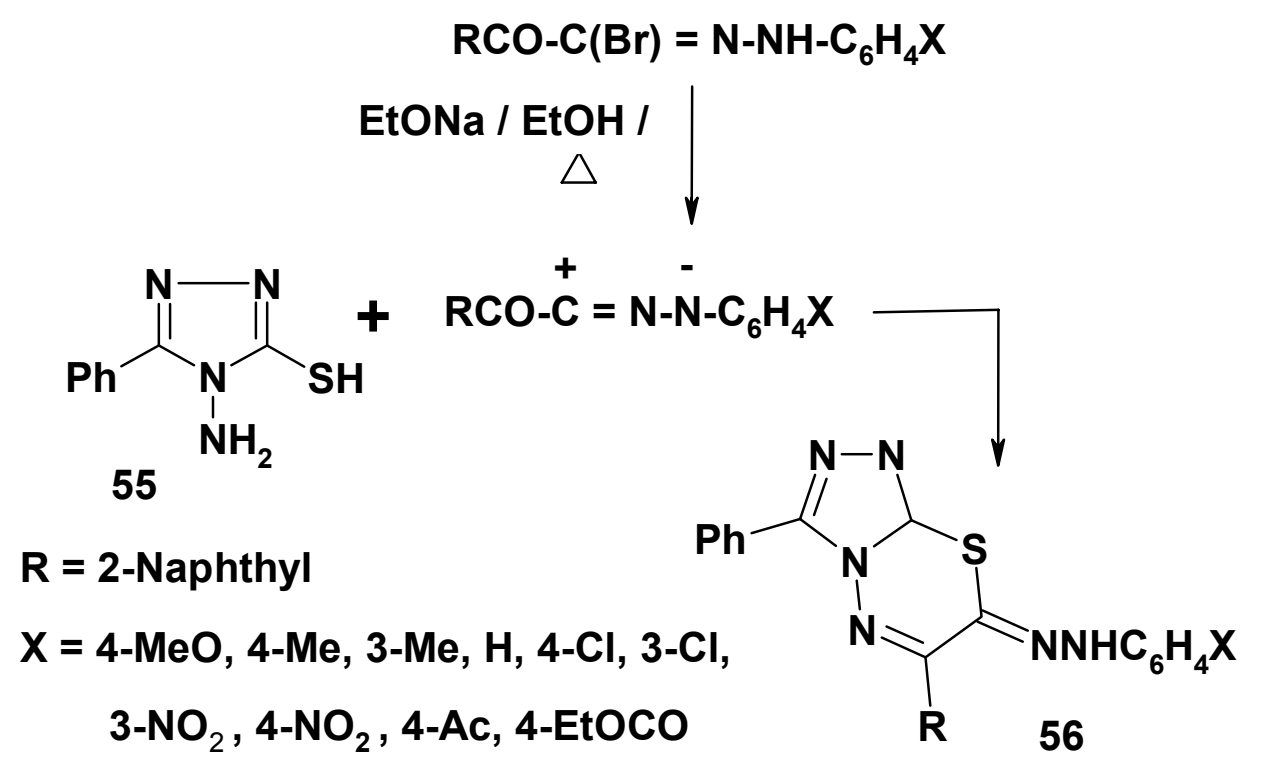

\section{Scheme 22}

\subsection{Aminotetrazoles}

Reactions of C-acyl- $N$-arylnitrilimines with 5-aminotetrazoles 57 gave a mixture of the aminotriazoles 60 and 61 via elimination of hydrazoic acid from the initially formed regioisomeric cycloadducts $\mathbf{5 8}$ and $\mathbf{5 9}$, respectively (Scheme 23). ${ }^{29}$

On the other hand, reaction of 5-amino-1-substituted-tetrazoles 57A with $C$-phenyl- $N$-(4nitrophenyl)nitrilimine was reported to give 1,3,5-trisubstituted-1,2,4-triazoles 62 in $41-50 \%$ yields (Scheme 24). ${ }^{37}$ 


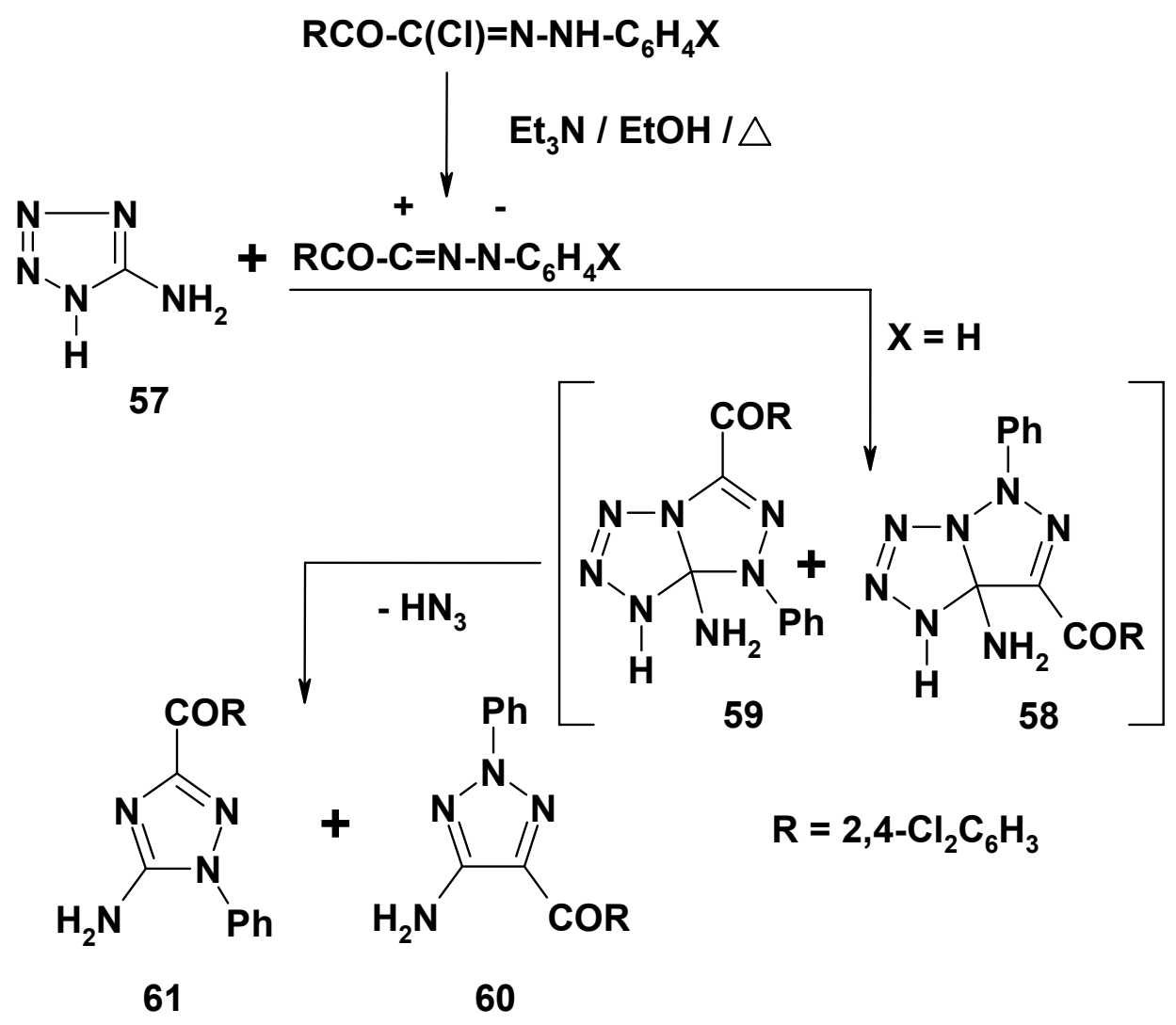

Scheme 23

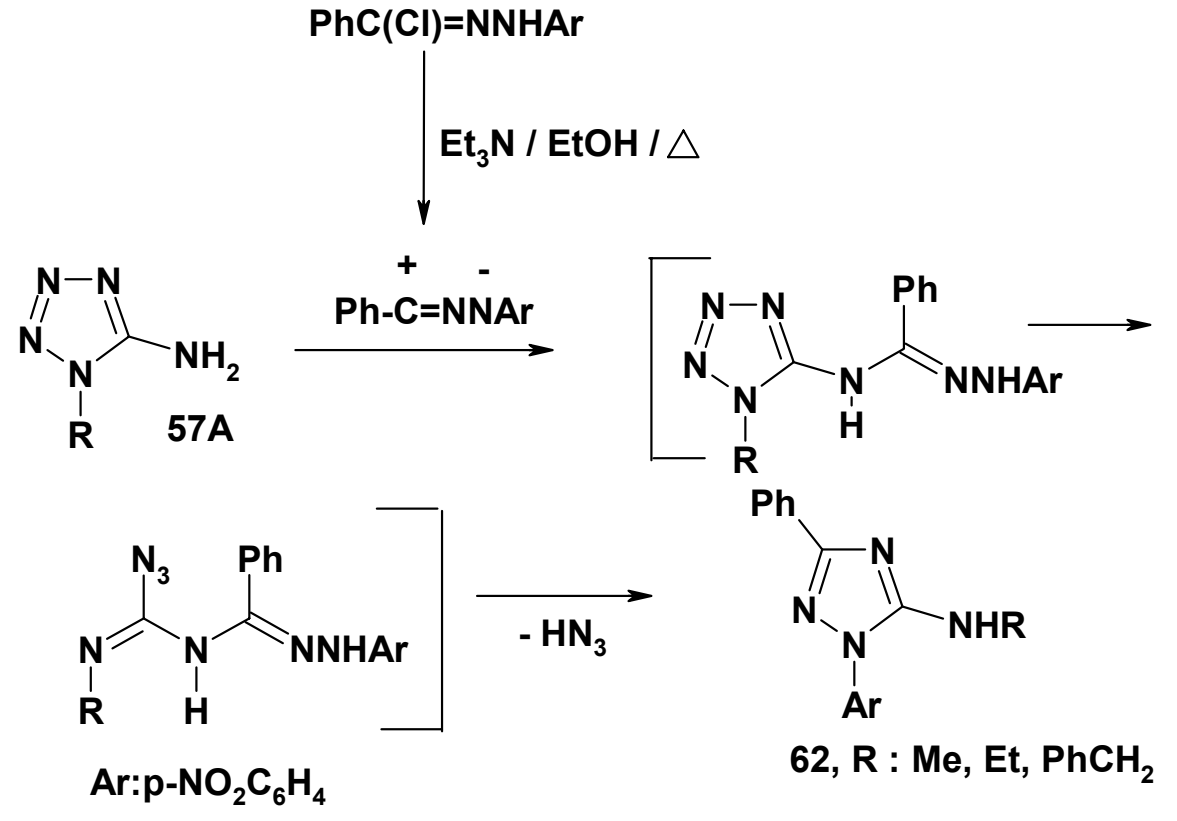

Scheme 2 


\section{Reactions with aminoazines}

\subsection{Aminopyridines}

Reaction of 2-aminopyridine 63 with $N$-phenyl-2-oxopropanehydrazonoyl chloride in refluxing ethanol gave one product in $70 \%$ yield that was identified as 2-methyl-3-arylazo imidazo[1,2a]pyridine $64 .^{24}$ Similar reaction of 2-aminopyridine 63 with ethyl $N$ phenylhydrazonochloroacetate yielded 65 (Scheme 25). ${ }^{24}$
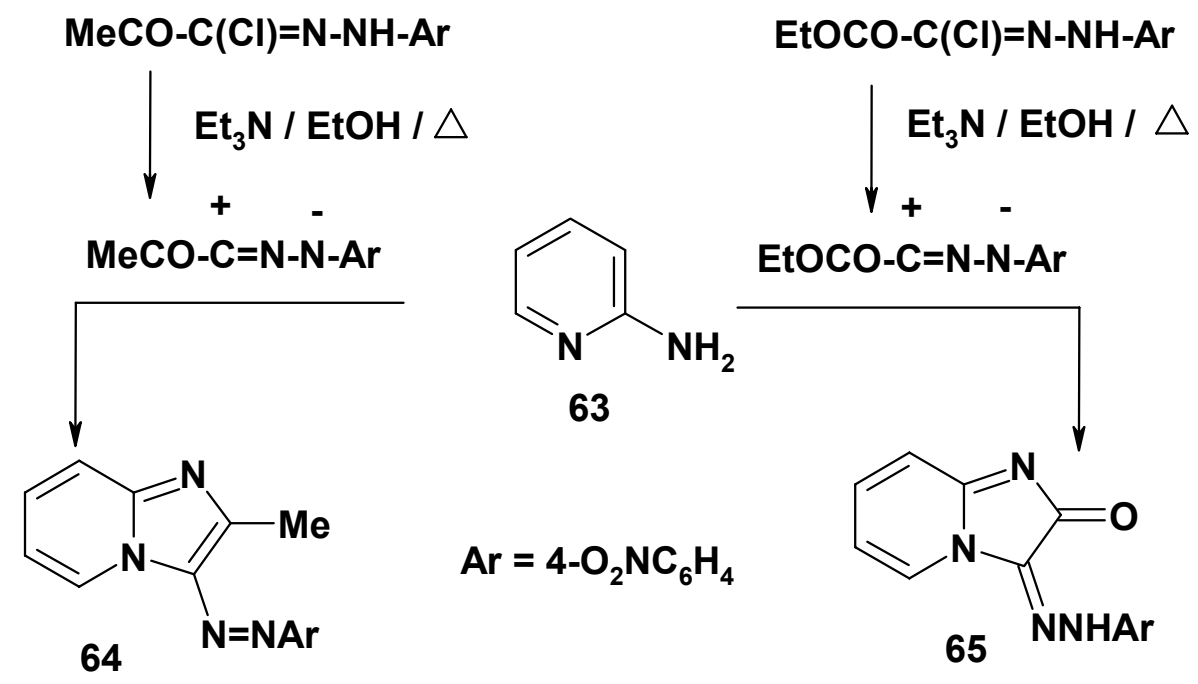

\section{Scheme 25}

However, the reaction of $\mathbf{6 3}$ with the nitrilimines, derived from $N$-(pyrazol-5-yl) 2oxohydrazonoyl halides in refluxing ethanol in the presence of triethylamine or piperidine, was found to give $\mathbf{6 6}$ in $80 \%$ yield. The formation of the latter seems to result via intramolecular addition of the generated nitrilimines. ${ }^{38,39}$ In this case, 2-aminopyridine acted as a base catalyst. (Scheme 26). 


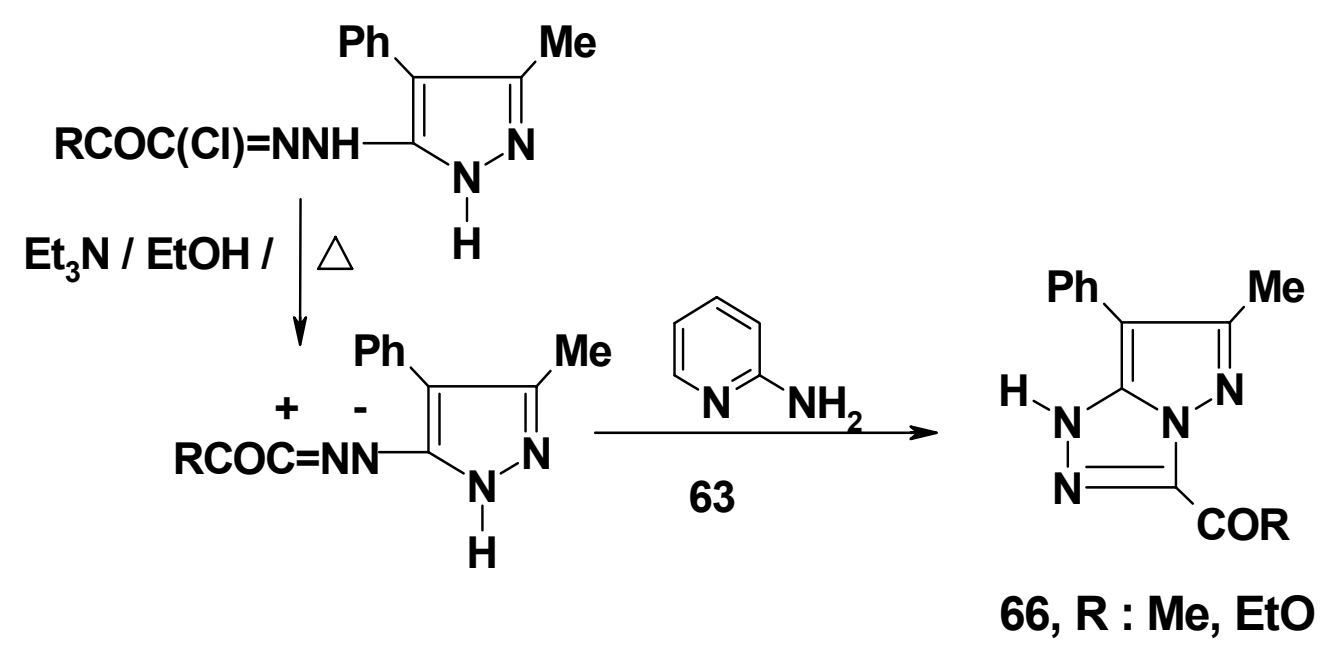

Scheme 26

In an earlier report ${ }^{40}$, it was indicated however that reaction of 2-aminopyridine 63 with $C$ phenyl- $N$-benzenesulfonylnitrilimine yields 3-phenyl 1,2,4-triazolo[4,3-a]pyridine 67 in 54\% yield (Scheme 27).

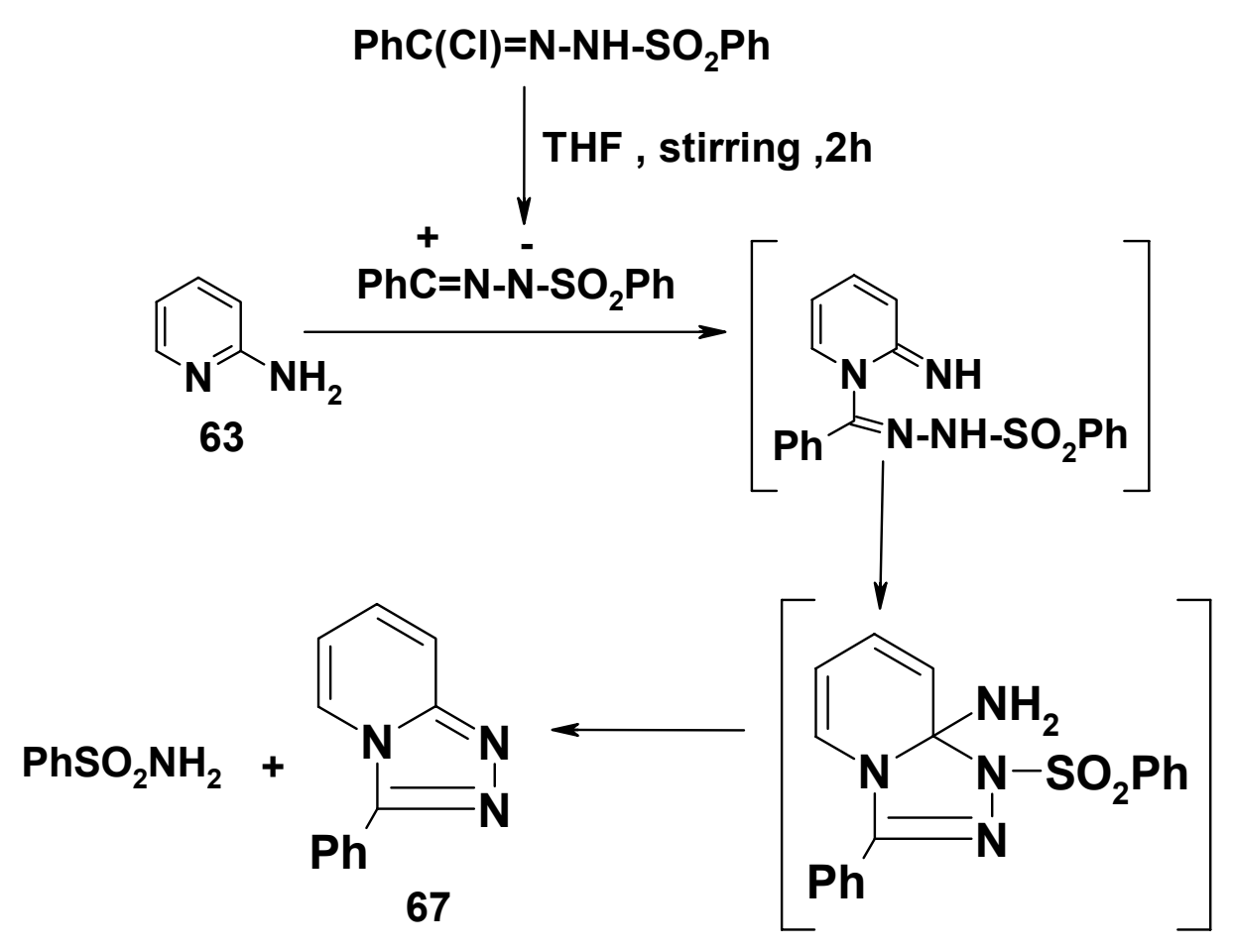

Scheme 27 


\subsection{Aminopyrimidines}

The reaction of 2-aminopyrimidine $\mathbf{6 8}$ with $C$-acyl- $N$-phenylhydrazonoyl halides was reported to give the corresponding 2-substituted-3-phenylazo-imidazo[1,2-a]pyrimidines 69 (Scheme 28). ${ }^{24}$

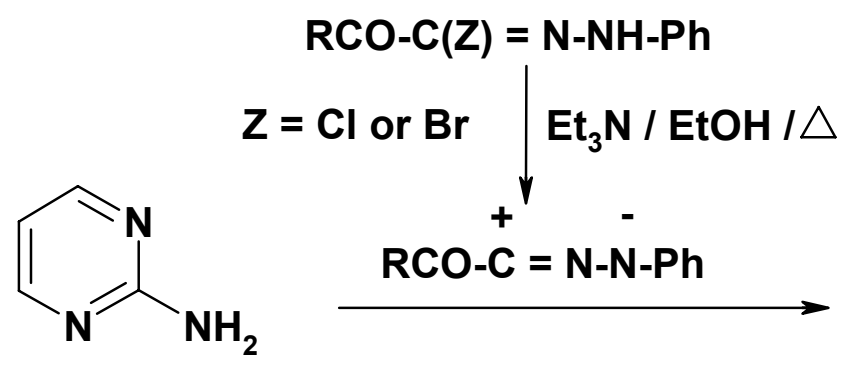

68<smiles>[R]c1nc2ncccn2c1N=[NH+]</smiles>

69, R : Me, Ph

\section{Scheme 28}

However, the reaction of 2-aminopyrimidine $\mathbf{6 8}$ with $C$-phenyl- $N$-phenylsulfonylnitrilimine yielded 3-phenyl-5-triazolo[4,3-a]pyrimidine 70 in 42\% yield (Scheme 29). ${ }^{40}$<smiles>Nc1ncccn1</smiles>

68

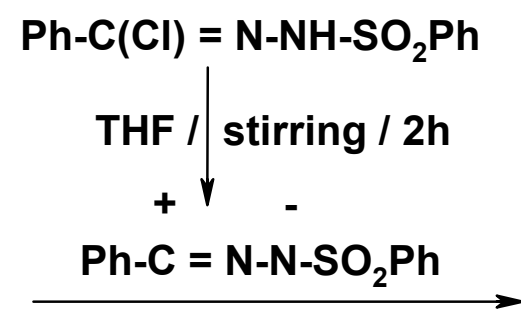<smiles>CCCc1nnc2ncccn12</smiles>

70

\section{Scheme 29}

Recently it was reported that reaction of nitrilimines with 3-amino-6-methyl-4-oxo-2 (3H)pyrimidinethione $71 \mathrm{~A}$ in boiling ethanol in presence of triethylamine, furnished pyrimido[1,2b] $[1,2,4,5]$ tetrazines 72 in $35-66 \%$ yields. ${ }^{41}$ Analogous reaction of the same nitrilimines with 3- 
amino-6-phenyl-2-methylthio-4(3H)-pyrimidinone 71B in refluxing ethanol in the presence of triethylamine afforded also 72 (Scheme 30$).{ }^{41,42}$

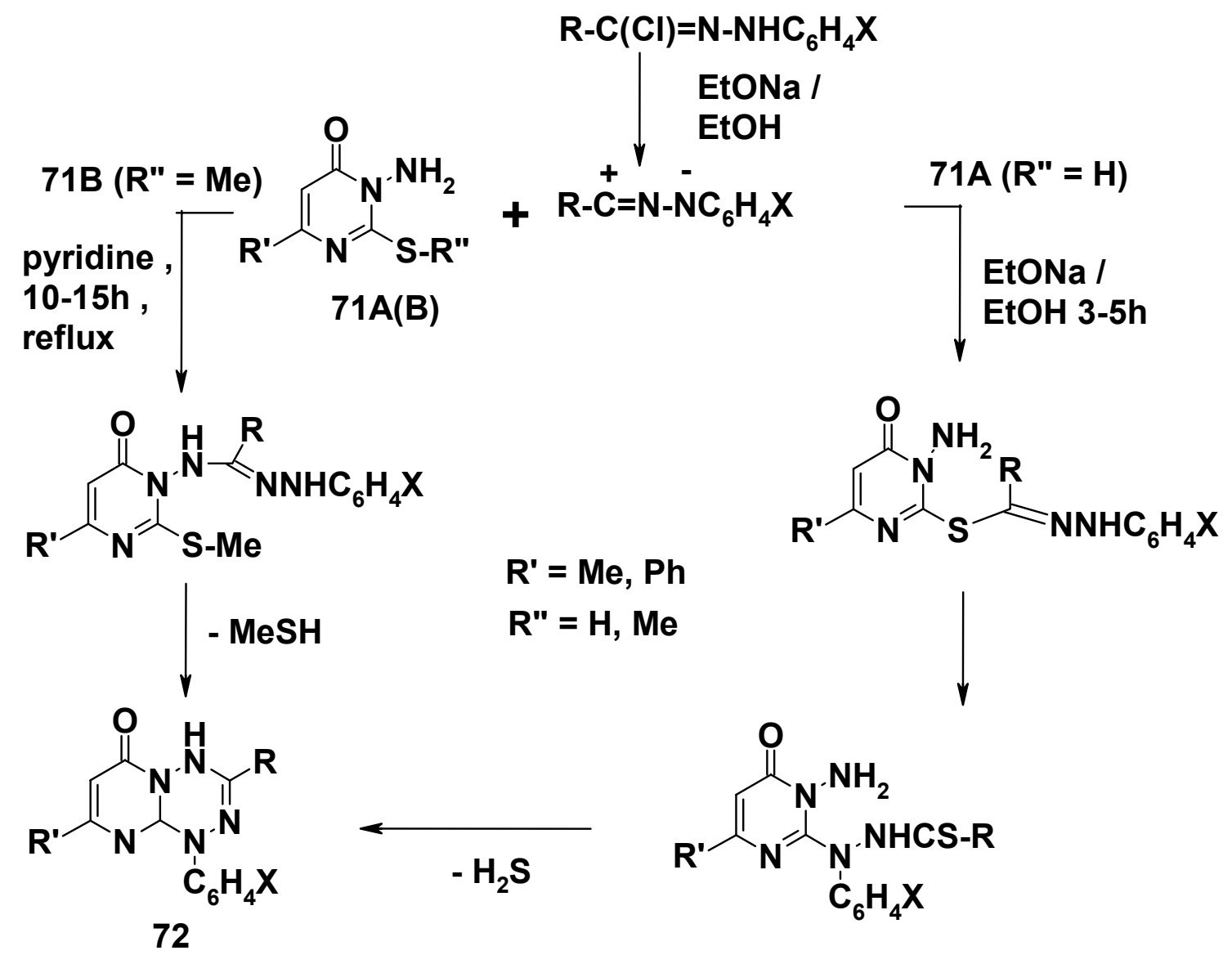

R / X : EtOCO / H, PhNHCO / H, MeCO / 4-Me, PhCO / H, 2-naphthoyl / H, Ph / H, Me / 4-NO2, $\mathrm{PhCH}=\mathrm{CH} / \mathrm{H}, 2$-thenoyl / H, $\mathrm{ArN}=\mathrm{N} / \mathrm{XC}_{6} \mathrm{H}_{4}$

\section{Scheme 30}

Similarly, 3-arylazo-1,4-dihydro-1,8-disubstituted-6H-pyrimido[1,2- $b][1,2,4,5]$-tetrazin-6ones 73 were recently reported to be obtained in good yields by reaction of $C$-arylazo- $N$ phenylnitrilimines, derived from the respective 3-chloro-1,5-diarylformazans, with 3-amino-6substituted-2-thiouracils 71A or their 2-methylthio analogs $71 \mathbf{B}$ (Scheme 31). ${ }^{43}$ 


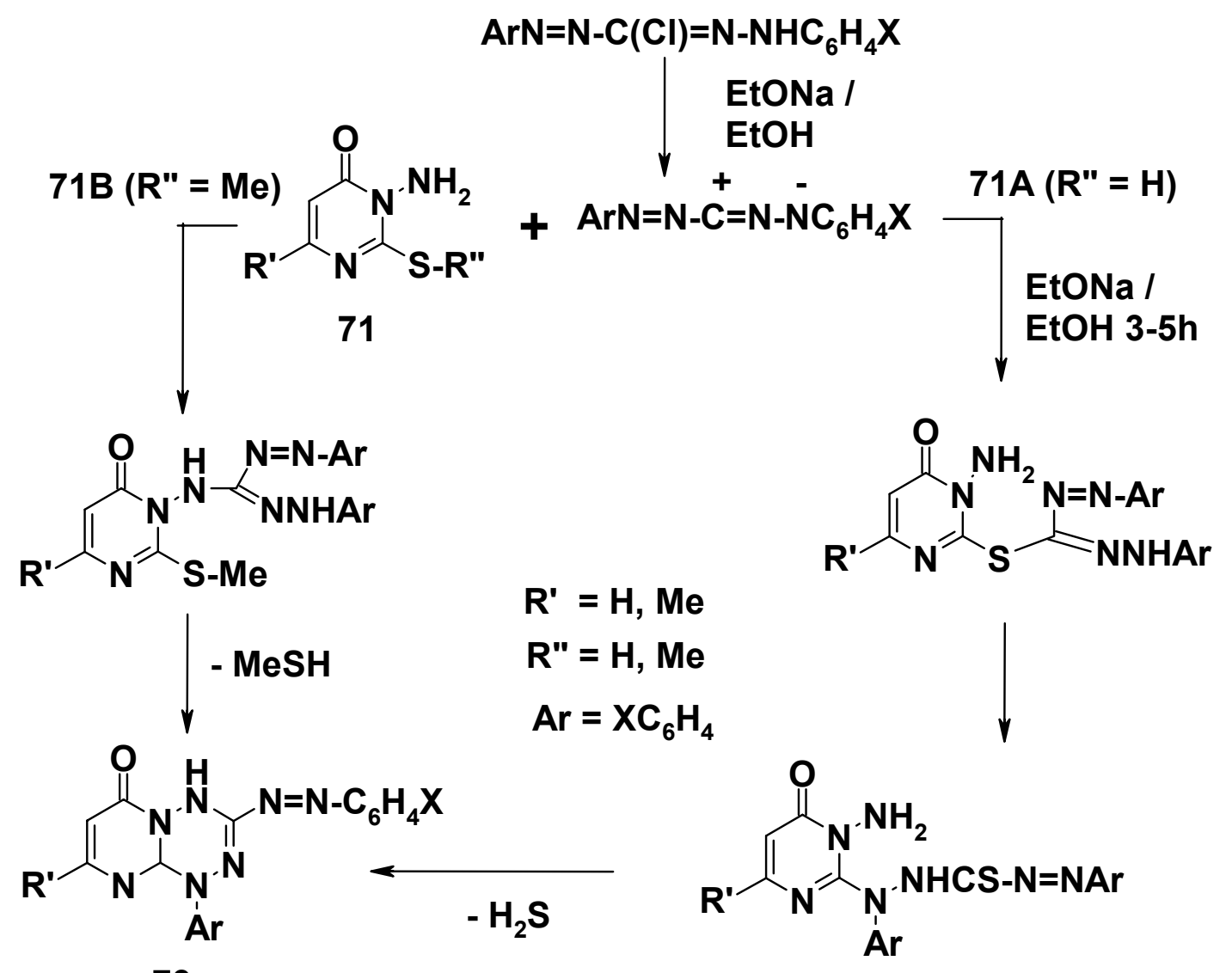

73

$$
\mathrm{X}: \mathrm{H}, 4-\mathrm{Me}, 4-\mathrm{MeO}, 3-\mathrm{Cl}, 4-\mathrm{Cl}, 3-\mathrm{NO}_{2}, 4-\mathrm{NO}_{2} \text {, }
$$

\section{Scheme 31}

Reaction of nitrilimines with 6-amino-2-thiouracil $\mathbf{7 4}$ in refluxing dioxane afforded regioselectively 7-amino-1,3-disubstituted-1,2,4-triazolo[4,3-a]pyrimidin-5(1H)-one $\mathbf{7 5}^{44,45}$ The product 75 was used as precursor for synthesis of pyrido[2,3- $d][1,2,4]$ triazolo[4,3-a]pyrimidine$5,6(1 H, 9 H)$-diones $\mathbf{7 8}$ in $65-82 \%$ yields by its treatment with (Z)-2-benzylamino-3dimethylaminopropenoate $\mathbf{7 6}$ in refluxing acetic acid to give $\mathbf{7 7}$ which was next cyclized by the action of sodium ethoxide in ethanol to give $\mathbf{7 8}$ (Scheme 32 ). ${ }^{45}$ 


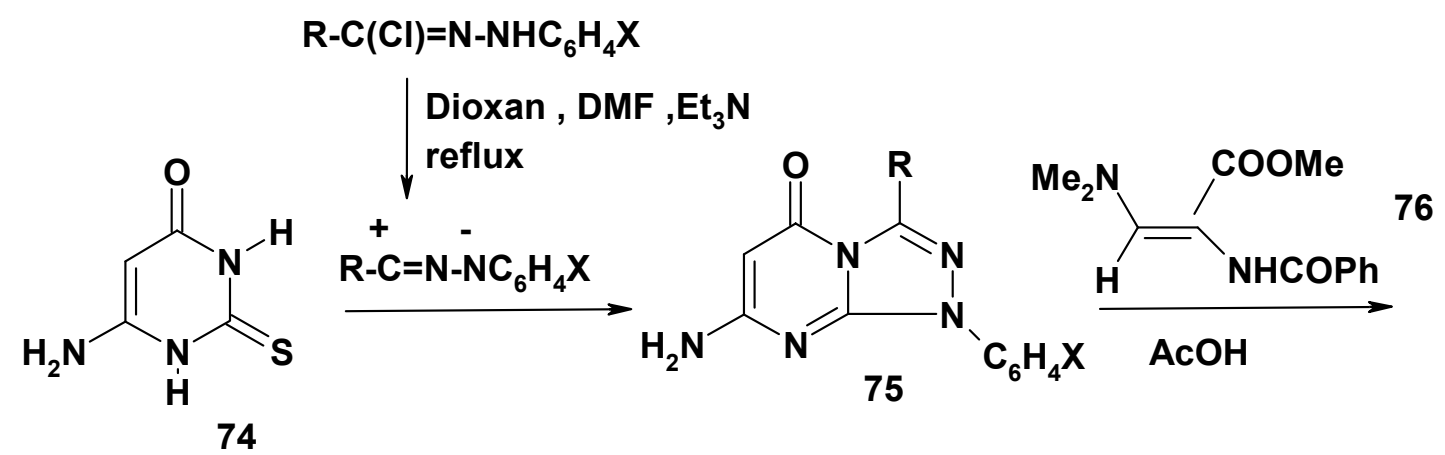

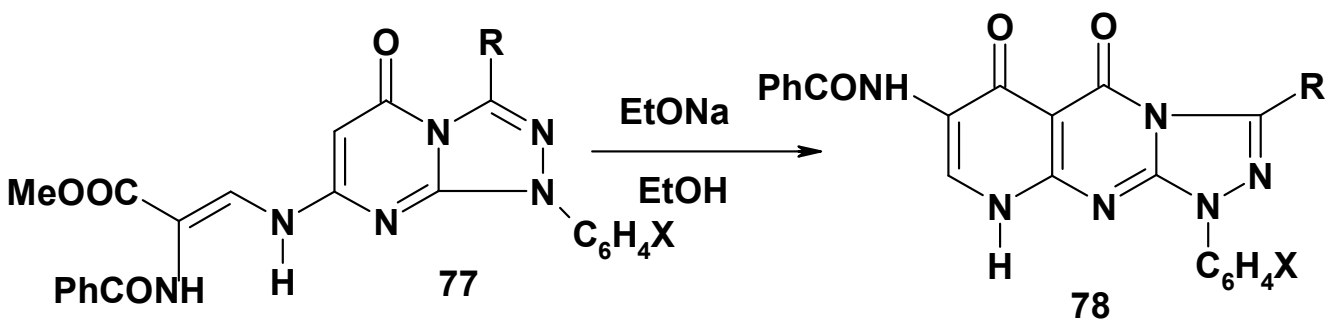

\section{R / X : Ph / H, EtOCO / H, PhNHCO / H, PhNHCO / 4-Me, PhCO / H, $\mathrm{MeCO} / \mathrm{H}, \mathrm{MeCO} / 4-\mathrm{Me}$}

\section{Scheme 32}

Similarly, 6-phenylamino-2-thiouracil and its 5-substituted derivative 79 reacted with $C$ ethoxycarbonyl- $N$-arylnitrilimines in chloroform and gave the respective 1,2,4-triazolo[4,3a]pyrimidin-5(1H)-ones $\mathbf{8 0}^{44}$ in $65-72 \%$ yields. Heating each of the products $\mathbf{7 5}$ and $\mathbf{8 0}$ with acetyl chloride and chloroacetyl chloride was reported to result in $C$-acetylation rather than the $\mathrm{N}$-acetylation and yielded the respective 6-acyl derivatives $81{ }^{44}$ Also, nitrosation and azo coupling of each of $\mathbf{7 5}$ and $\mathbf{8 0}$ yielded the respective 6-nitroso- and 6-arylazo derivatives $\mathbf{8 2}$ and 83 (Scheme 33). ${ }^{44}$

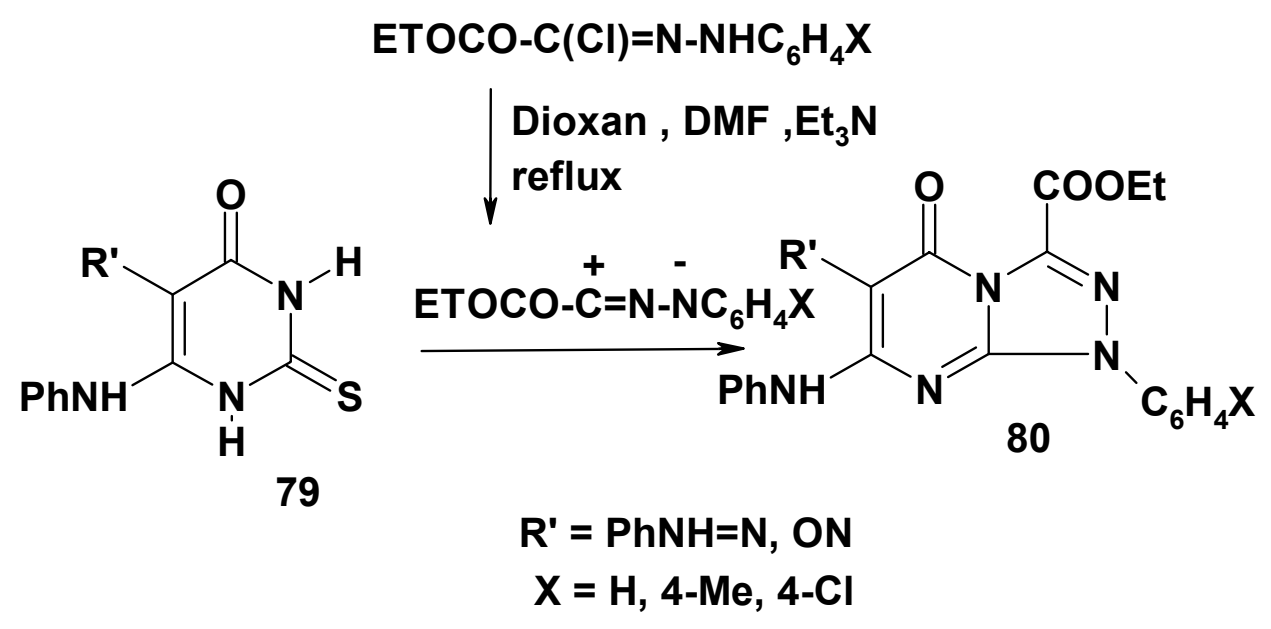

Scheme 33 
<smiles>[R16]c1cc(=O)n2c(C(=O)OCC)nn(-c3ccccc3)c2n1</smiles>

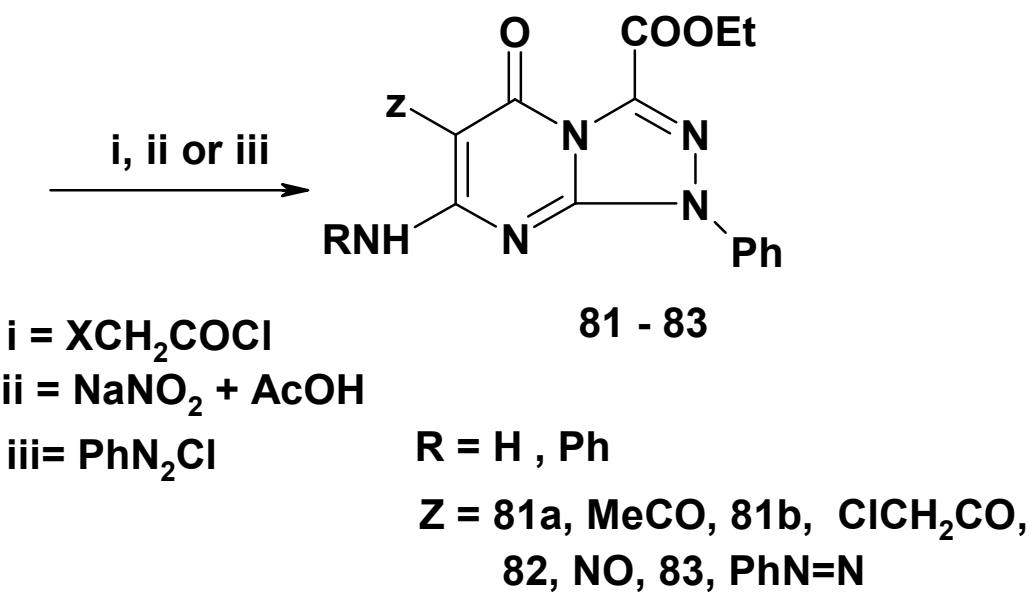

Reaction of 6-amino-2-thiouracil 74 with $C, N$-diphenylnitrilimine in dioxane under reflux yielded 84. The other isomeric structure 85 was discarded on the basis of the IR and ${ }^{13} \mathrm{C}$-NMR evidence. ${ }^{46}$ When compound $\mathbf{8 4}$ was refluxed with benzaldehyde in acetic acid, it yielded $\mathbf{8 6}$ in $80 \%$ yield (Scheme 34$)$.

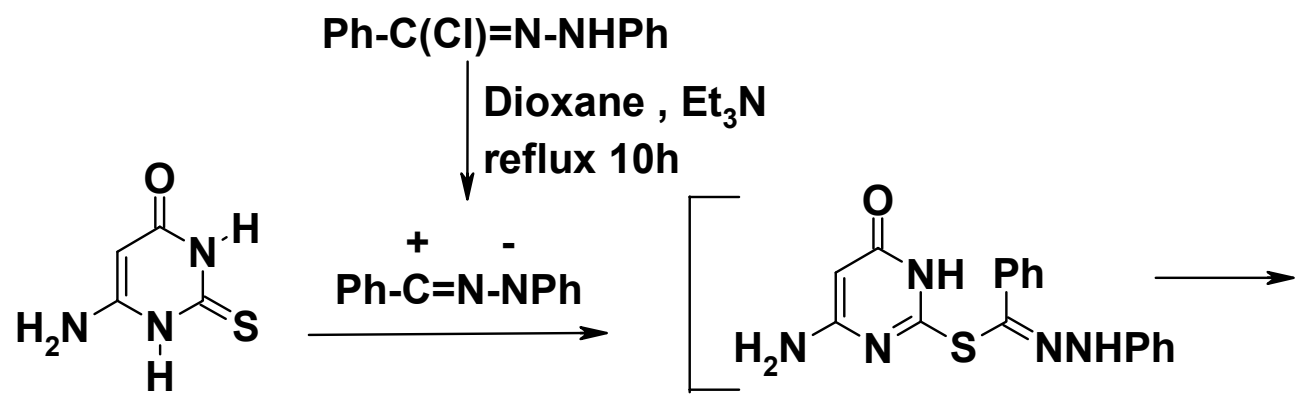

74

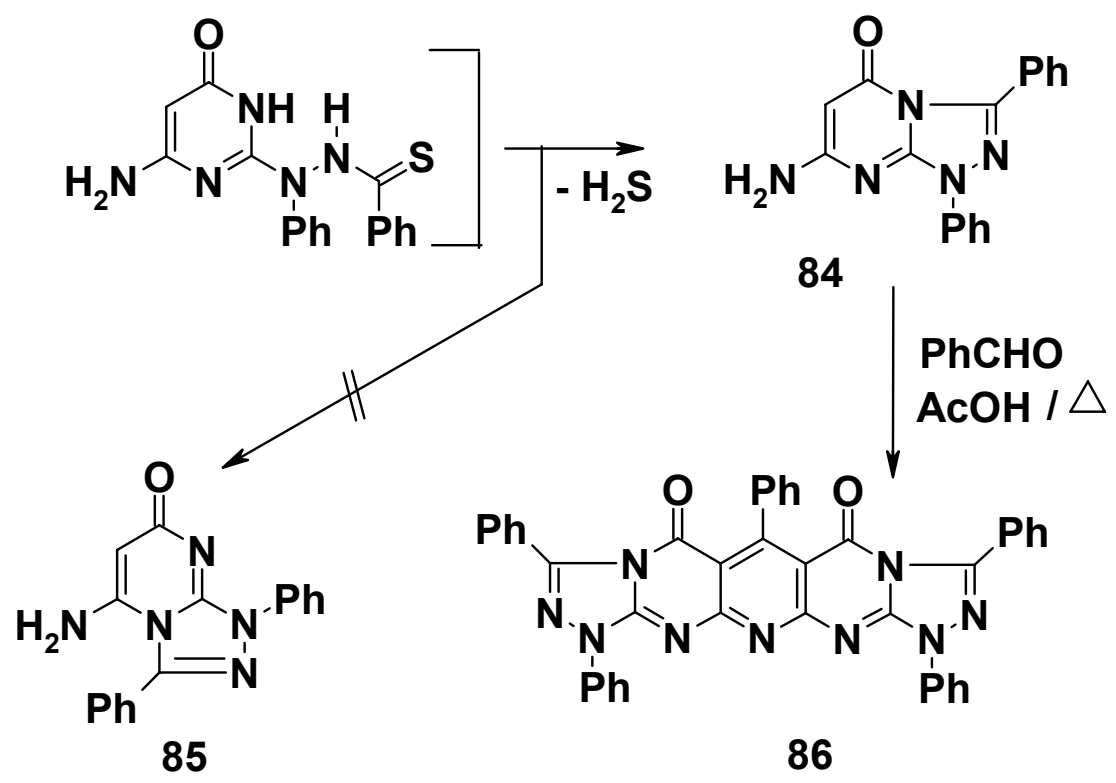

Scheme 34 
Reactions of various nitrilimines with 3-amino-4-oxo-2(3H)-quinazolinethione 87A in ethanol were reported to yield the respective $6 H$-1,2,4,5-tetrazino[3,2-b]quinazolines 90 in 70$92 \%$ yields as end products. The latter were shown to be formed via the initial formation of the thiohydrazonates $\mathbf{8 8}$ which underwent tandem Smiles rearrangement to give $\mathbf{8 9}$ and cyclocondensation to give $\mathbf{9 0}$ as end products. ${ }^{47}$ When the 2-methylthio derivative 87B was used in place of $87 \mathrm{~A}$ in these reactions, the products 90 were also obtained. ${ }^{47}$ In this case, the reaction was assumed to proceed through the hydrazidine intermediate 91 which in turn cyclized to give 90 (Scheme 35). ${ }^{47}$

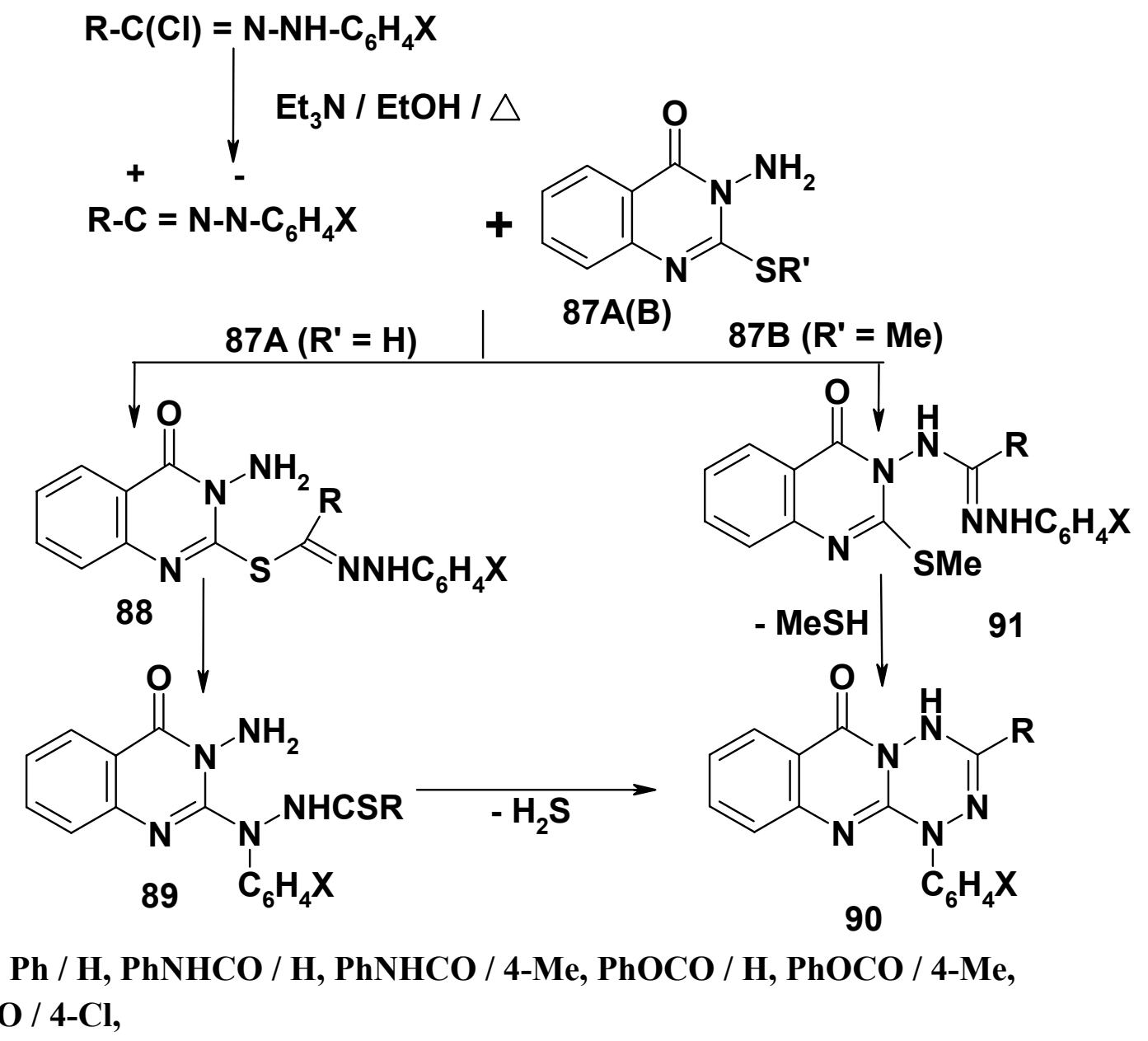

\section{Scheme 35}

Very recently, it was reported that reaction of 92A with nitrilimines, generated in situ from the hydrazonoyl halides in dioxane in the presence of triethylamine at reflux, resulted in the formation of the respective pyrazolo[3,4-d]pyrimido[1,2-b][1,2,4,5]tetrazine $93 .{ }^{48}$ The latter products were also obtained by reaction of 2-methylthio derivative 92B with the same nitrilimines (Scheme 36). 


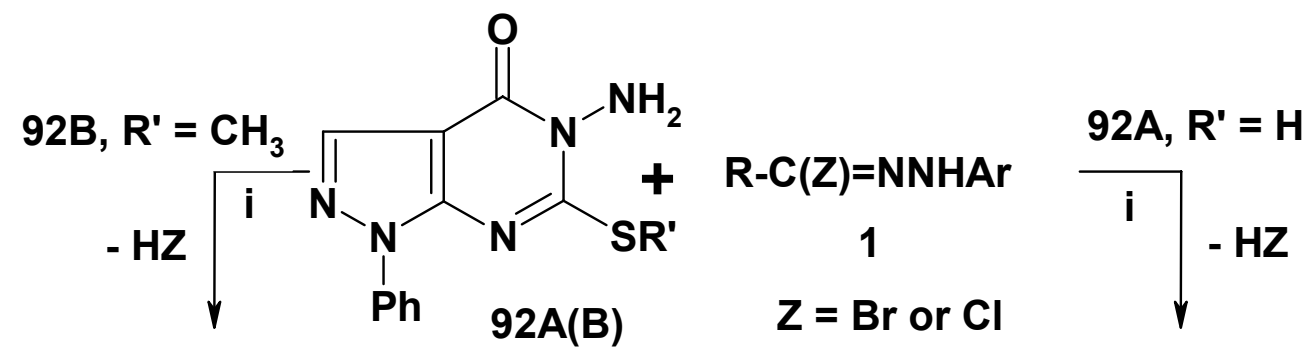<smiles>[R]C(=N[GaH])Nn1c(SC)nc2c(cnn2-c2ccccc2)c1=O</smiles><smiles>[R]C1=NN([Ge])c2nc3c(c(CC)nn3-c3ccccc3)c(=O)n2N1</smiles><smiles>[R]C(=N)Sc1nc2c(cnn2-c2ccccc2)c(=O)n1N</smiles>

$$
\mathrm{i}=\mathrm{Et}_{3} \mathrm{~N} / \text { dioxane } / \text { heat } ; \mathrm{Ar}=\mathrm{XC}_{6} \mathrm{H}_{4}
$$

$\mathrm{R} / \mathrm{X}$, a, Ph / H; b, Ph / 4-NO ; c, Ac / H; d, Ac / 4-NO

e, Ac / 4-Me; f, Ac / 4-Cl; g, Ac / 4-MeO; h, EtOCO / H;

i, EtOCO / 4-NO ${ }_{2}$; j, EtOCO / 4-Me; k, EtOCO / 4-Cl;

I, PhNHCO / H; m, PhNHCO / 4-Me; n, PhNHCO / 4-Cl;

o, PhCO / H; q, PhCO / 4-Me; u, PhCO / 4-Cl

Scheme 36

Similarly, reaction of 3-amino-2,3,5,6,7,8-hexahydro-2-thioxobenzo $\quad[4,5]$ thieno[2,3d]pyrimidin-4(1H)-ones 94 and its 2-methylthio derivative 95 with nitrilimines in refluxing ethanol afforded the fused tetrazine derivatives 96 in 64-90\% yields as end products (Scheme 37). ${ }^{49}$ 


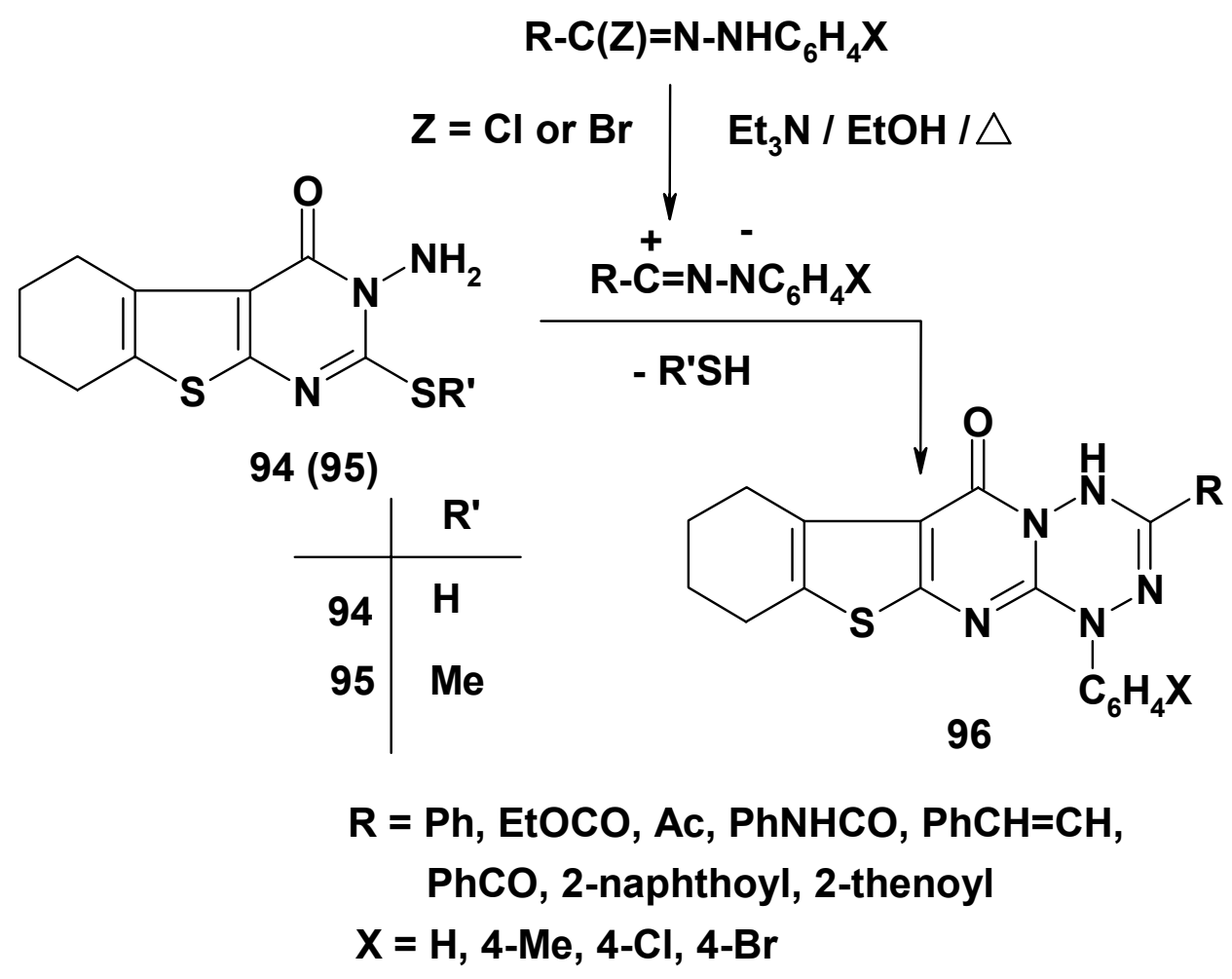

Scheme 37

\subsection{Aminopyrazines}

2-Aminopyrazine 97 reacted with $C, N$-diphenylnitrilimines and yielded pyrazolo[3,4- $b]$ pyrazine derivatives 98 in 35-60\% yields via elimination of ammonia from the initially formed cycloadduct. ${ }^{18,19}$ However, similar reaction of 2-aminopyrazine 97 with $C$-acetyl- $N$-phenylnitrilimine was reported to give the respective amidrazone 99 as end product (Scheme 38). ${ }^{18}$ 


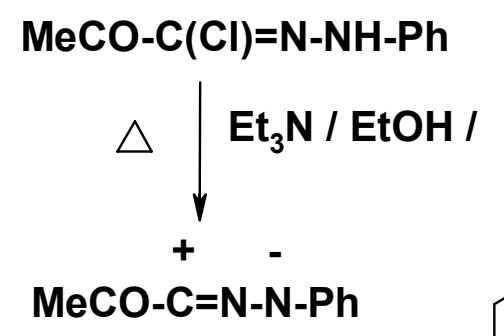<smiles>C/C=C/CCCCCC(=O)C(C)=Nc1cnccn1</smiles>

99

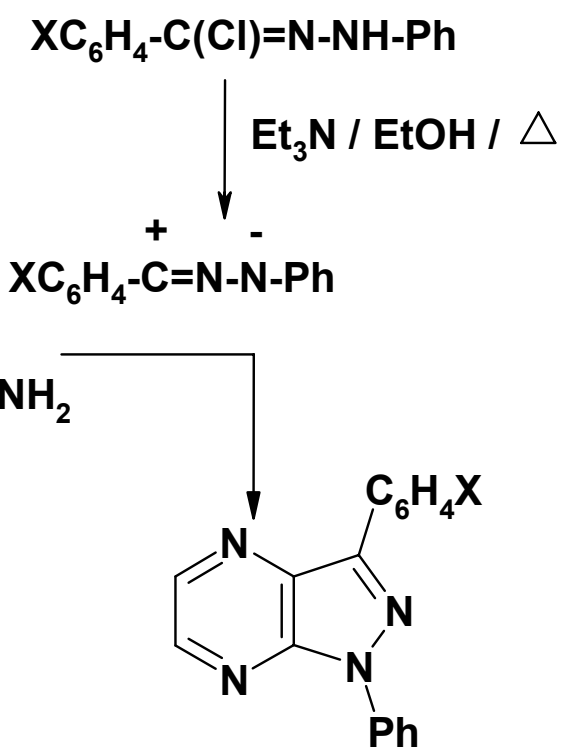

98, X : H, 4-Cl

\section{Scheme 38}

\subsection{Amino-1, 2,4-triazines}

Very recently Shawali et al. ${ }^{43,50}$ reported that reaction of nitrilimines with either 4-amino-2,3dihydro-6-substituted-3-thioxo-[1,2,4]triazin-5(4H)-ones 100A or 4-amino-2,3-dihydro-3methylthio-6-substituted-[1,2,4]triazin-5(4H)-ones 100B gave the respective $[1,2,4]$ triazino[4,3b] $[1,2,4,5]$ tetrazine derivatives $\mathbf{1 0 1}$ in $40-95 \%$ yield (Scheme 39 ). 


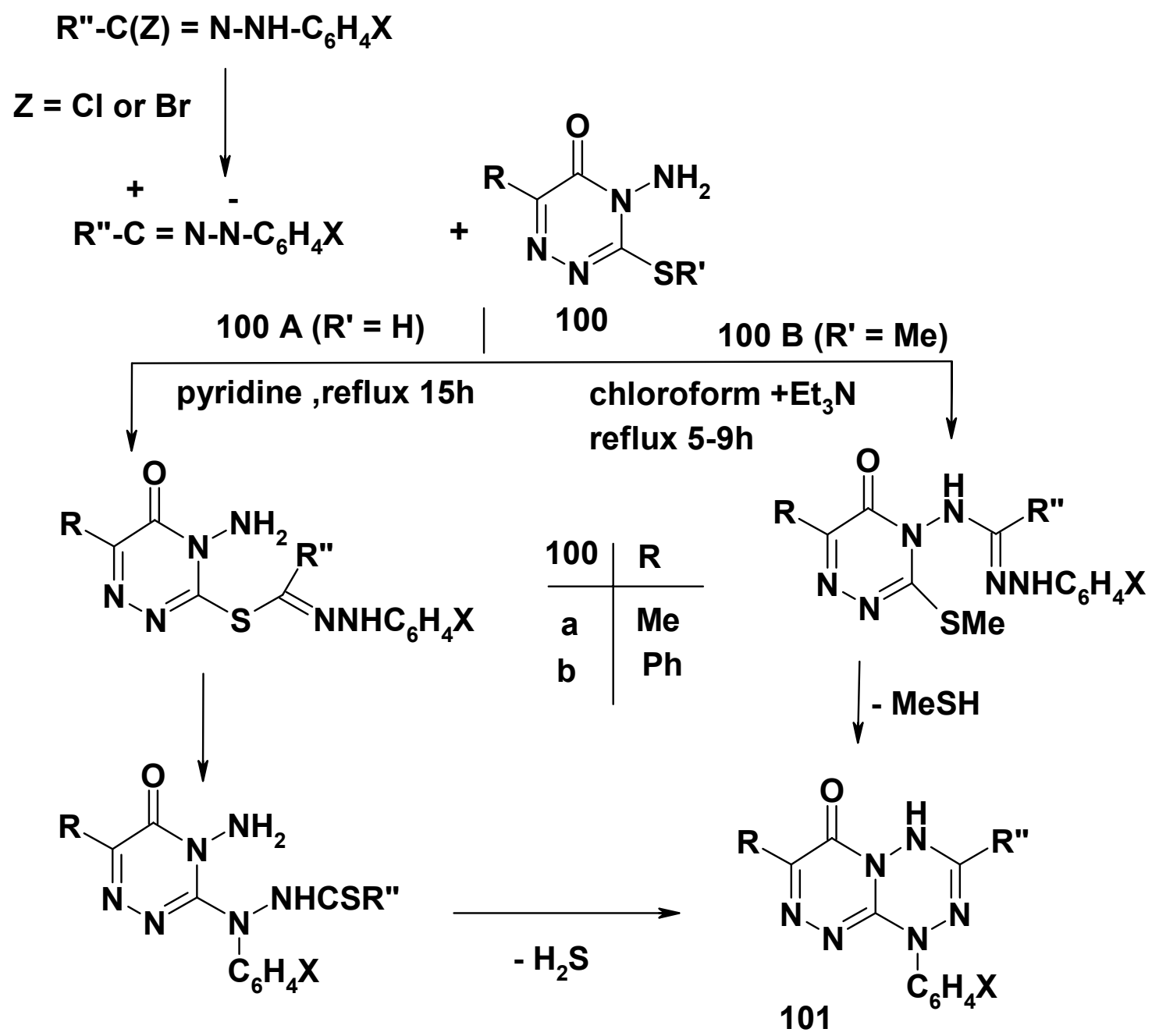

R / R" : Me / EtOCO, Me / PhNHCO, Me / MeCO, Me / 2-naphthoyl, $\mathrm{Me} /$ 2-thenoyl, $\mathrm{Ph} / \mathrm{PhNHCO}, \mathrm{Ph} / \mathrm{MeCO}, \mathrm{Me} / \mathrm{XC}_{6} \mathrm{H}_{4} \mathrm{~N}=\mathrm{N}$ $\mathrm{X}: \mathrm{H}, 4-\mathrm{Me}, 4-\mathrm{Cl}, 4-\mathrm{MeO}, 3-\mathrm{Me}, 3-\mathrm{Cl}, 4-\mathrm{NO}_{2}$

Scheme 39

\section{Reactions with enamines}

There are four types of enamines, namely the acyclic enamines 102, endocyclic enamines $\mathbf{1 0 3}$, exocyclic enamines 104 and heterocyclic enamines 105 (Chart 1). The substituent $\mathrm{X}$ is usually an electron-withdrawing group such as $\mathrm{CN}, \mathrm{RCO}, \mathrm{ROCO}$, and $\mathrm{NO}_{2}$. According to the nature of such a substituent, enamines are classified into further groups. For example, when $\mathrm{X}$ is $\mathrm{CN}$, acyl and COOR, such enamines are referred to as enaminonitriles, enaminones and enaminoesters. If the alpha hydrogen of acyclic enamine is substituted by a substituted amino group, such enamines are referred to as ketene aminals 106 and $\mathbf{1 0 7}$ (Chart 1). 
<smiles>[X]C=C([R])N([R])[R]</smiles>

102<smiles>[X]C1=C([R])N([R])CCC1</smiles>

105<smiles>[X]C1=C(N([R])[R])CCCCC1</smiles>

103<smiles>[X]C=C([R10])[R12]</smiles>

106<smiles>[X]C=C1CCCCCN1[R]</smiles>

104<smiles>[X]C=C1N([R])CCCCN1[R]</smiles>

$$
\begin{aligned}
R=R^{\prime} & =\text { alkyl group }=M e, E t \\
R^{\prime} R^{\prime} & =-\left(\mathrm{CH}_{2}\right)_{n}-; \quad n=4,5,6 \\
X & =\mathrm{CN} ; \text { ArCO; ROCO }
\end{aligned}
$$

\section{Chart 1}

\subsection{Acyclic enamines}

\subsubsection{Enamines}

Reactions of $C$-ethoxycarbonyl- $N$-phenylnitrilimine, derived from ethyl $N$-phenyl hydrazonochloroacetate, with 2-[(N-methyl- $N$-phenylamino $)]-1$-butene 108A and $\alpha-[(N$-methyl$\mathrm{N}$-phenyl)amino]styrene 108B were reported to give the respective 5-substituted pyrazole derivatives 109A and 109B, which upon hydrolysis afforded the respective acids 110A and 110B, respectively (Scheme 40). ${ }^{51}$ 


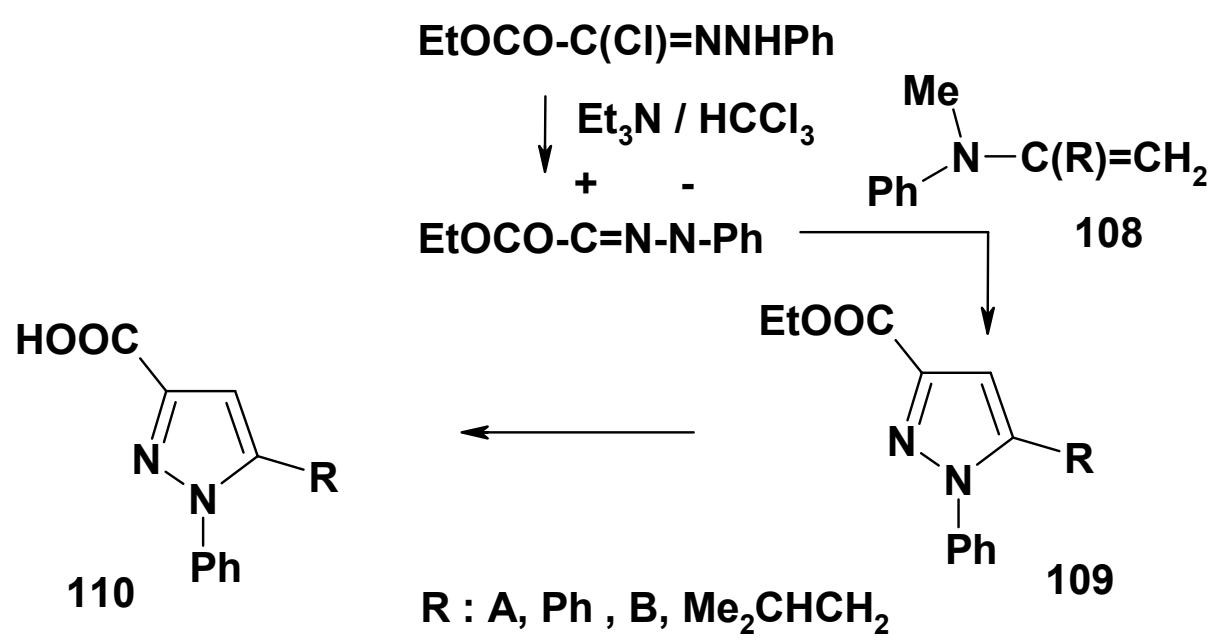

Scheme 40

Other 1,3,4-trisubstituted-pyrazoles 112 were also prepared in 55-73\% yields by reactions of enamines 111 with various nitrilimines (Scheme 41). ${ }^{52,53}$

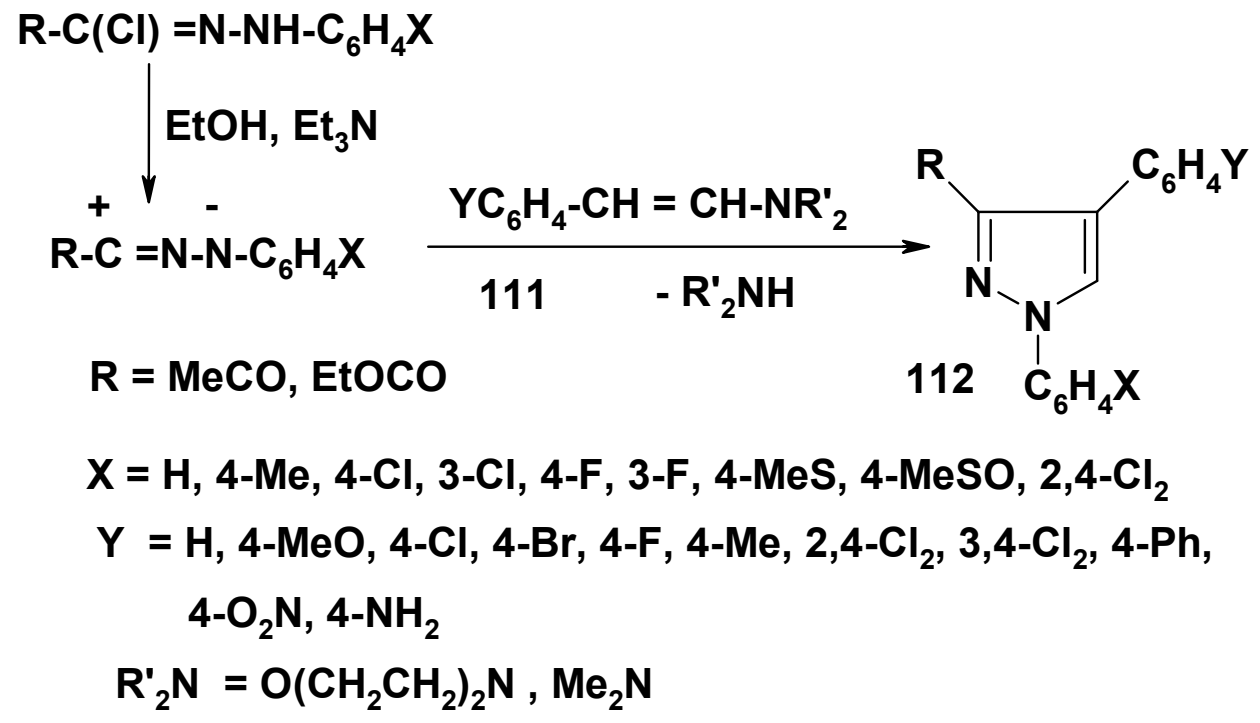

\section{Scheme 41}

The 1,3-dipolar cycloaddition of $N$-aryl- $C$-ethoxycarbonylnitrilimine with enamine 113 was reported to give the pyrazoline cycloadduct 114, which underwent deamination when heated in dioxane in the presence of hydrochloric acid to give $\mathbf{1 1 5}$ as end product (Scheme 42). ${ }^{54}$ 


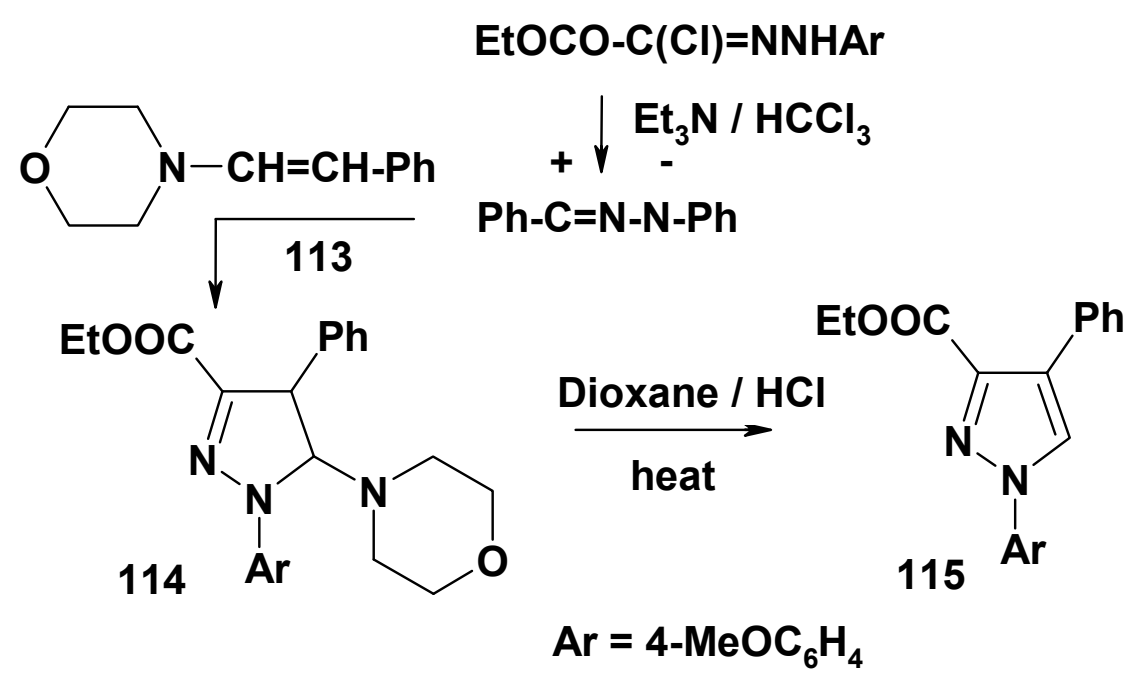

Scheme 42

Other 1,4-diarylpyrazole derivatives 118 were prepared in 90-95\% yield via reaction of nitrilimines with resinbound piperazine enamines 116 followed by cleavage of the initially formed resin-bound pyrazoline cycloadducts 117 by heating them in DCM containing 3\% trifluroacetic acid. During this treatment, piperazine is eliminated to give $\mathbf{1 1 8}$ as end products (Scheme 43). ${ }^{55}$

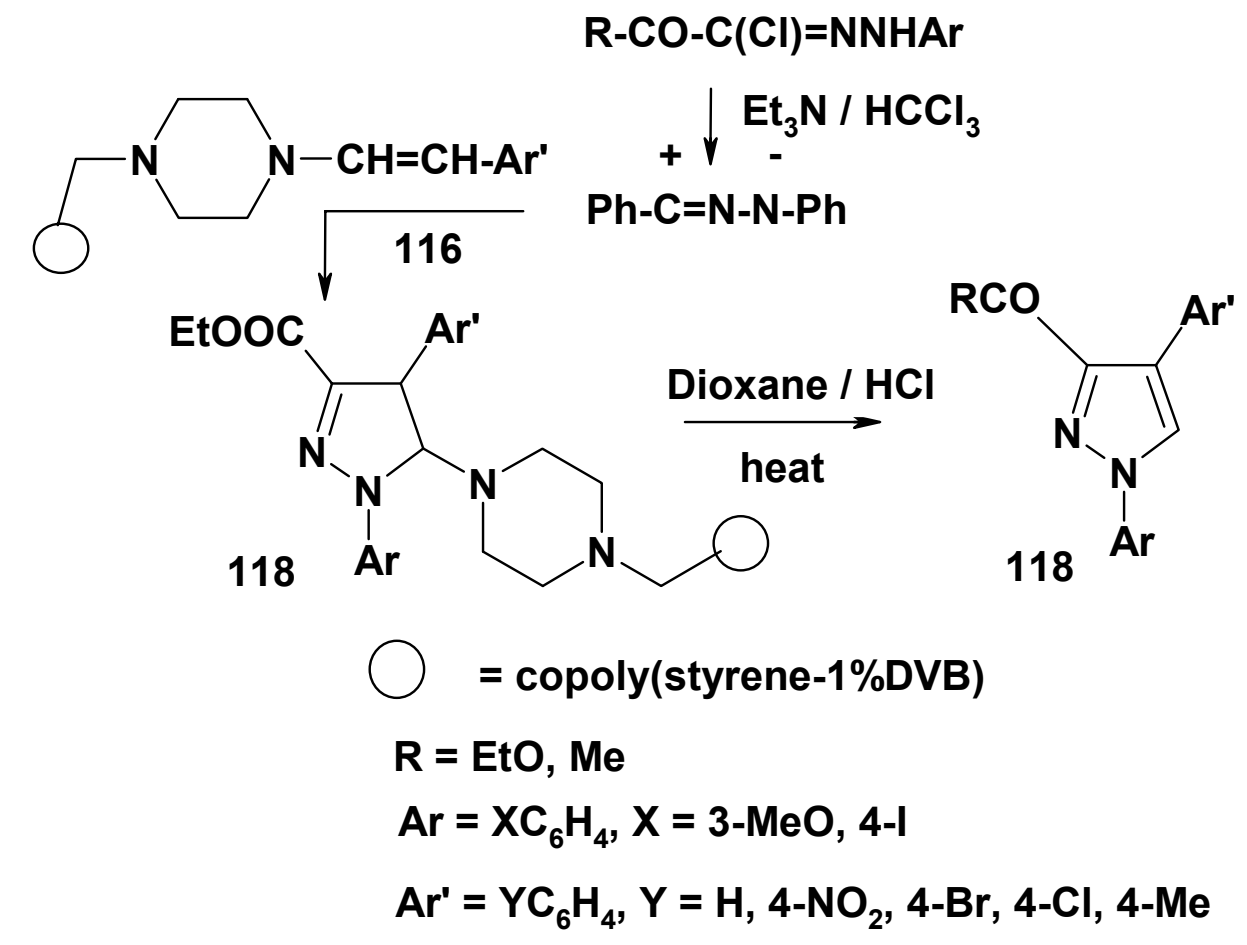

Scheme 43 
The reaction of $\beta$-vinylenamine 119 with diphenylnitrilimine was reported to be site-selective as it occurred at the unsubstituted $\mathrm{C}=\mathrm{C}$ double bond to give only $\mathbf{1 2 0}$ in $39 \%$ yield (Scheme 44$).{ }^{56}$

\section{$\mathrm{PhC}(\mathrm{Cl})=\mathrm{NNHPh}$}

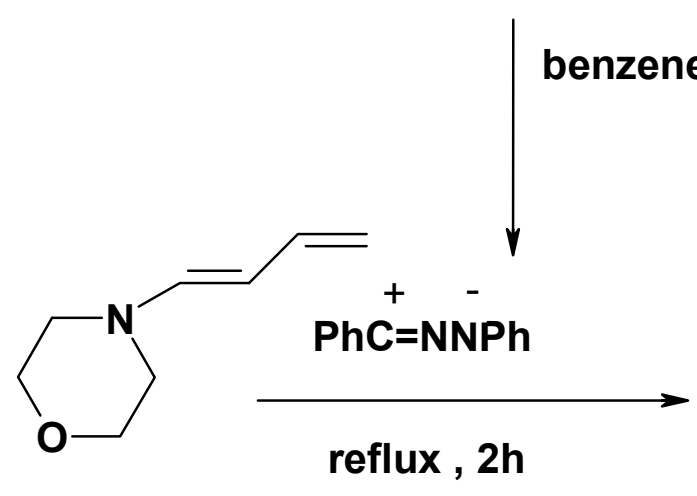

119

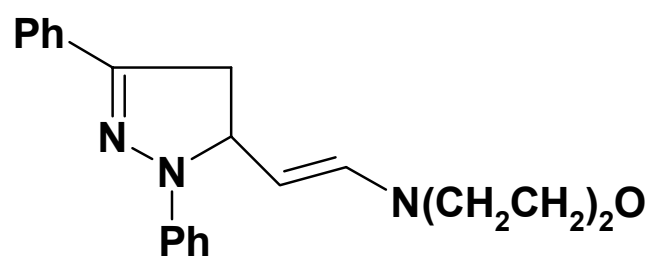

120

\section{Scheme 44}

In another report, it was indicated, however, that the reaction of the enamine 121 with $C, N$ diarylnitrilimines in benzene at room temperature gave a mixture of four products namely 122125 in $12-53 \%$ yields. ${ }^{54}$ When this reaction was conducted at $80^{\circ} \mathrm{C}$ only the products $\mathbf{1 2 4}$ and 125 were produced (Scheme 45). ${ }^{54}$ 


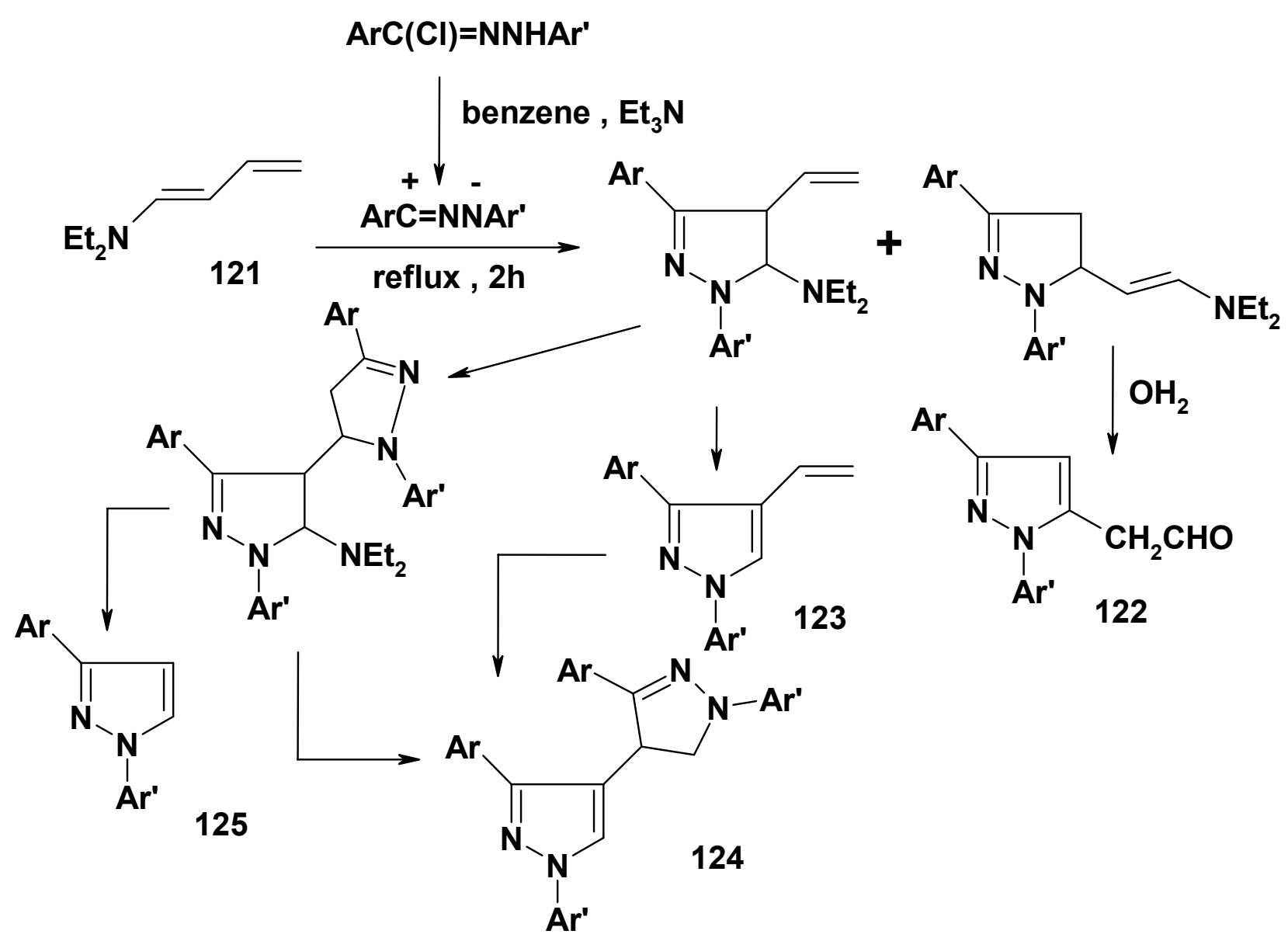

$\mathrm{Ar} / \mathrm{Ar} r^{\prime}=\mathrm{Ph} / \mathrm{Ph}, \mathrm{Ph} / 4-\mathrm{ClC}_{6} \mathrm{H}_{4}, \mathrm{Ph} / 4-\mathrm{NO}_{2} \mathrm{C}_{6} \mathrm{H}_{4}, 4-\mathrm{NO}_{2} \mathrm{C}_{6} \mathrm{H}_{4} / \mathrm{Ph}$

\section{Scheme 45}

The reactions of $C$-acyl- $N$-arylnitrilimines with the enamines $\mathbf{1 2 6}$ in benzene yielded the pyrazole derivatives $\mathbf{1 2 7}$ in $45-65 \%$ yields. ${ }^{57}$ The latter products underwent deamination upon heating in ethanol in the presence of hydrochloric acid to afford the aminopyrazole derivative 128 in $85-96 \%$ yields (Scheme 46 ). ${ }^{57}$ 


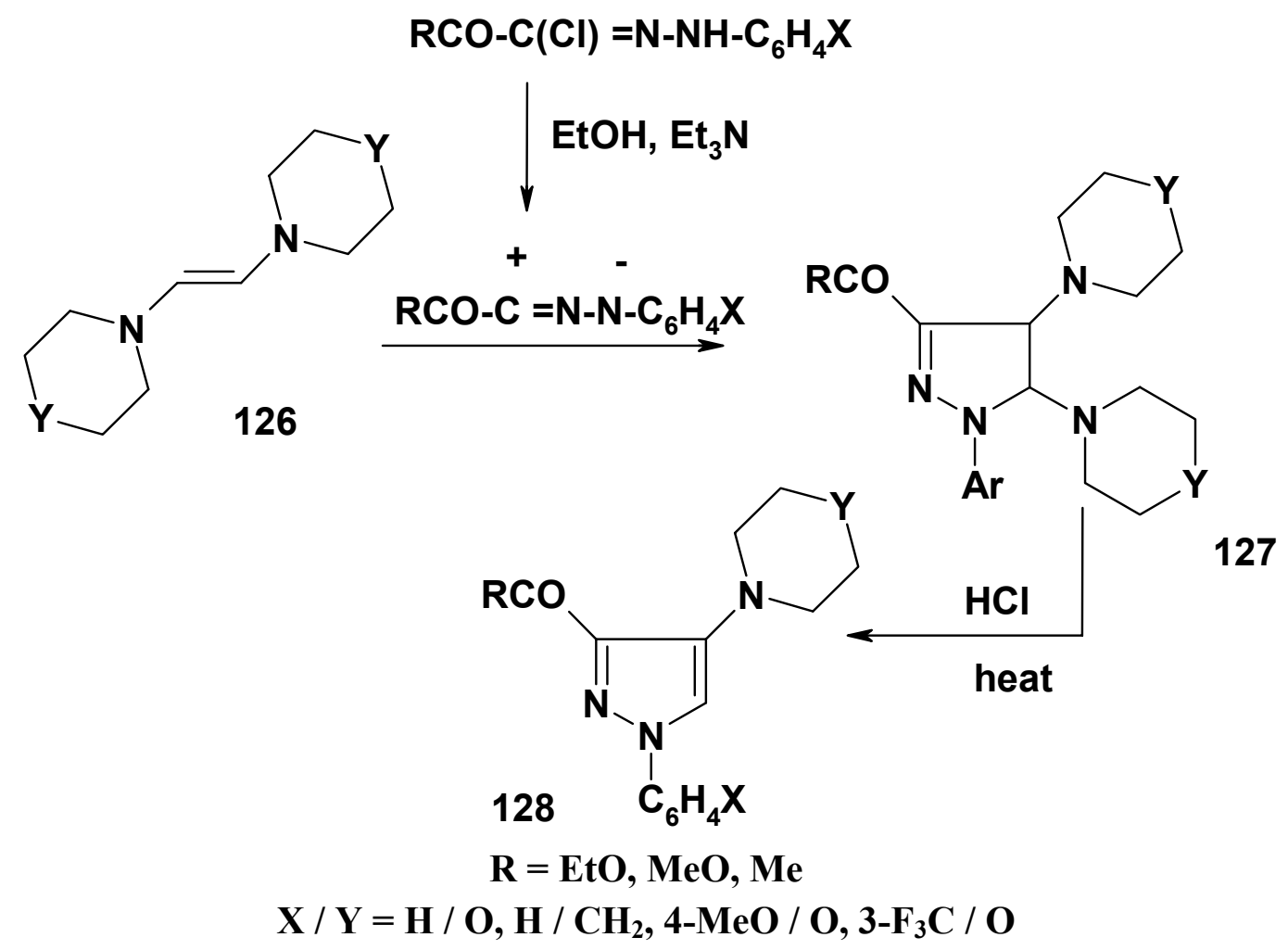

\section{Scheme 46}

Reaction of 2-phenylthioenamine 129 with $C, N$-diphenylnitrilimine yielded 4-phenylthio1,3-diphenylpyrazole 130 in $40 \%$ yield (Scheme 47$){ }^{58}$

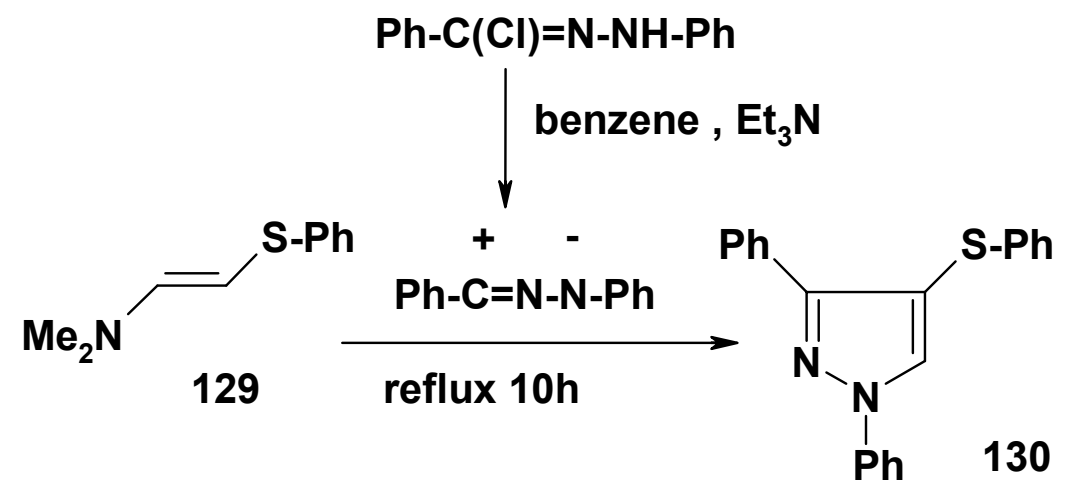

\section{Scheme 47}

Reactions of $C, N$-diaryl nitrilimines with each of the enamines 131A and 131B yielded pyrazolines 132 and 133 in $70 \%$ and $80 \%$ yields, respectively. Heating each of the latter products in ethanol in presence of hydrochloric acid afforded in both cases the the respective pyrazole derivatives 134 in $90 \%$ yield (Scheme 48 ). ${ }^{59}$ 


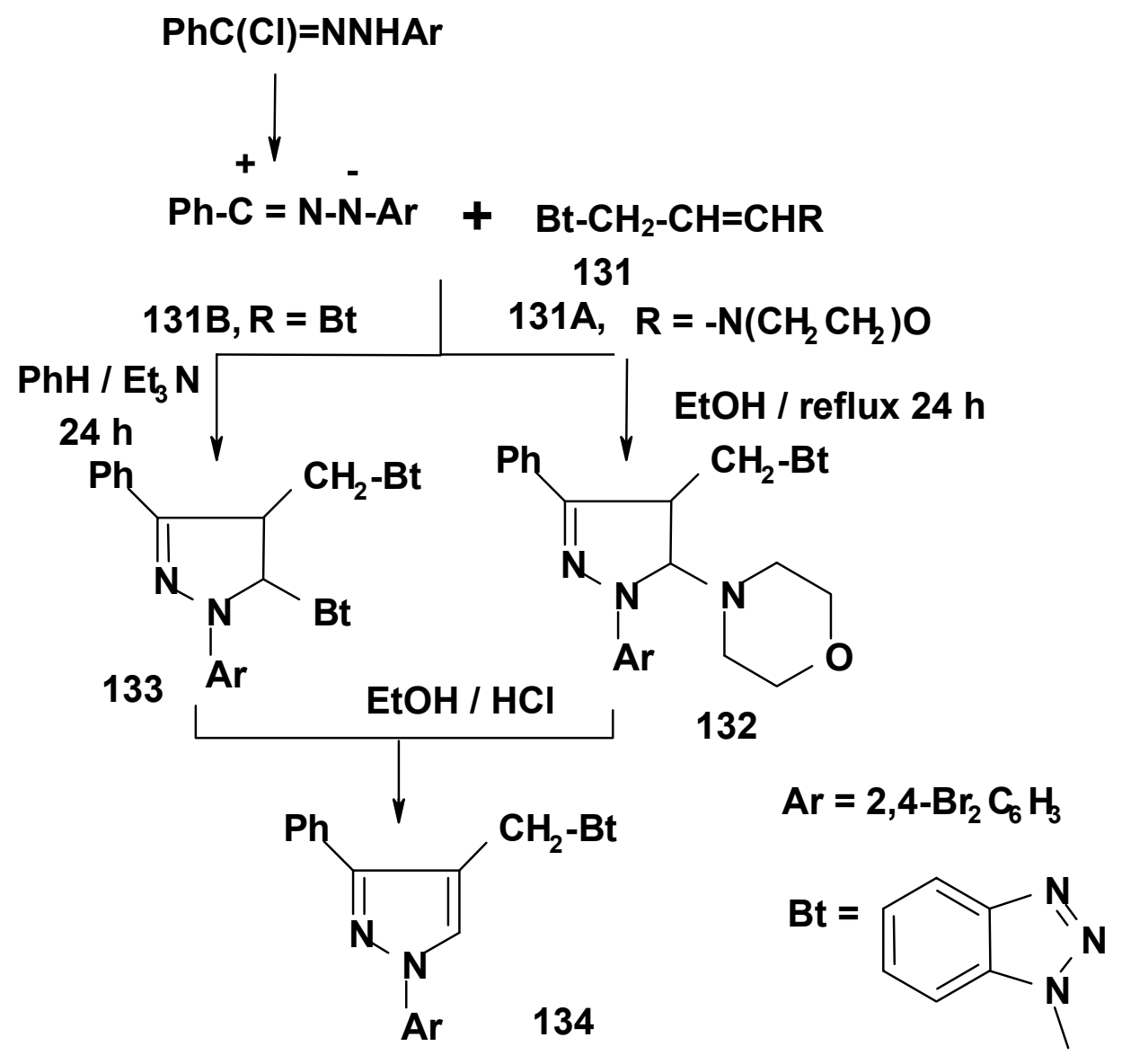

Scheme 48

$C, N$-Diphenylnitrilimine reacted with the enamines 135 and gave 1,3,4-triphenylpyrazole cycloadducts 136 (Scheme 49). ${ }^{60}$
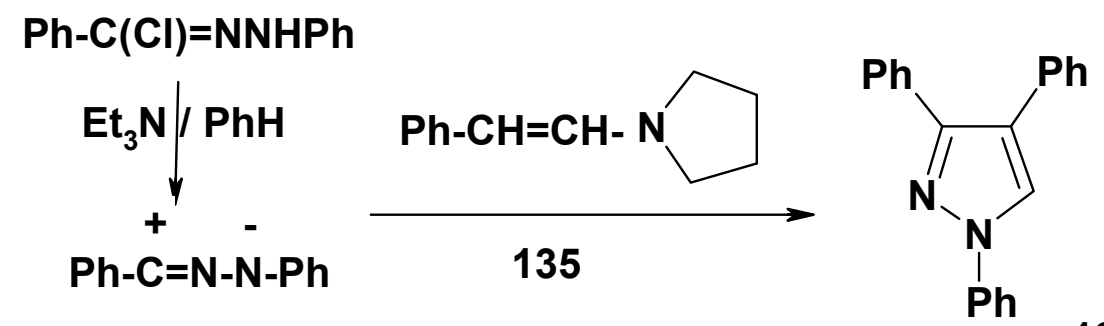

136

Scheme 49

\subsubsection{Enaminones}

Reactions of several enaminones of type 137 with each of $C$-aryl-, $C$-acyl-, $C$-ethoxycarbonyland $C$-cyano- $N$-arylnitrilimines, generated in situ by base catalyzed dehydrohalogenation of the 
respective hydrazonoyl halides, proved to be regioselective and afforded the corresponding 1aryl-3,4-disubstituted-pyrazoles 138 in 2-90 \% yields (Scheme 50 ). ${ }^{61-66}$

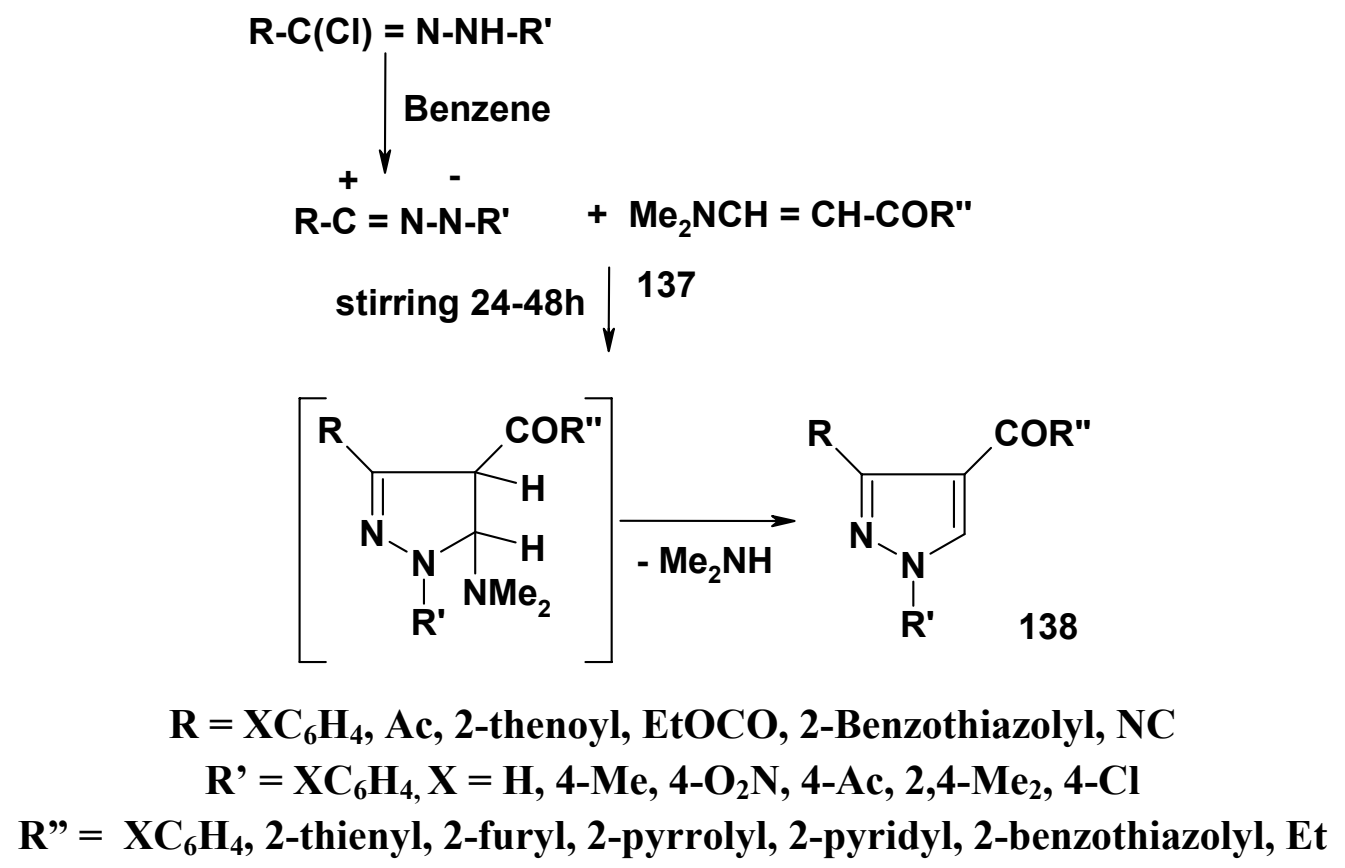

\section{Scheme 50}

Treatment of each of the products 138 having 3,4-diacyl and 3-ethoxycarbonyl-4-acyl groups each with hydrazine hydrate afforded the respective pyrazolo[3,4- $d]$ pyridazines 139 and 140 in $78-96 \%$ yields (Scheme 51). ${ }^{62-64,66}$

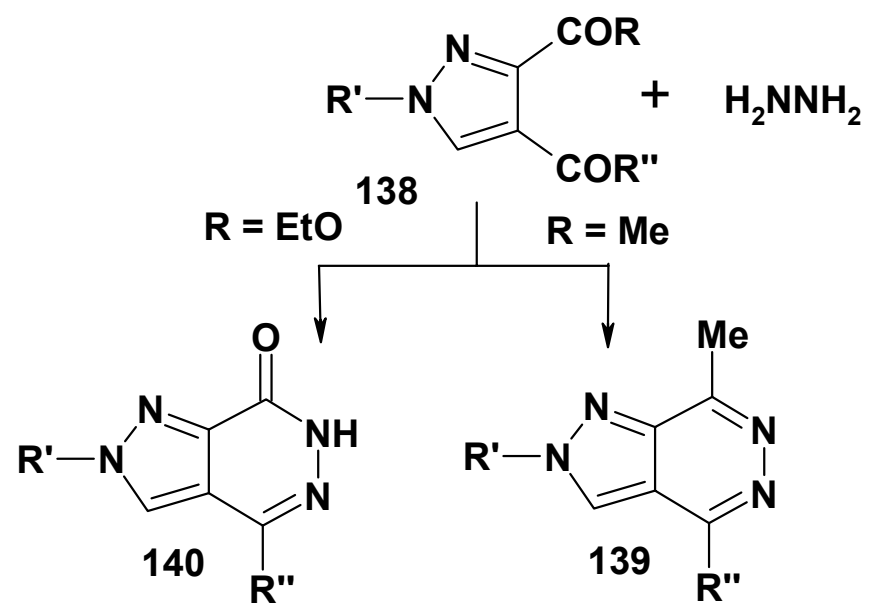

139, R' = Ph, 4-MeC $\mathrm{H}_{4} ; \mathrm{R}^{\prime \prime}=\mathrm{Ph}, 2$-thienyl, 2-pyridyl, Et, 2-benzothiazolyl

$140, R^{\prime}=4-02 \mathrm{NC}_{6} \mathrm{H}_{4}, \mathrm{R}^{\prime \prime}=2-$ pyridyl

Scheme 51 
Also, the enaminone 141 reacted with $C$-acetyl- $N$-phenylnitrilimine and afforded the pyrazole derivative 142 in $43 \%$ yield which upon treatment with hydrazine hydrate yielded 143 in $73 \%$ yield (Scheme 52 ). ${ }^{67}$

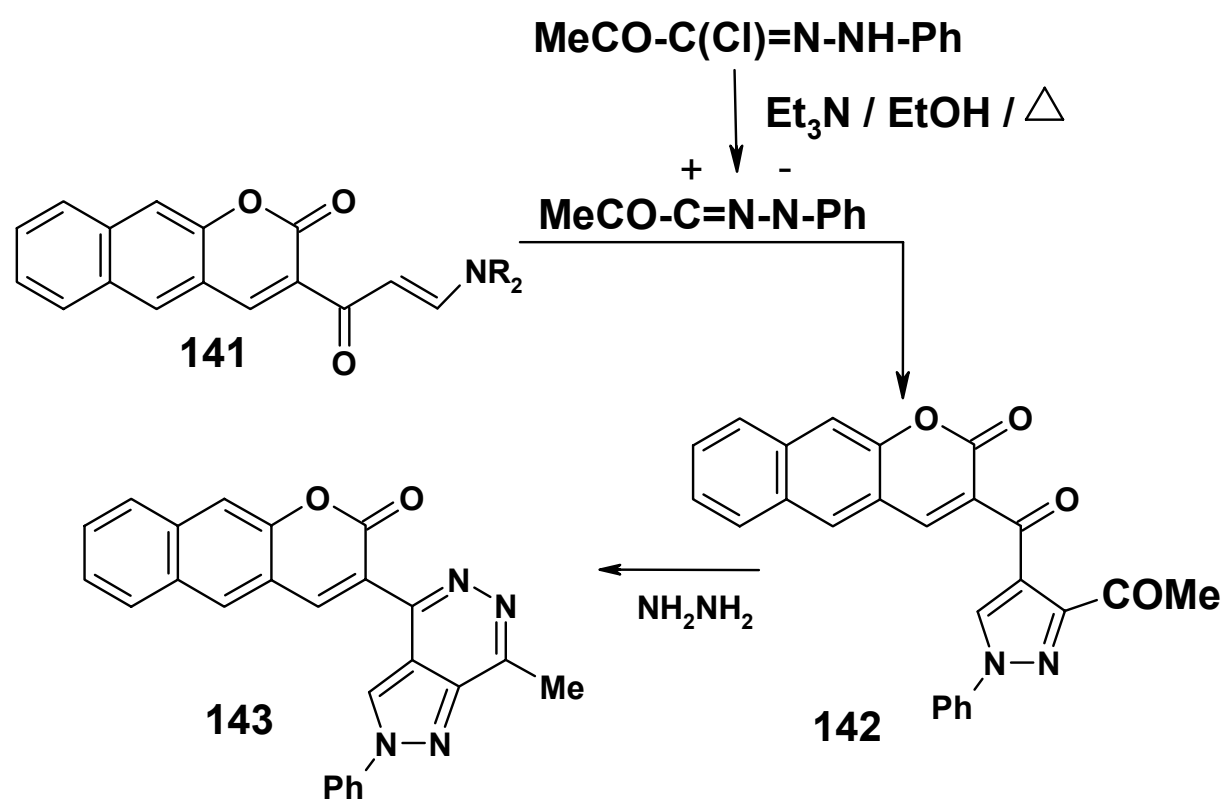

\section{Scheme 52}

Other 1,3,4-trisubstituted pyrazoles 145 were also prepared in 55-73\% yields by reactions of enaminones 144 with various nitrilimines (Scheme 53). ${ }^{52}$

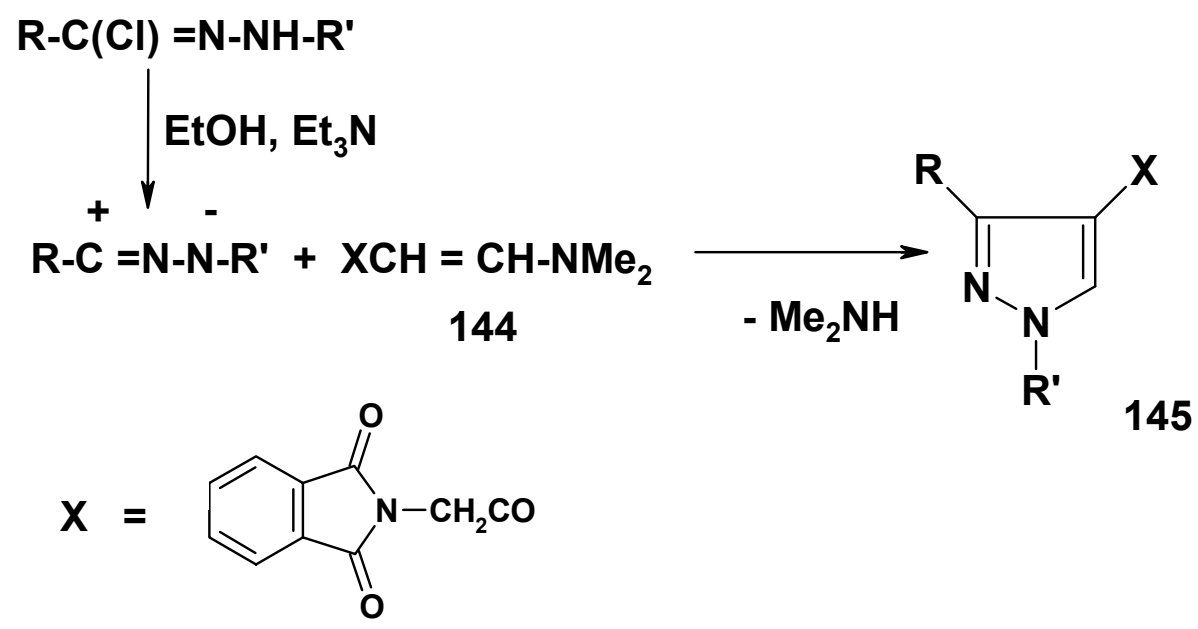

R / R' $=$ EtOCO / 4-ClC $6 \mathrm{H}_{4}$, EtOCO / 4-Me, $\mathrm{MeCO} / 4-\mathrm{ClC}_{6} \mathrm{H}_{4}$

Scheme 53 
Reaction of $C$-acetyl- $N$-phenylnitrilimine with ynaminonone 146 was reported to be siteselective. It yielded the pyrazole derivative 147 in $48 \%$ yield (Scheme 54 ). ${ }^{68}$

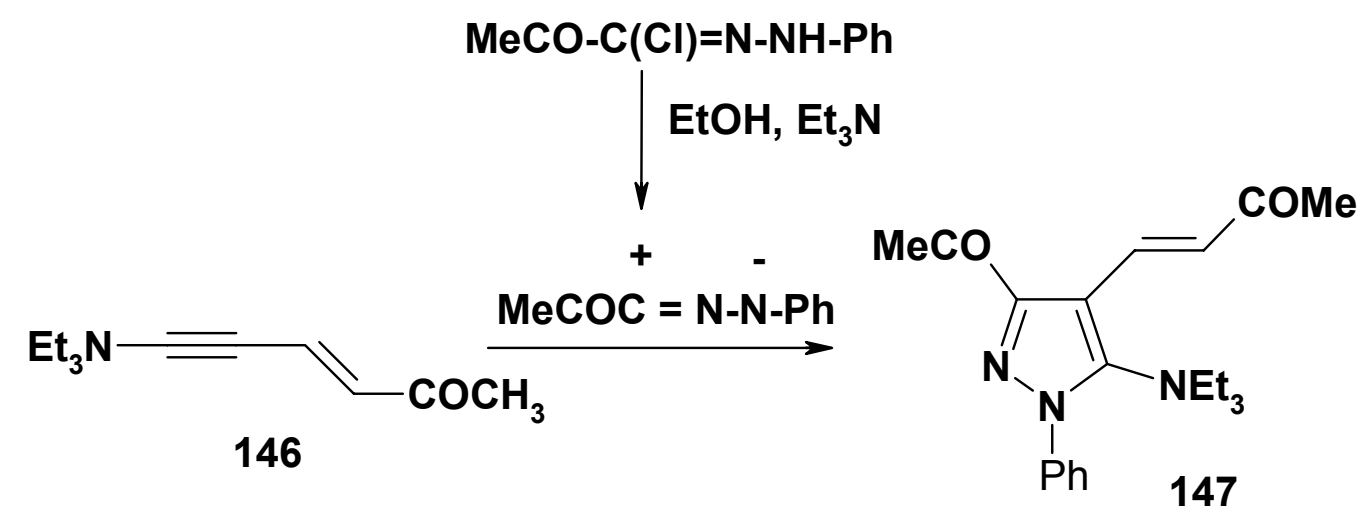

\section{Scheme 54}

In contrast to the foregoing results, it was indicated in one report that reaction of $C$-acetyl- $N$ phenylnitrilimine with the enaminone 148 afforded the 3,5-diacylpyrazole derivative 149 in 58 $\%$ yield instead of the expected 3,4-diacyl- analog 150. ${ }^{69}$ This regiochemical result seems to need further confirmation (Scheme 55).

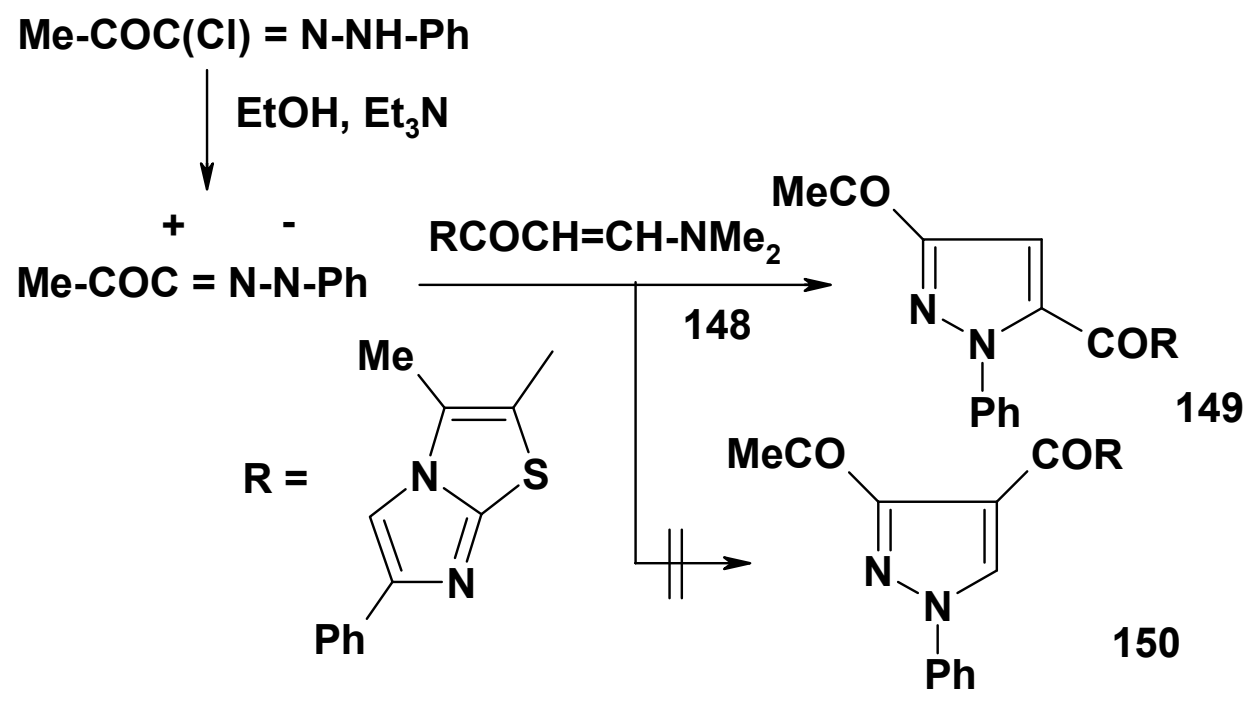

\section{Scheme 55}

\subsubsection{Nitroenamines}

Also, $N$-aryl nitrilimines reacted with nitroenamine 151 and afforded the respective 1-aryl-3nitro- 4-substituted pyrazoles 152 in 5-20\% yields (Scheme 56). ${ }^{70}$ 


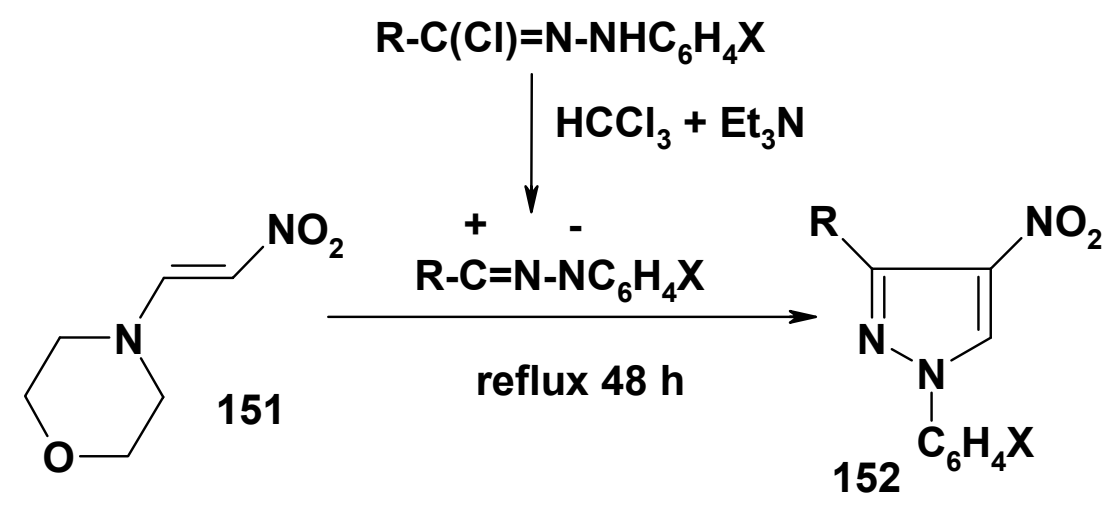

$\mathrm{R} / \mathrm{X}: \mathrm{Ph} / \mathrm{H}, \mathrm{EtOCO} / \mathrm{H}, \mathrm{EtOCO} / 4-\mathrm{NO}_{2}$

Scheme 56

Also, various 3,4-disubstituted-1-arylpyrazoles 154 were prepared in 55-73\% yields by reactions of enaminones 153 with various nitrilimines (Scheme 57). ${ }^{52}$

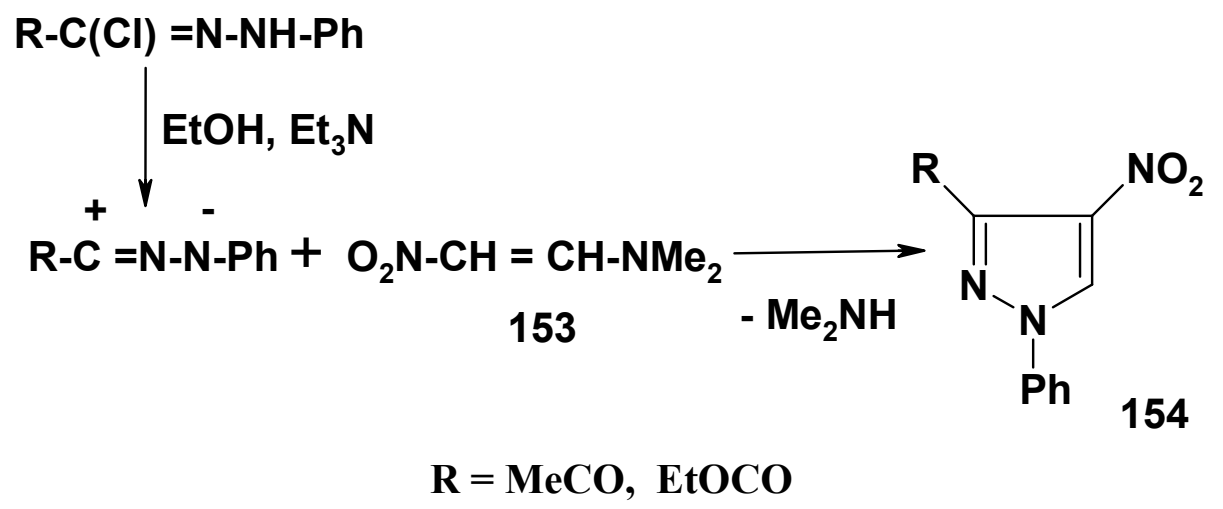

\section{Scheme 57}

\subsubsection{Enaminonitriles}

Various 1-aryl-4-cyano-3-substituted-pyrazoles 156 were also prepared in $55-73 \%$ yields by reactions of enamines $\mathbf{1 5 5}$ with various nitrilimines (Scheme 58). ${ }^{71}$ 


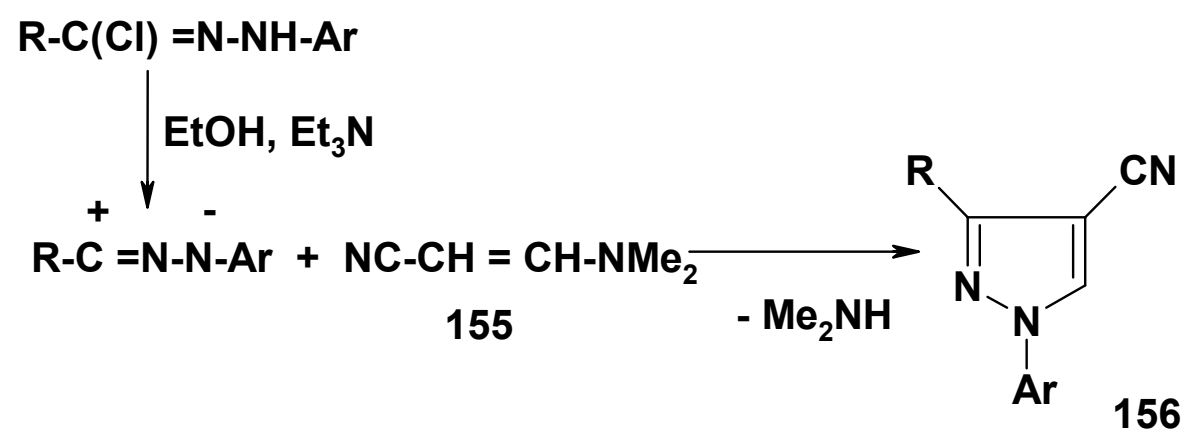

$\mathrm{Ar}=\mathrm{XC}_{6} \mathrm{H}_{4}$

$\mathrm{R} / \mathrm{X}=\mathrm{MeCO} /$ 4-Cl, EtOCO / 4-Cl, Ph / 4-NO, PhNHCO / 4-Cl

\section{Scheme 58}

Also, the reactions of $N$-aryl $C$-ethoxycarbonyl- and $C$-phenylaminocarbonyl- nitrilimines were reported to react with 1-cyanomethylenaminonitriles $\mathbf{1 5 7}$ in ethanol to give the respective pyrazolo[3,4-b]pyridines 159 in $55 \%$ yield. $^{72}$ In this case the reaction proceeds to give the pyrazole derivatives $\mathbf{1 5 8}$ that cyclize in situ to give $\mathbf{1 5 9}$ as end products (Scheme 59).

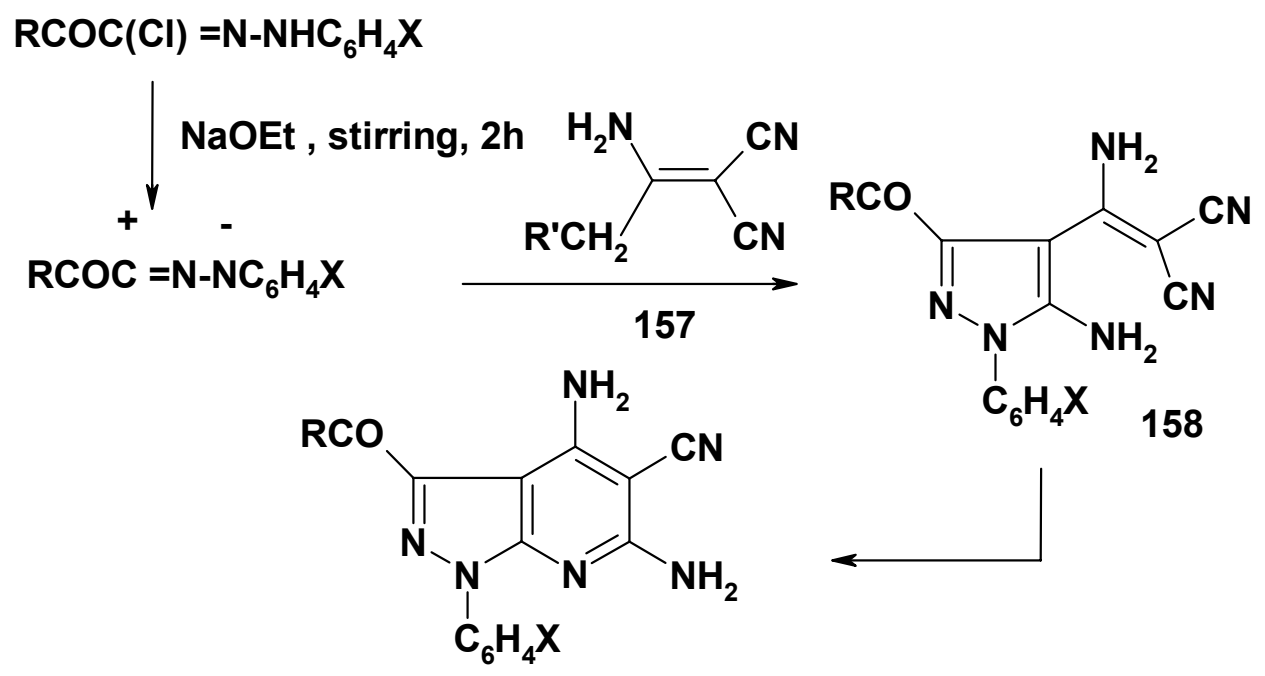

159, R / X : PhNH / 4-CI

\section{Scheme 59}

\subsubsection{Enaminoesters}

When a mixed solution of $C$-phenyl- $N$-benzenesulfonyl-nitrilimine and one equivalent of each of the enamino esters $\mathbf{1 6 0}$ in tetrahydrofuran was allowed to stand at room temperature, the respective pyrazole derivatives $\mathbf{1 6 1}$ were obtained in $87-89 \%$ yields. The same result was obtained when two equivalents of $\mathbf{1 6 0}$ were used (Scheme 60). ${ }^{73}$ 


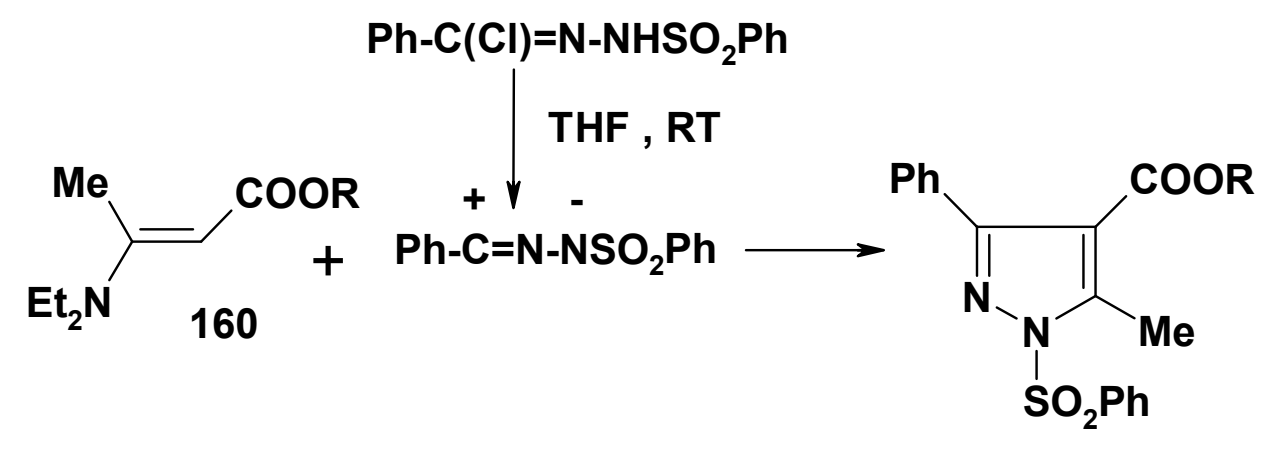

161, R : a, Me, b, $\mathrm{CH}_{2}=\mathrm{CH}-\mathrm{CH}_{2}$

Scheme 60

However, similar reaction of $C$-phenyl- $N$-phenylsulphonylnitrilimine with enaminoester 162 yielded no pyrazole. It gave instead a mixture of 163 and 164 (13\% yield) and/or 165 in $48 \%$ yield (Scheme 61). ${ }^{73}$
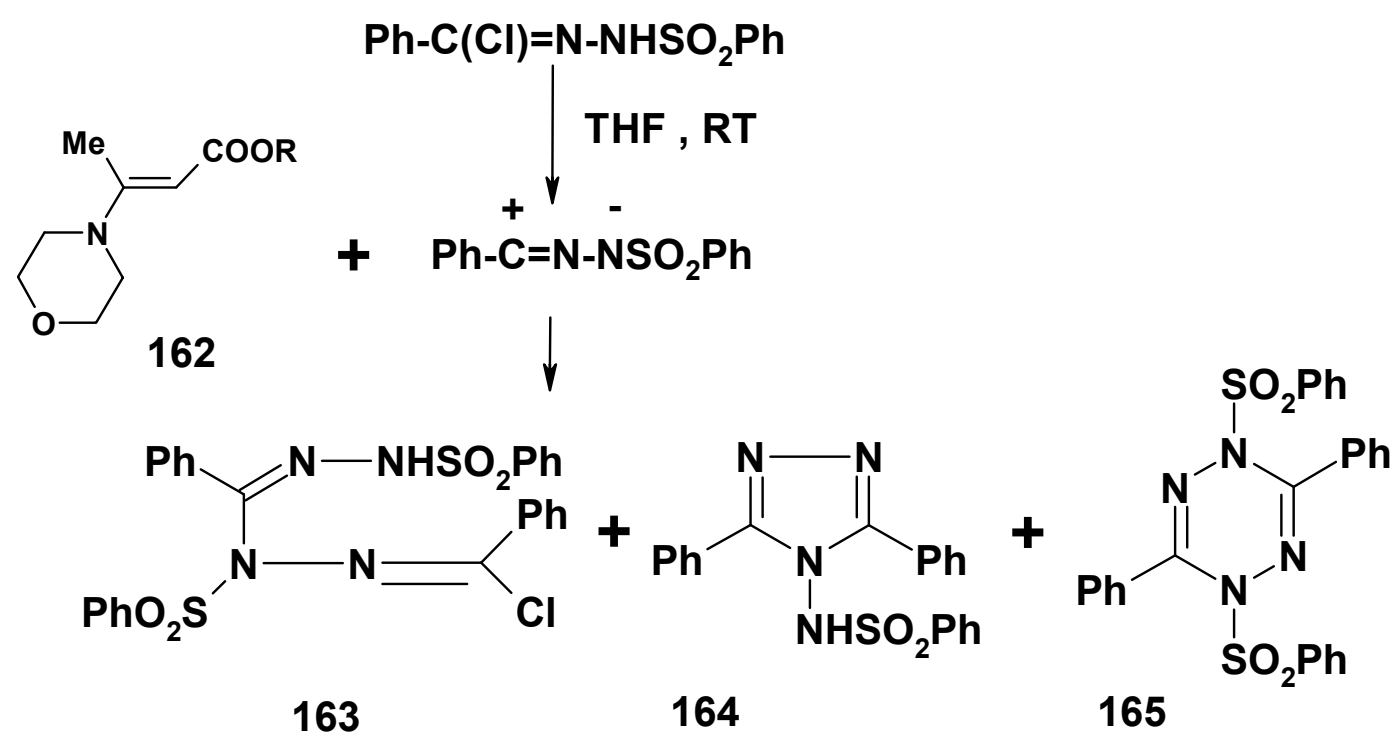

Scheme 61

$C, N$-Diphenylnitrilimine reacted with the 1-substituted enaminoester 166 to afford the pyrazole derivative $\mathbf{1 6 7}$ in $26 \%$ yield (Scheme 62). ${ }^{74}$ 


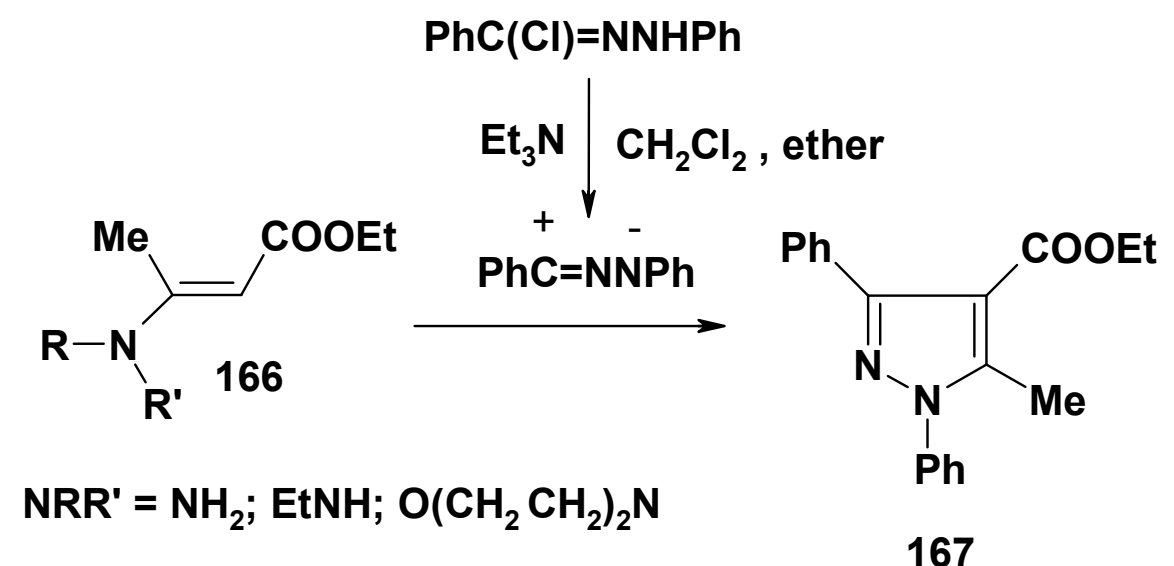

Scheme 62

Reaction of $N$-aryl- $C$-ethoxycarbonyl-nitrilimine with 1-ethoxycarbonylmethylenaminonitriles 168 gave the respective pyrano[2,3-c]pyrazole 170 in $52 \%$ yield. $^{72}$ In this case, it seems that the enamine 168 behaves as active methylene compound that reacts with nitrilimine to give the pyrazolone intermediate $\mathbf{1 6 9}$ which cyclizes in situ to yield $\mathbf{1 7 0}$ as end product (Scheme 63).

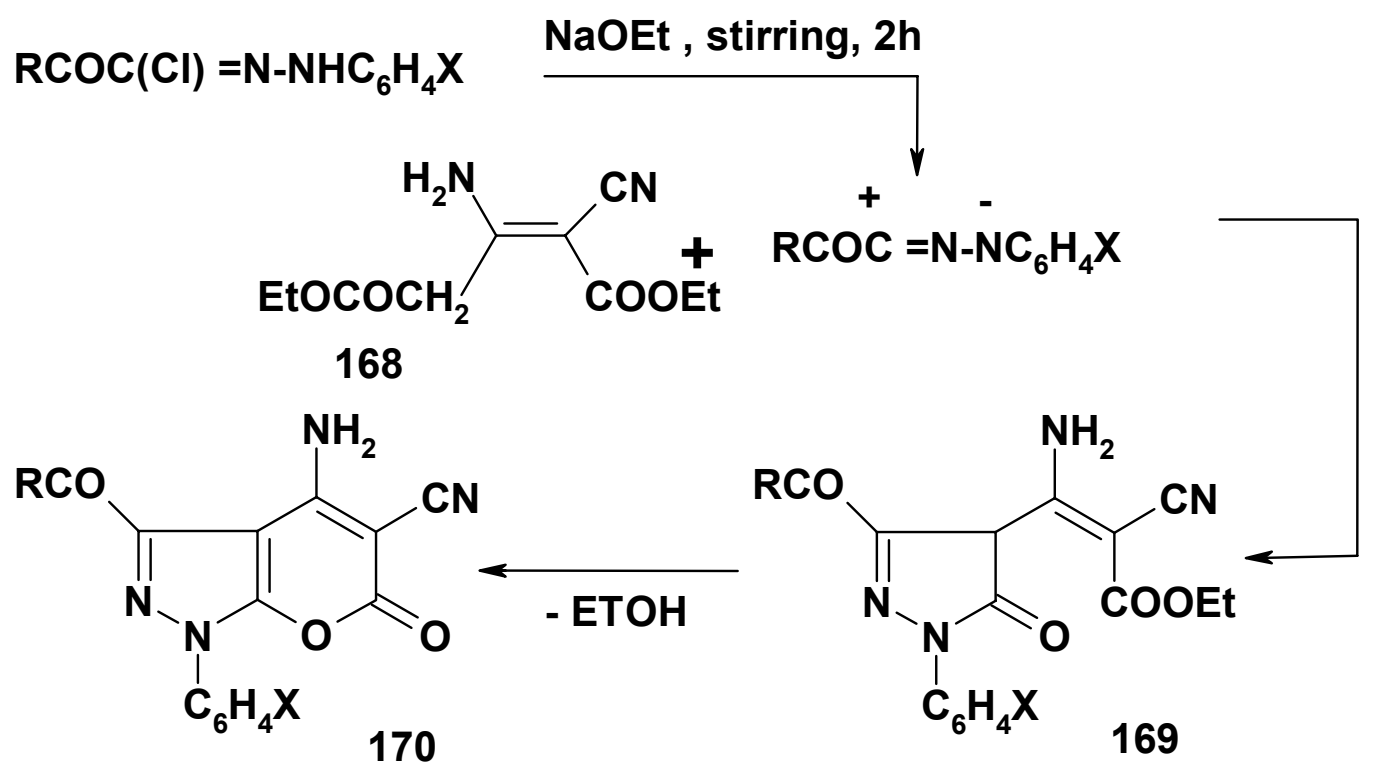

R / X : EtO / 4-Me

\section{Scheme 63}

$C, N$-Diphenylnitrilimine reacted with the enamines $\mathbf{1 7 1}$ and $\mathbf{1 7 2}$ and gave the pyrazoline cycloadducts 173 and 174, respectively. ${ }^{60}$ However, similar reaction of 172 with other 
nitrilimines afforded the pyrazole derivatives $\mathbf{1 7 5}$ which upon treatment with hydrazine hydrate yielded 176 (Scheme 64 ). ${ }^{75,76}$

$\mathrm{Ph}-\mathrm{C}(\mathrm{Cl})=\mathrm{NNHPh}$
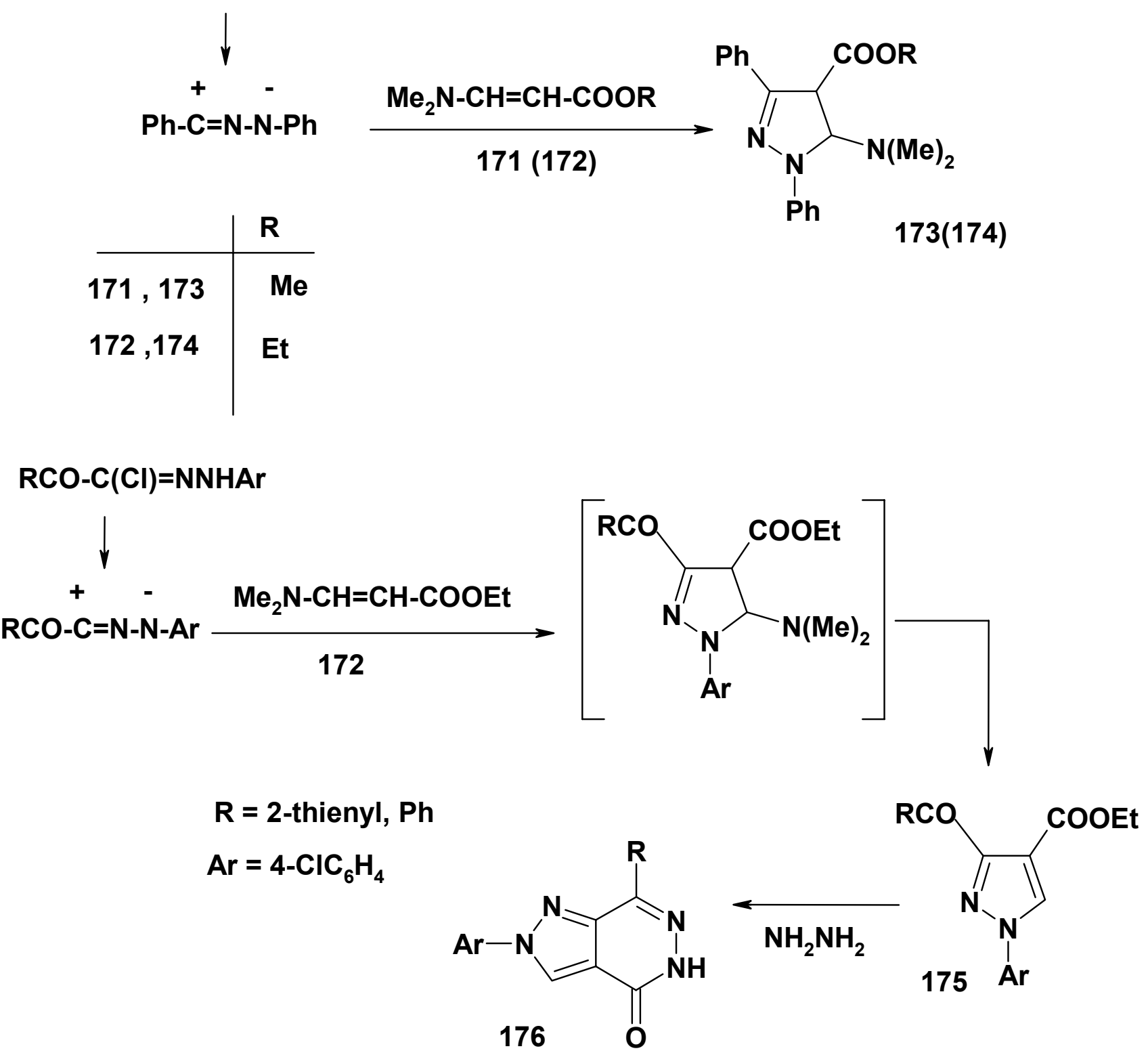

\section{Scheme 64}

$\mathrm{N}$-[Bis(diisopropylamino)(methyl)phosphonio]-C-[bis(diisopropylamino)-thioxophosphoranyl]nitrilimine 177 was reported to undergo cycloaddition to the enamino-ester 178 via LUMO(dipole) controlled reaction to give the cycloadduct 179 in $78 \%$ yield which upon heating afforded the pyrazole derivatives $\mathbf{1 8 0}$ in $75 \%$ yield (Scheme 65$){ }^{77}$ 


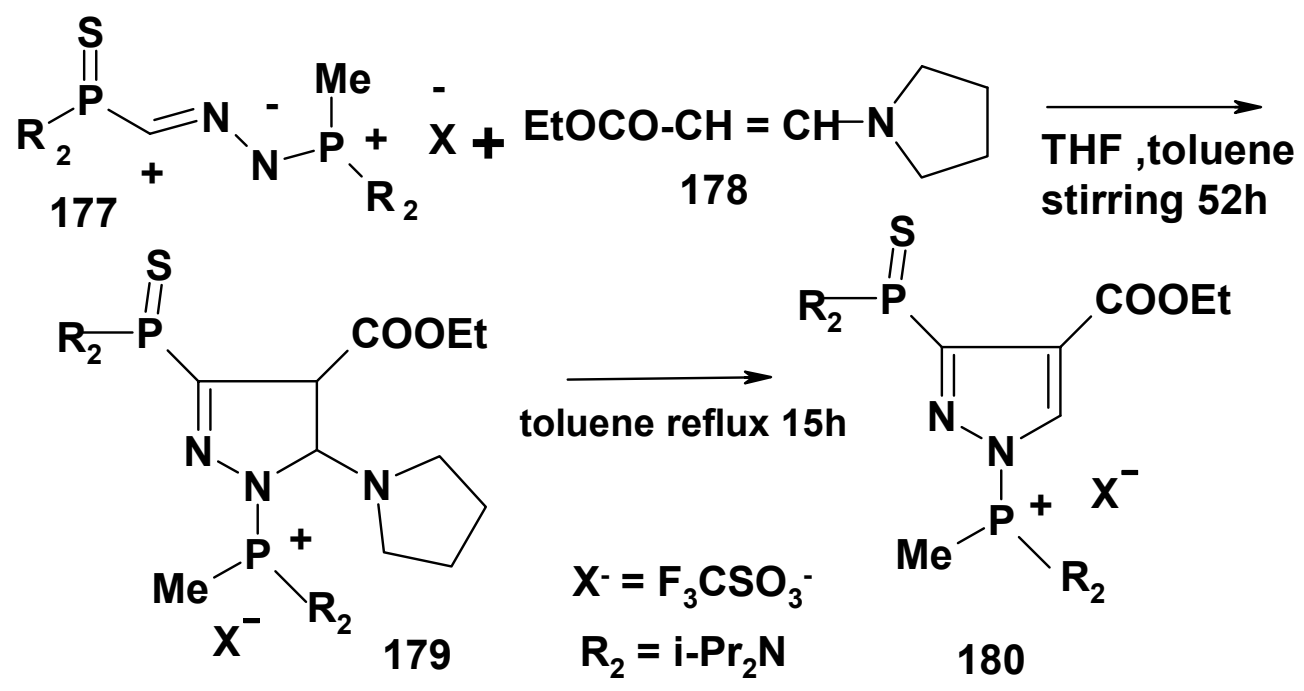

Scheme 65

\subsection{Endocyclic enamines}

Reaction of $C$-phenyl- $N$-benzenesulfonylnitrilimine with 1-diethylaminocyclohexene 181A was reported to give a mixture of four products namely 163-165 in $1.4,42,2.7$ and $4 \%$ yields, respectively (Scheme 66). ${ }^{73}$

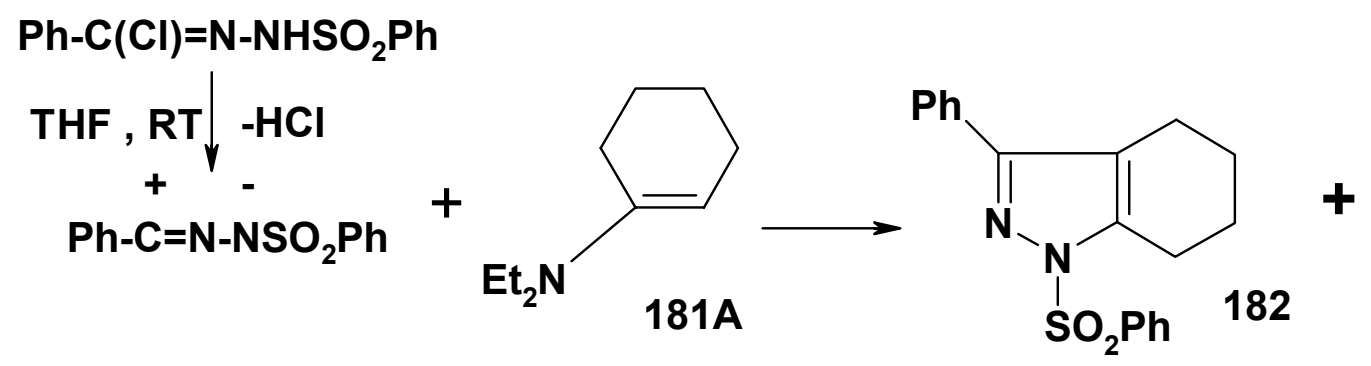<smiles>O=S(=O)(Nn1c(-c2ccccc2)nnc1-c1ccccc1)Oc1ccccc1</smiles>

Scheme 66 
However, similar reaction of the same nitrilimine with the morpholinoenamine analog $183 \mathrm{~A}$ afforded only the tetrazine derivative 165 in $48 \%$ yield. ${ }^{73}$ In this case, it seems that the enamine 183A functions only as a base catalyst (Scheme 67).
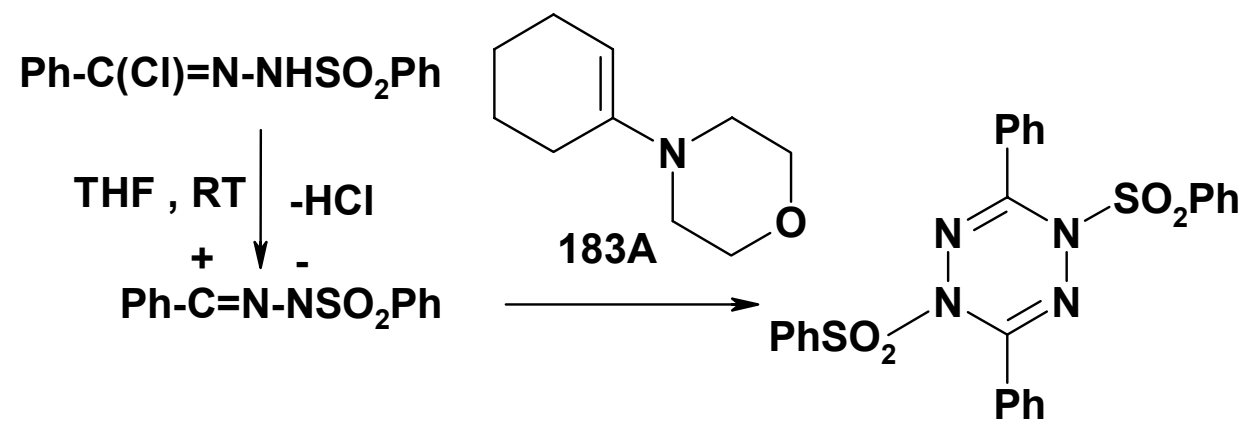

165

Scheme 67

Cycloalkanone enamines $183 \mathrm{~A}(\mathrm{~B})$ were also reported to react with $C$-ethoxycarbonyl- $N$ phenylnitrilimine to yield in each case the respective cycloalka[c]pyrazoles 184 in 32-67\% yields and a mixture of $E$ - and $Z$-isomers of the amidrazone 185. ${ }^{78}$ In another report, this same reaction was reported to afford only 184 (Scheme 68). ${ }^{60}$
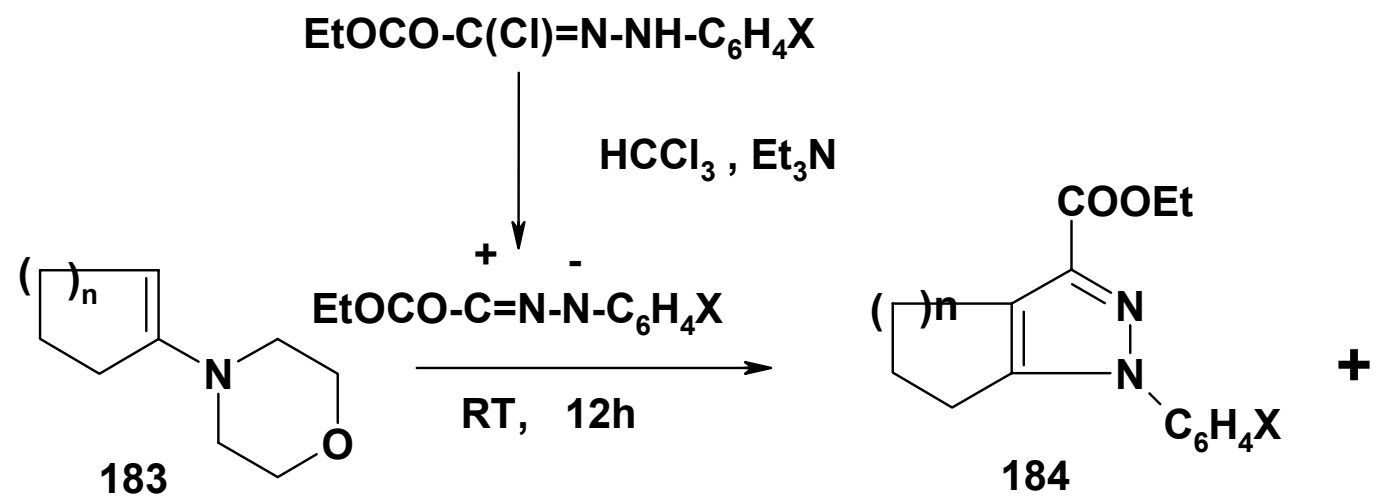

$$
\text { 183: } A, n=1, B, n=2
$$

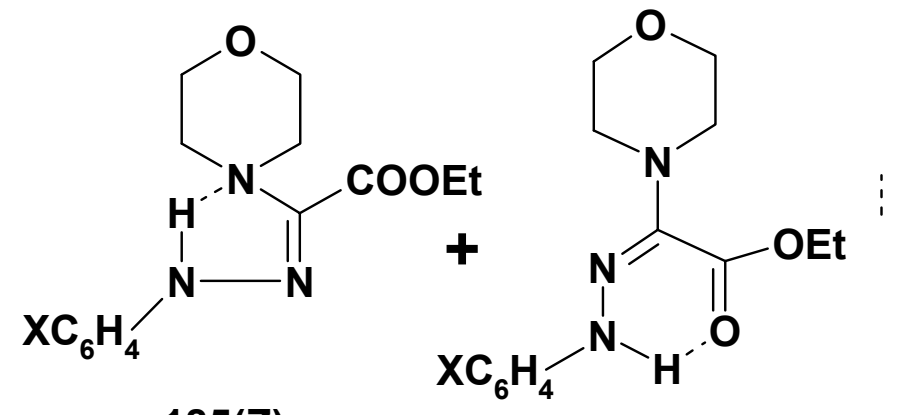

185(Z)

185(E)

$\mathrm{n}=1, \mathrm{X}=\mathrm{H}, 4-\mathrm{Cl}, 3-\mathrm{NO}_{3}, \mathrm{n}=\mathbf{2}, \mathrm{X}=\mathrm{H}, 3-\mathrm{NO}_{3}, 4-\mathrm{Cl}, 4-\mathrm{F}, 3-\mathrm{F}_{3} \mathrm{C}, 4-\mathrm{Me}$

\section{Scheme 68}


The reactions of 2-arylidenecycloalkanone enamines 186 with the same nitrilimines were reported to be site selective as they yielded the respective cycloalka[c]pyrazoles $\mathbf{1 8 7}$ in $20-37 \%$ yields (Scheme 69). ${ }^{79}$

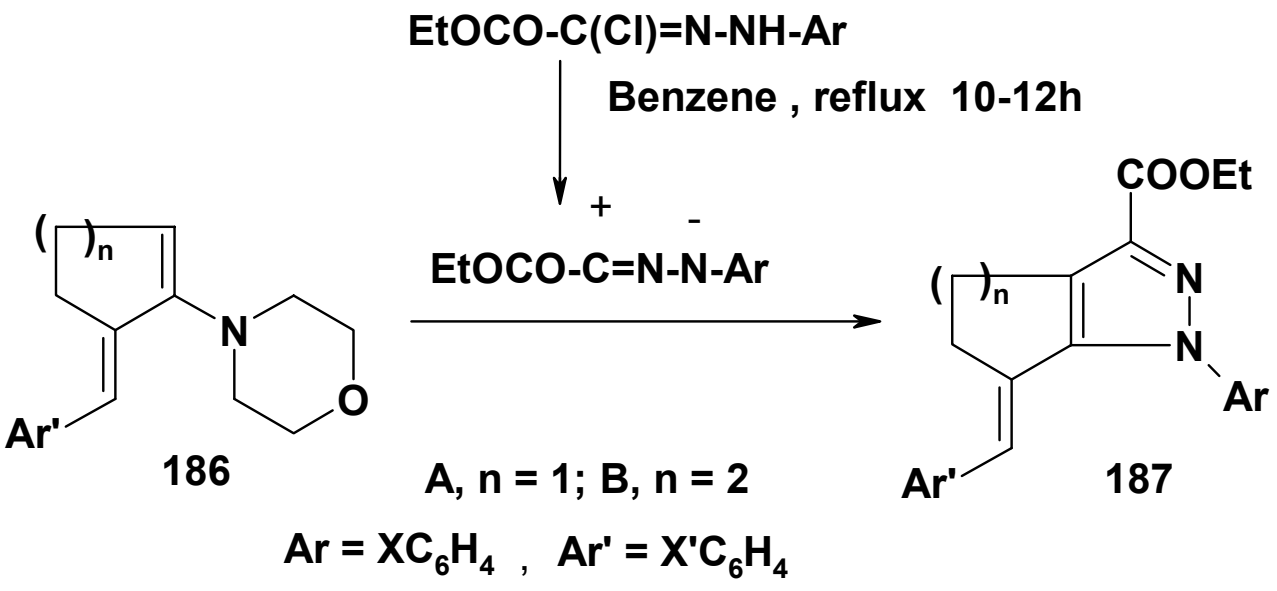

$\mathrm{n}=1, \mathrm{X} / \mathrm{X}^{\prime}=4-\mathrm{F} / \mathrm{H}, 4-\mathrm{F} / 4-\mathrm{NO}_{2}, 3-\mathrm{F}_{3} \mathrm{C} / 2,4-\mathrm{Cl}_{2}$.

$\mathrm{n}=2, \mathrm{X} / \mathrm{X}^{\prime}=4-\mathrm{F} / \mathrm{H}, \mathbf{4 - F} / 4-\mathrm{Cl}, 3-\mathrm{F}_{3} \mathrm{C} / 4-\mathrm{Cl}$.

\section{Scheme 69}

Similarly, the cycoalkapyrazole derivatives 190 and 191 were prepared by reaction of the respective cycloalkenone enamines 188 and 189 each with aryl- $C$-ethoxycarbonyl- $N$ - nitrilimines in chloroform (Scheme 70). ${ }^{51}$

\section{$\operatorname{EtOCOC}(\mathrm{Cl})=\mathrm{NNHAr}$}

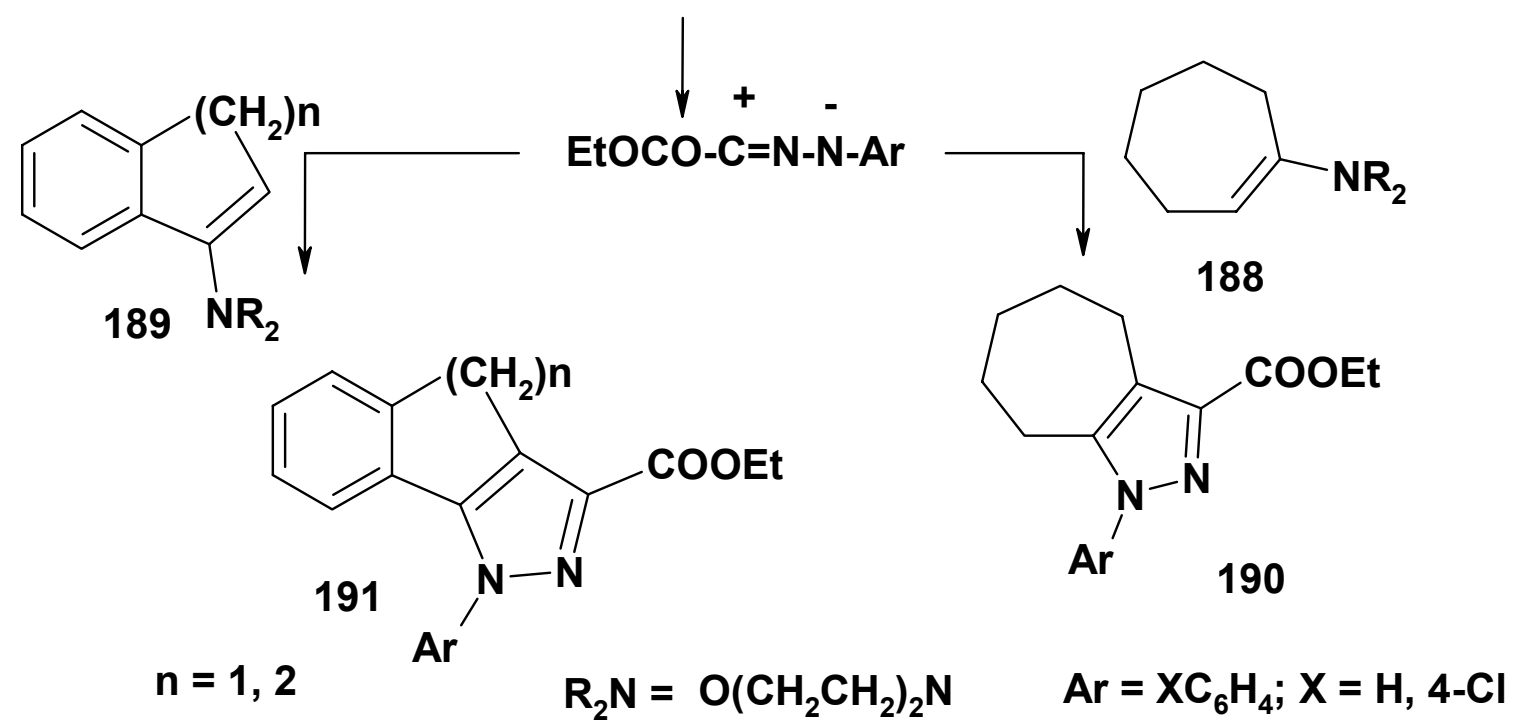

Scheme 70 
Reaction of $N$-phenylnitrilimines with each of 1-morpholinocyclohexene and its 4-methyl derivative 192 yielded the respective 1-phenyl-3-acetyl-4,5,6,7-tetrahydroindazoles 193 (Scheme $71) .^{51}$

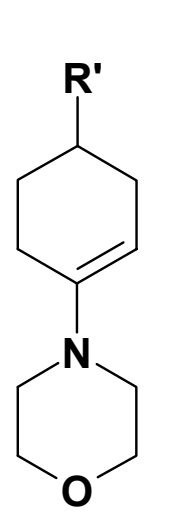

192
$\mathrm{RCO}-\mathrm{C}(\mathrm{Cl})=\mathrm{N}-\mathrm{NH}-\mathrm{Ph}$

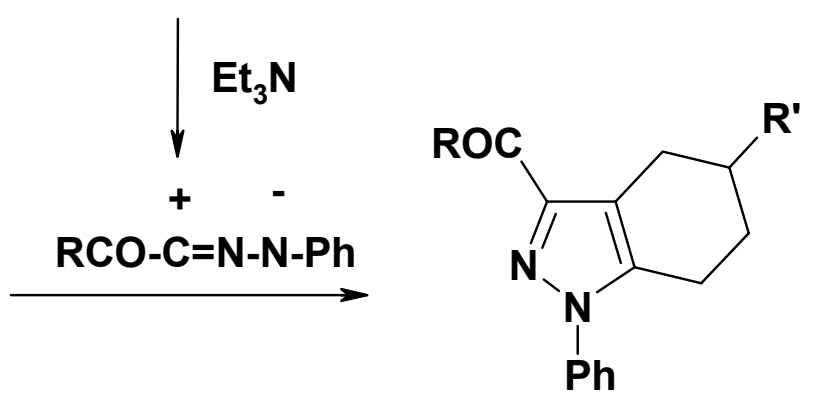

193

R / R' = EtO / Me, EtO / H, Me / H, Me / Me

\section{Scheme 71}

Similarly, 1-phenyl-3-ethoxycarbonyl-8,9-dihydronaphtho[1,2-c]pyrazole 196 was obtained from reaction of $\mathbf{1 9 4}$ with nitrilimine. Hydrolysis of the $\mathbf{1 9 5}$ followed by decarboxylation of the resulting acid afforded 196 (Scheme 72). ${ }^{51}$

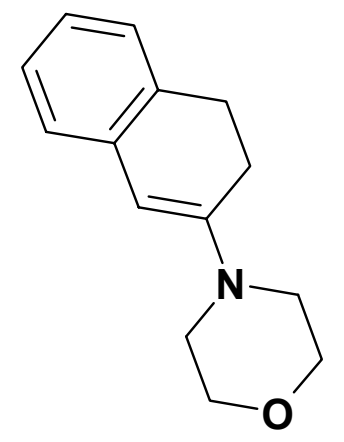

EtOCO-C(CI)=N-NH-Ph

194

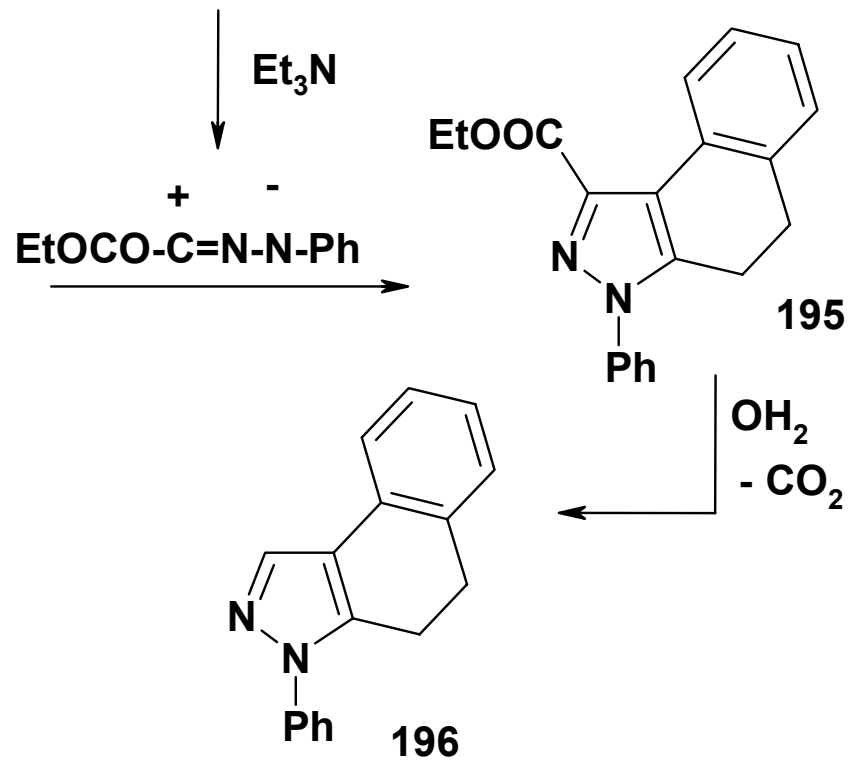

Scheme 72 
Reaction of phosphorinanon-4-enamine (197) with $C, N$-diphenylnitrilimine yielded 198 in $21 \%$ yield (Scheme 73$){ }^{80}$<smiles>O=P1(c2ccccc2)CC=C(N2CCCC2)CC1</smiles>

197

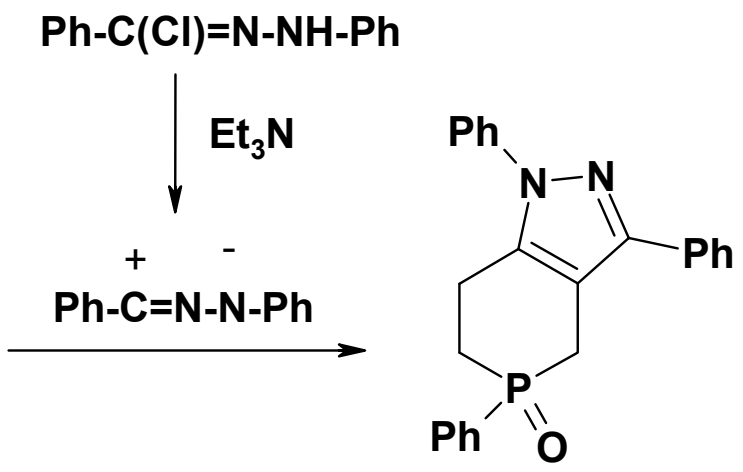

198

\section{Scheme 73}

The reaction of 3,3-dimethyl-1-indanone-enamine 199 with $C, N$-diarylnitrilimine gave the cycloadducts 200 in $50 \%$ yield which, by treatment with $2 \mathrm{M}$ aqueous hydrochloric acid in refluxing ethanol, led to the indeno[3,2-c]pyrazoles 201. The regiochemistry of the cycloadduct was established by ${ }^{13} \mathrm{C}$ NMR spectra where the signal of $\mathrm{C}(3 \mathrm{a})$ appears as doublet at $\delta 58.8$ and that of $\mathrm{C}(8 \mathrm{~b})$ appears as singlet at $\delta 98.3$ (Scheme 74$){ }^{81}$

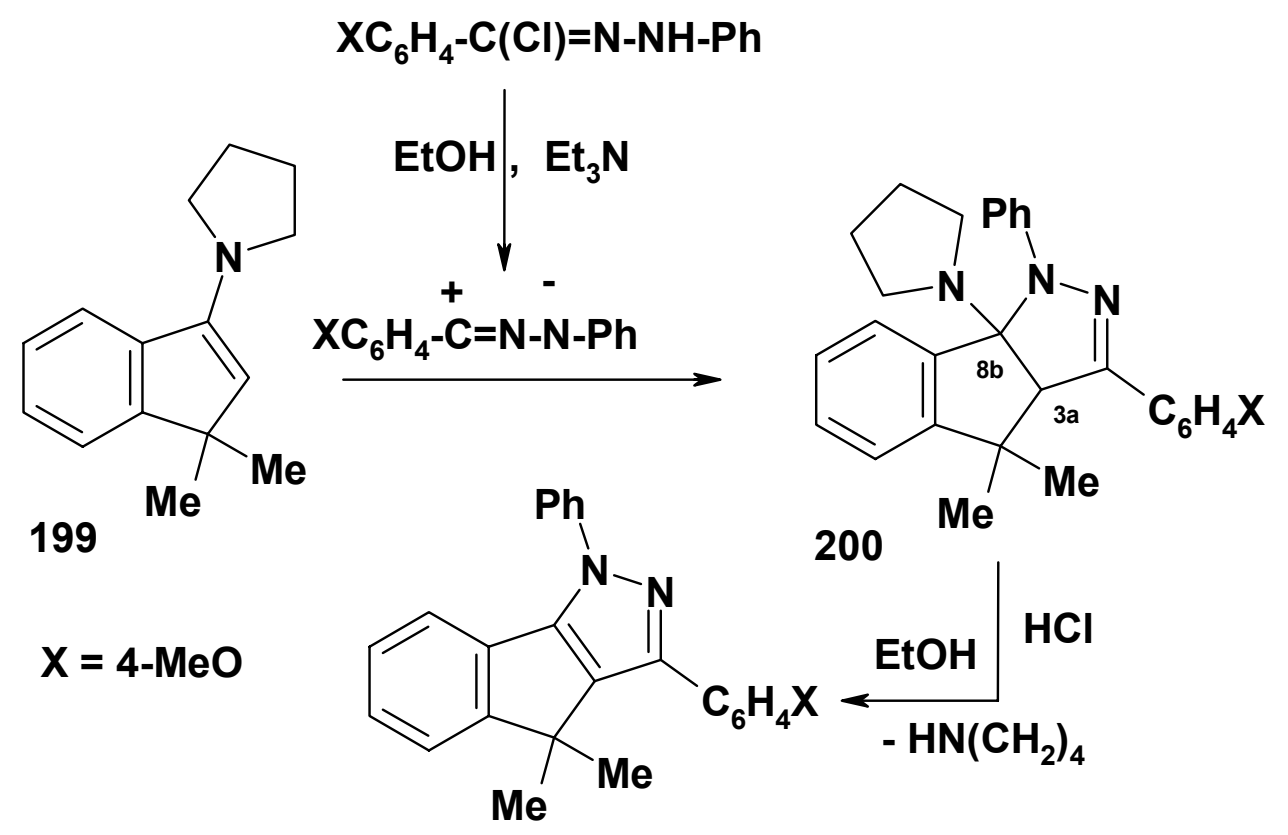

201

Scheme 74 
Reaction of 1,1-dimethyl-2-indenone enamines (202) with $C, N$-diarylnitrilimines was also reported to be regiospecific yielding the respective cycloadduct $\mathbf{2 0 3}$ in $80-88 \%$ yields. Treatment of the latter with trifluoroacetic acid at room temperature afforded indeno[2,3-c]pyrazoles 204 (Scheme 75). ${ }^{81}$<smiles>[R]N([R])C1=Cc2ccccc2C1(C)C</smiles>

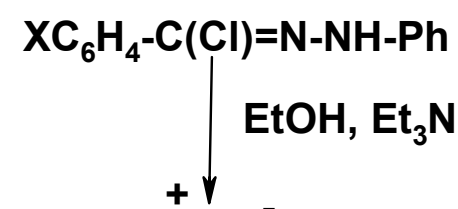

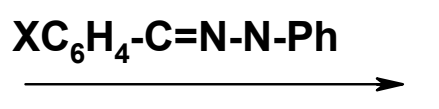

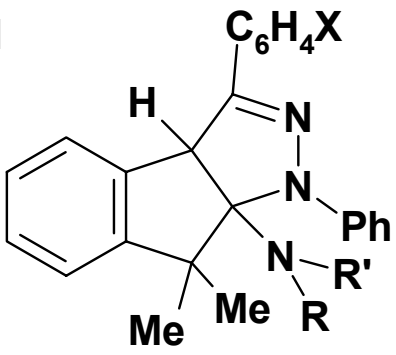<smiles>[X]c1nn(-c2ccccc2)c2c1-c1ccccc1C2(C)C</smiles>

$\mathrm{CF}_{3} \mathrm{COOH}, \mathrm{RT}$

204, X : 4-Me, H

\section{Scheme 75}

Reactions of $C, N$-diphenylnitrilimine with each of the isomeric enamines 205 and 207 are regioselective and afforded the isomeric 1H-4,5-dihydronaphtho[4,3-c]pyrazoles 206 and $1 H$ 4,5-dihydronaphtho[3,4-c]pyrazoles 208 in $52-70$ and $57-75 \%$ yields, respectively (Scheme 76). ${ }^{82}$<smiles>[R]C1C=C(N2CCCC2)c2ccccc2C1[R]</smiles>

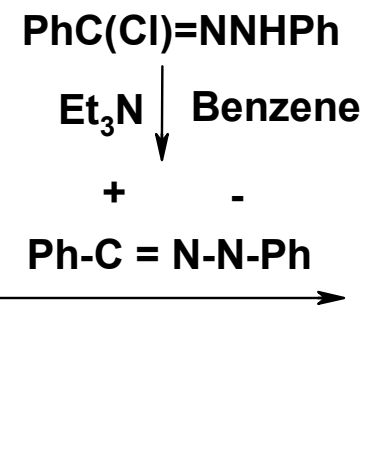

05<smiles>[R]C1c2ccccc2-c2c(c(-c3ccccc3)nn2-c2ccccc2)C1[R]</smiles>

206

206: $R / R^{\prime}=H / H, M e / H, H / M e$ 


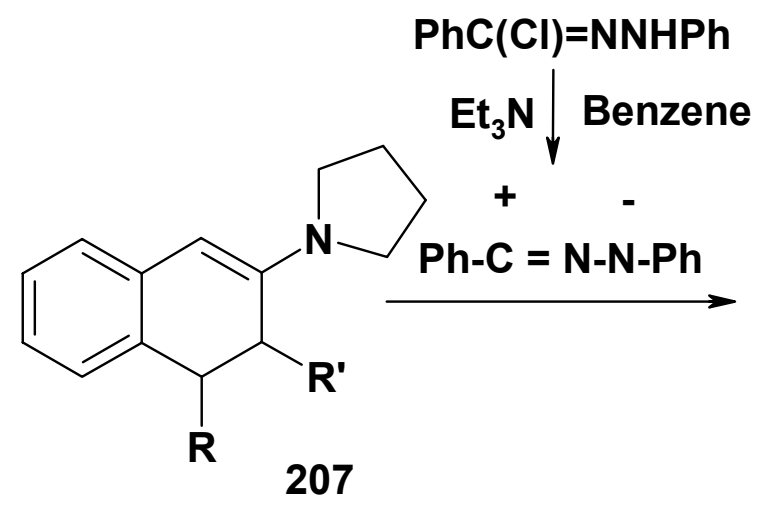

208: $R / R^{\prime}=H / H, M e / H, H / M e$<smiles>[R]C1c2ccccc2-c2c(-c3ccccc3)nn(-c3ccccc3)c2C1[R]</smiles>

\section{Scheme 76}

3-Pyrrolidinobenzo[ $b]$ furan (209) reacted with $C, N$-diarylnitrilimines in benzene and gave a mixture of the tautomeric adducts 210 and 211. The latter product 211 was found to be the major product and it was assumed to result from ring cleavage of $\mathbf{2 1 0}$ (Scheme 77). ${ }^{83}$

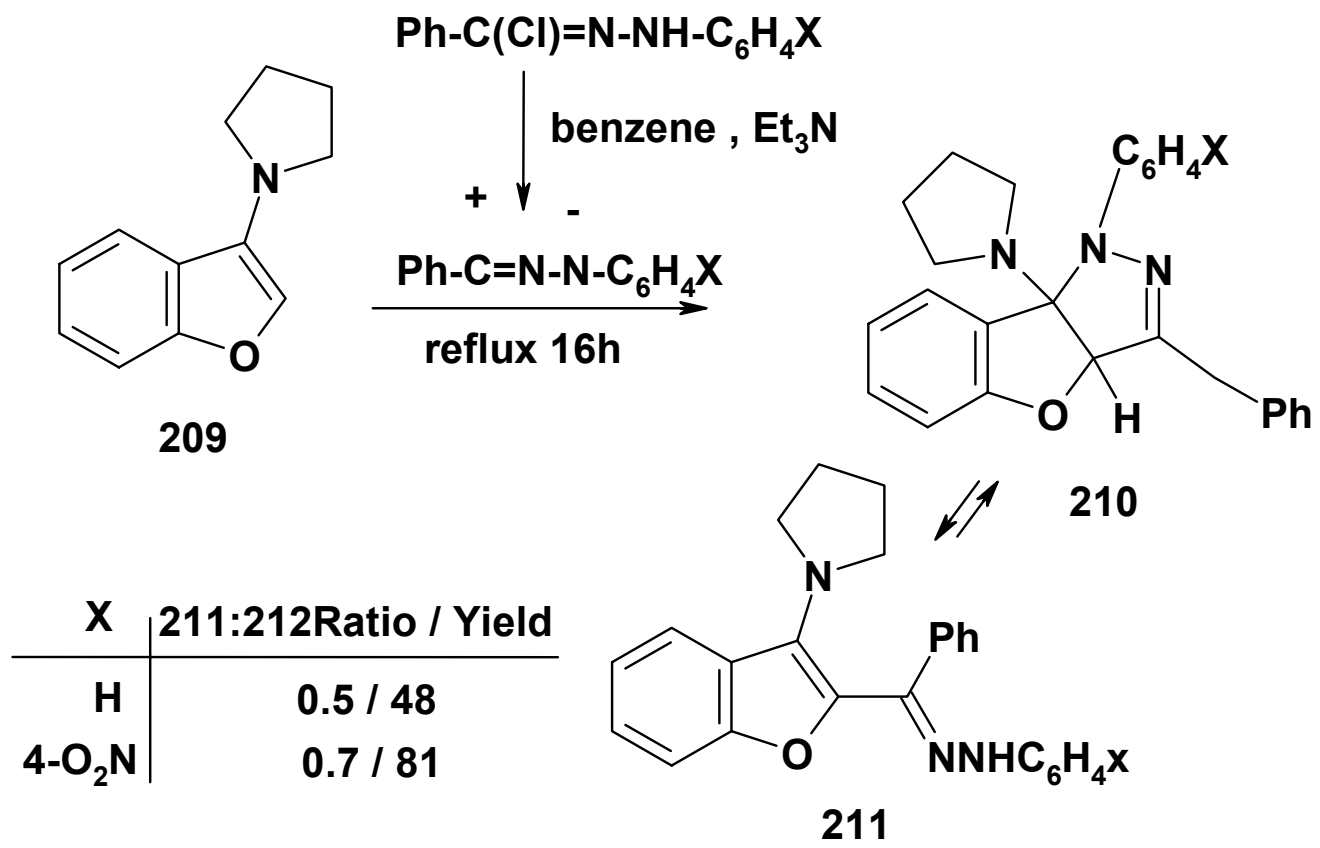

\section{Scheme 77}

However, reaction of the enamine 212 with $C, N$-diphenylnitrilimine in benzene was reported to give 3,3a-dihydro-1,3-diphenyl-3a-pyrrolidino-pyrazolo[3,4-c][2]benzopyran-5(2H)-one 
(214) in 44\% yield. $^{84}$ The latter 214 was assumed to result via prototropic shift from the initial cycloadduct 213 (Scheme 78).

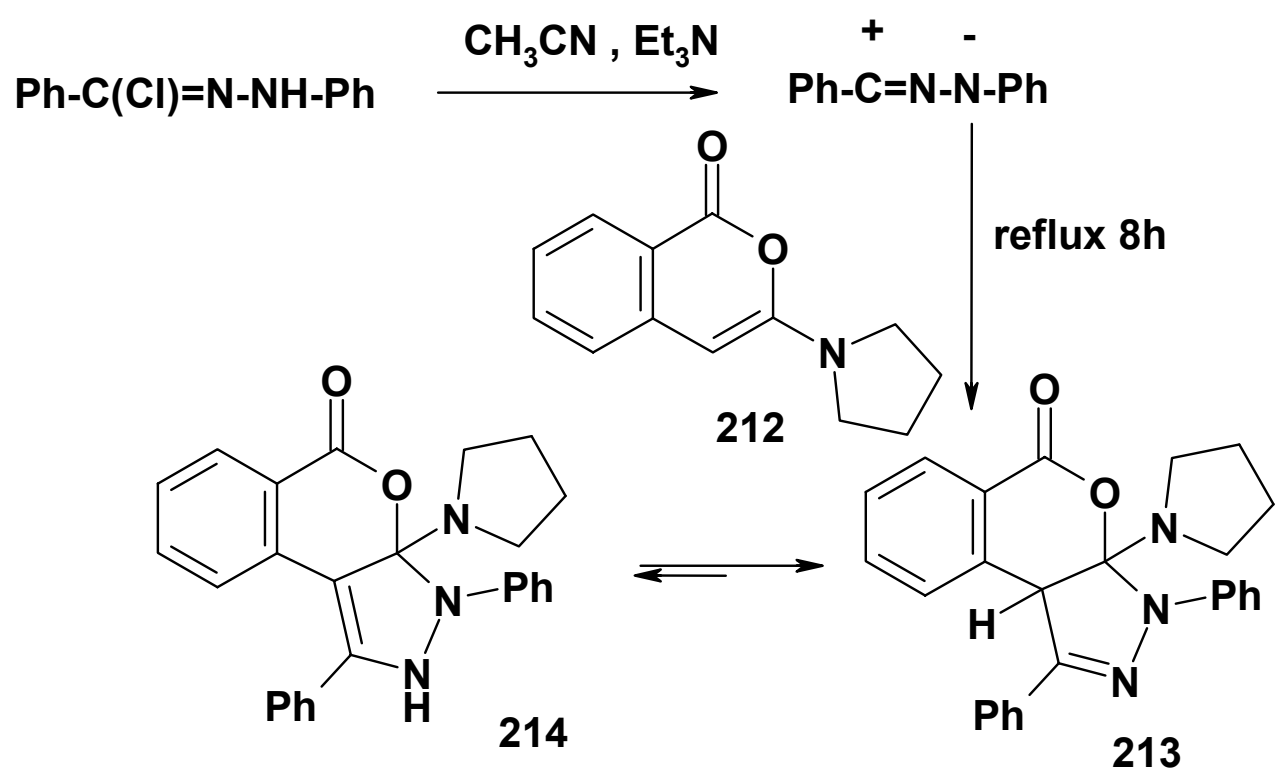

\section{Scheme 78}

1-Aryl-4-Methyl-5-(1-morpholinyl)-1,2,3-triazole (215) reacted with $C, N$-diphenylnitrilimine in benzene to give 1,3-diphenyl-5-arylaminomethylene-pyrazoles (217) in 17-50\% yields. ${ }^{85}$ In this case it seems that nitrilimine cycloadded to the methylene tautomer of 215 to give the spirocycloadduct $\mathbf{2 1 6}$ which then underwent in situ ring cleavage to give $\mathbf{2 1 7}$ in 17-50\% yields as end product. Acid hydrolysis of the latter 217 afforded the aldehyde 218 (Scheme 79). ${ }^{85}$ 


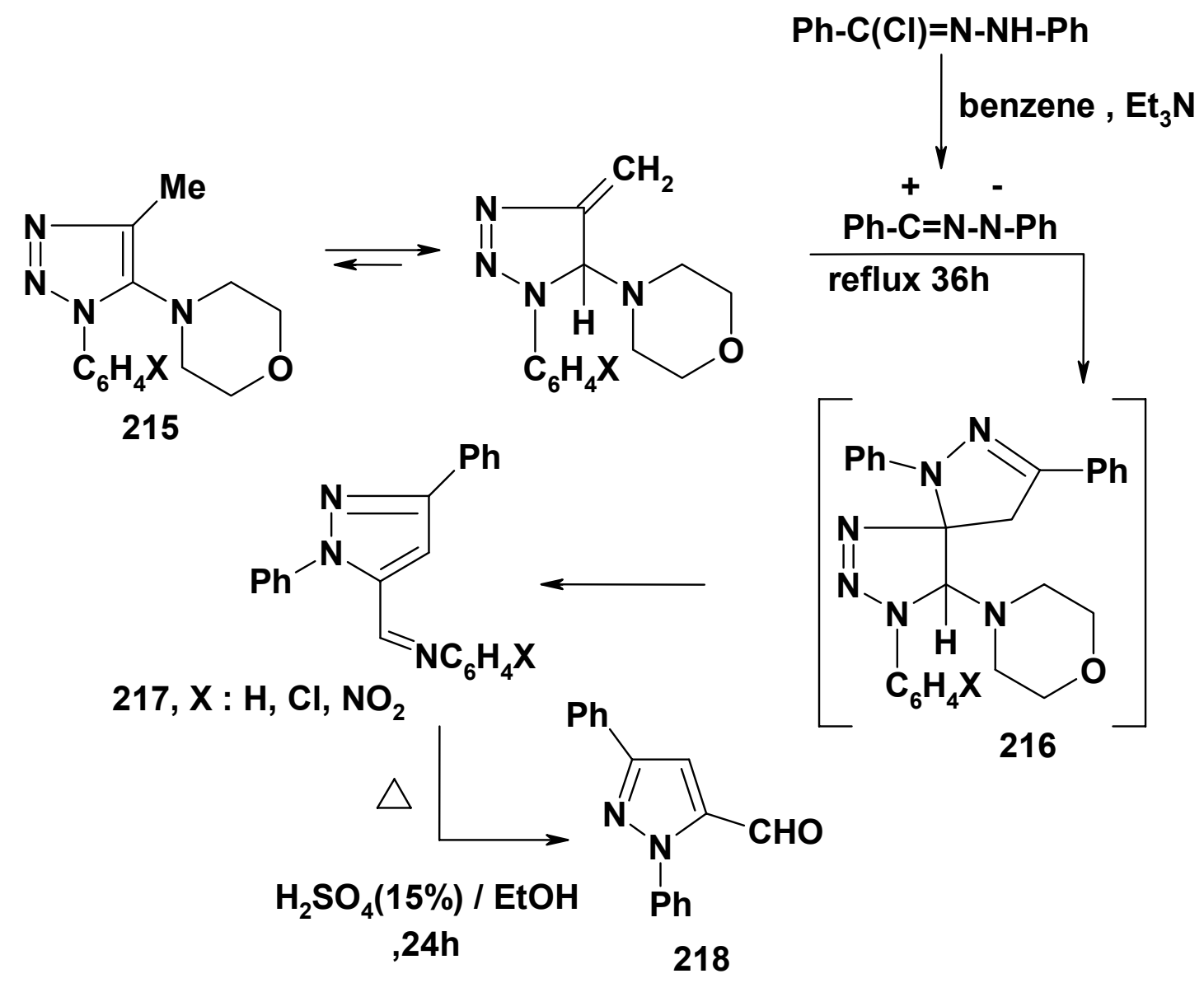

Scheme 79

\subsection{Exocyclic enamines}

$C, N$-Diarylnitrilimines were reported to cycloadd to the exocyclic enamine 219 to give the respective cycloadducts $\mathbf{2 2 0}$ which underwent in situ ring cleavage and elimination of isocyanate molecule to yield the pyrazolecarboxamides 221 as end products (Scheme 80). ${ }^{86}$ 


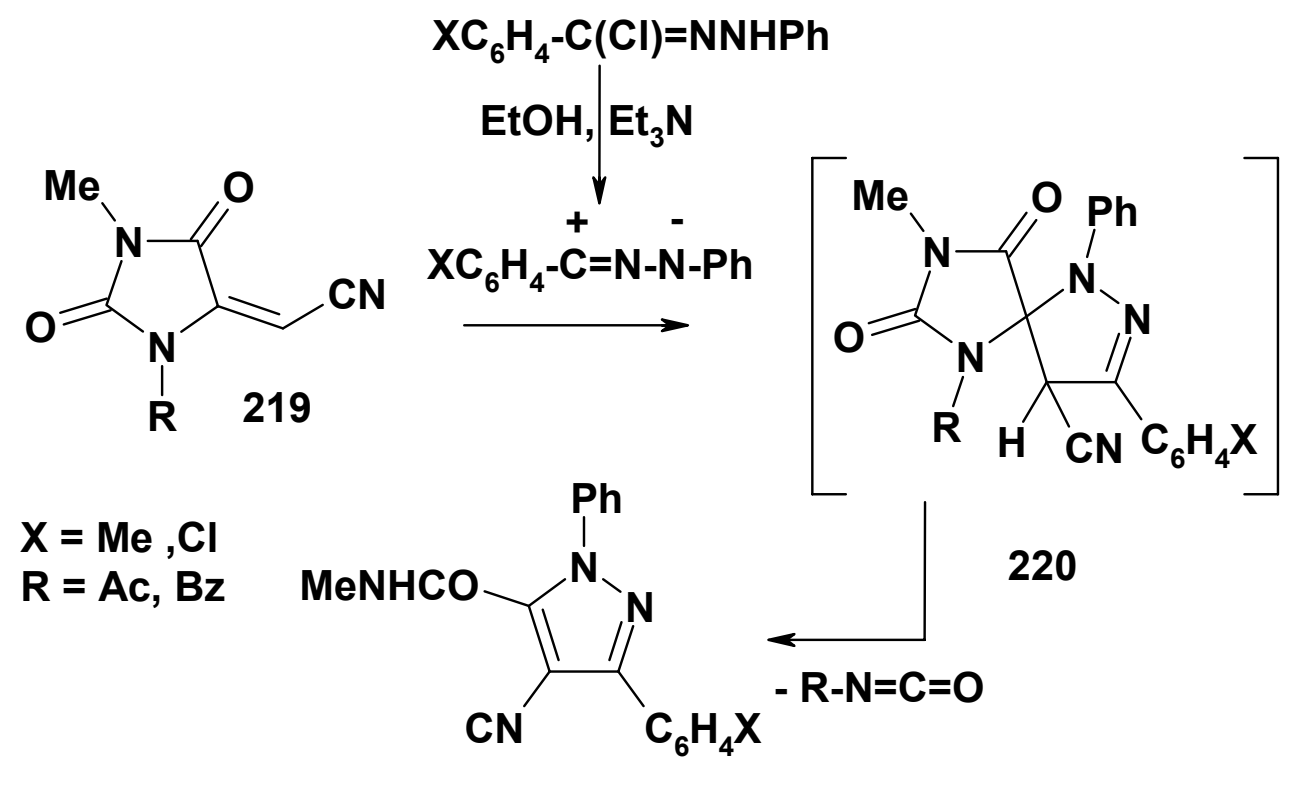

221

\section{Scheme 80}

The reaction of 1-ethoxycarbonylmethylene-3,4-dihydro-6,7-dimethoxy-isoquinoline (222) with $C, N$-diphenylnitrilimine in chloroform was reported to yield $\mathbf{2 2 3}$ in $80 \%$ yield instead of the expected 1,3-adduct 224. ${ }^{87}$ However, reaction of 222 with $C$-acyl- $N$-arylnitrilimines gave the respective 5,6-dihydropyrrolo[2,1-a]-5,6-dihydroisoquinolines (225) in 78-82\% yields. ${ }^{87}$ Further evidence is required to confirm the structure of the claimed product $\mathbf{2 2 5}$ and to explain why the regiochemistry of $C$-diphenylnitrilimine is different from that of $C$-acylnitrilimines in their reactions with 222 (Scheme 81). 


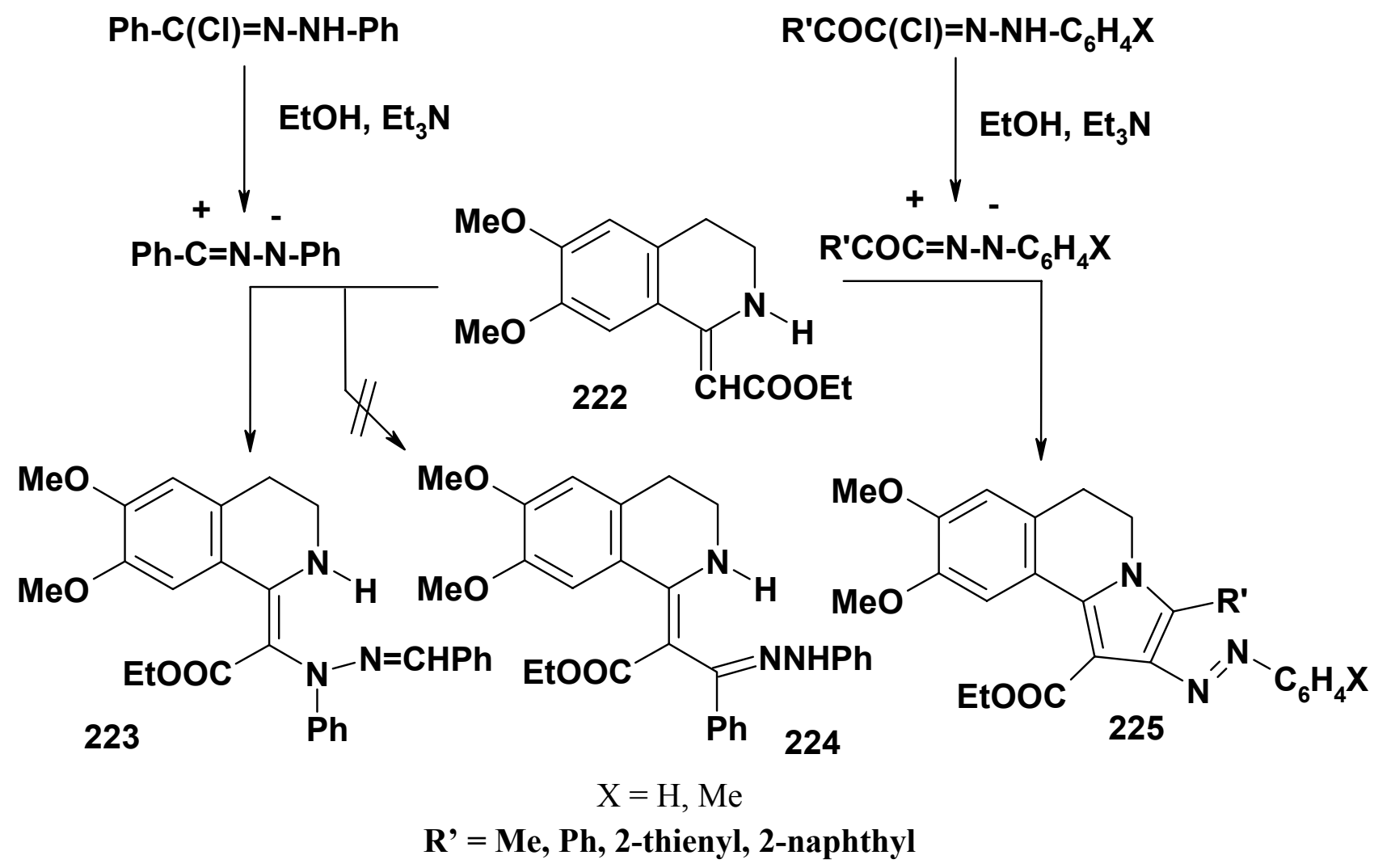

\section{Scheme 81}

The reaction of $C, N$-diphenylnitrilimine with the exocyclic enamine 226 led to a mixture of 227 and 228 in 36-38\% and 23-39\% yields, respectively. ${ }^{88}$ The latter product 228 was assumed to be formed via cycloaddition to the carbonyl group followed by opening of the 1,3,4oxadiazoline ring and recyclization. ${ }^{85}$ When the products 227 were refluxed in trifluoroacetic acid, they underwent ring cleavage to give the respective 229 in $36-38 \%$ yields (Scheme 82 ). ${ }^{88}$ 


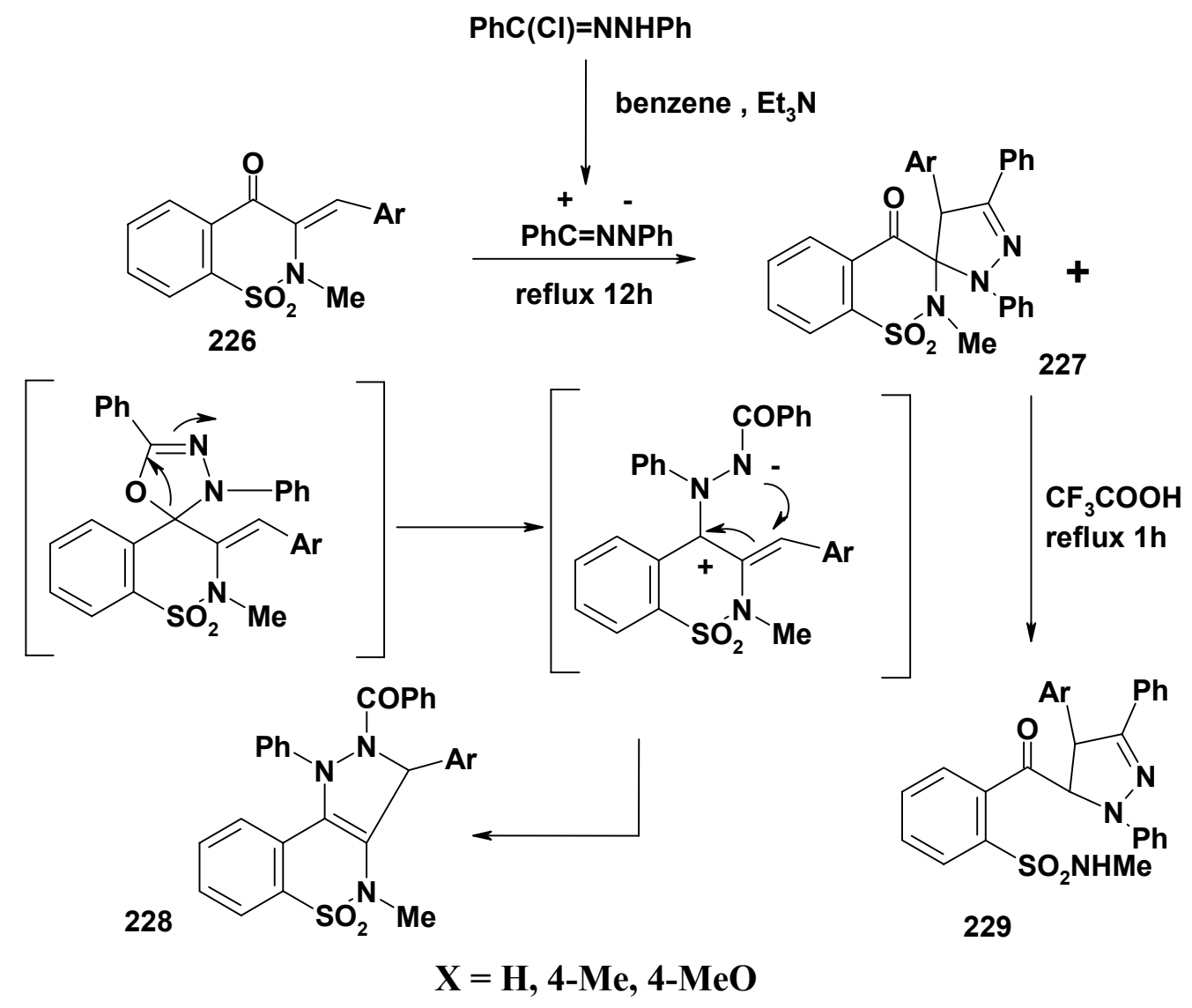

Scheme 82

In an earlier report, ${ }^{51}$ it was reported however that reactions of $C$-acetyl- and $C$ ethoxycarbonyl- $N$-phenylnitrilimines each with 1,2-dimethyl-4,5-dihydropyrrole 230A and 1,2dimethyl-1,4,5,6-tetrahydropyridine $230 \mathrm{~B}$ in chloroform in the presence of triethylamine afforded the respective pyrazole derivatives 231 (Scheme 83). ${ }^{51}$

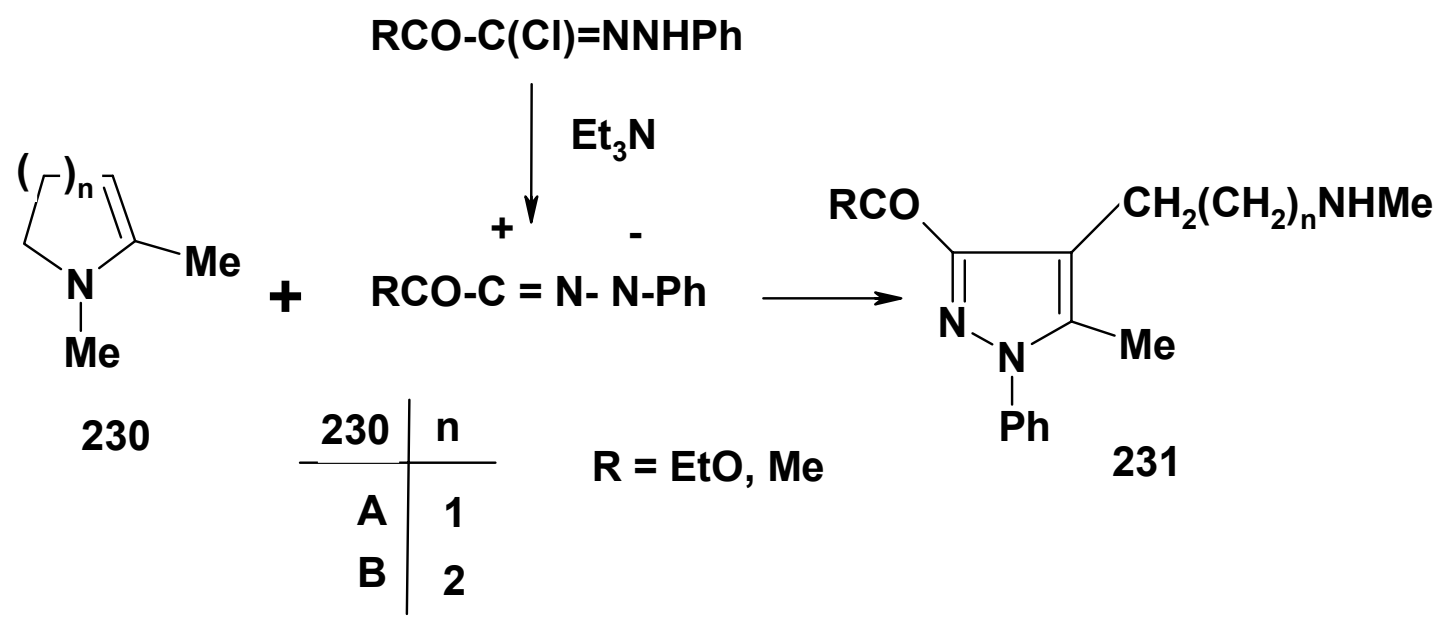

Scheme 83 


\subsection{Heterocyclic enamines}

Reaction of $N$-methylpyrrole 232 with $C$-acetyl- $N$-phenylnitrilimine gave a mixture of the two isomeric bis-cycloadducts $\mathbf{2 3 3}$ and $\mathbf{2 3 4}$ in $20 \%$ and $60 \%$ yields, respectively ${ }^{84}$ Refluxing each of the latter products in concentrated hydrochloric acid in ethanol furnished 4,4- and 3,4-bispyrazoles $\mathbf{2 3 5}$ and $\mathbf{2 3 6}$ each in $90 \%$ yield, respectively (Scheme 84). ${ }^{89}$

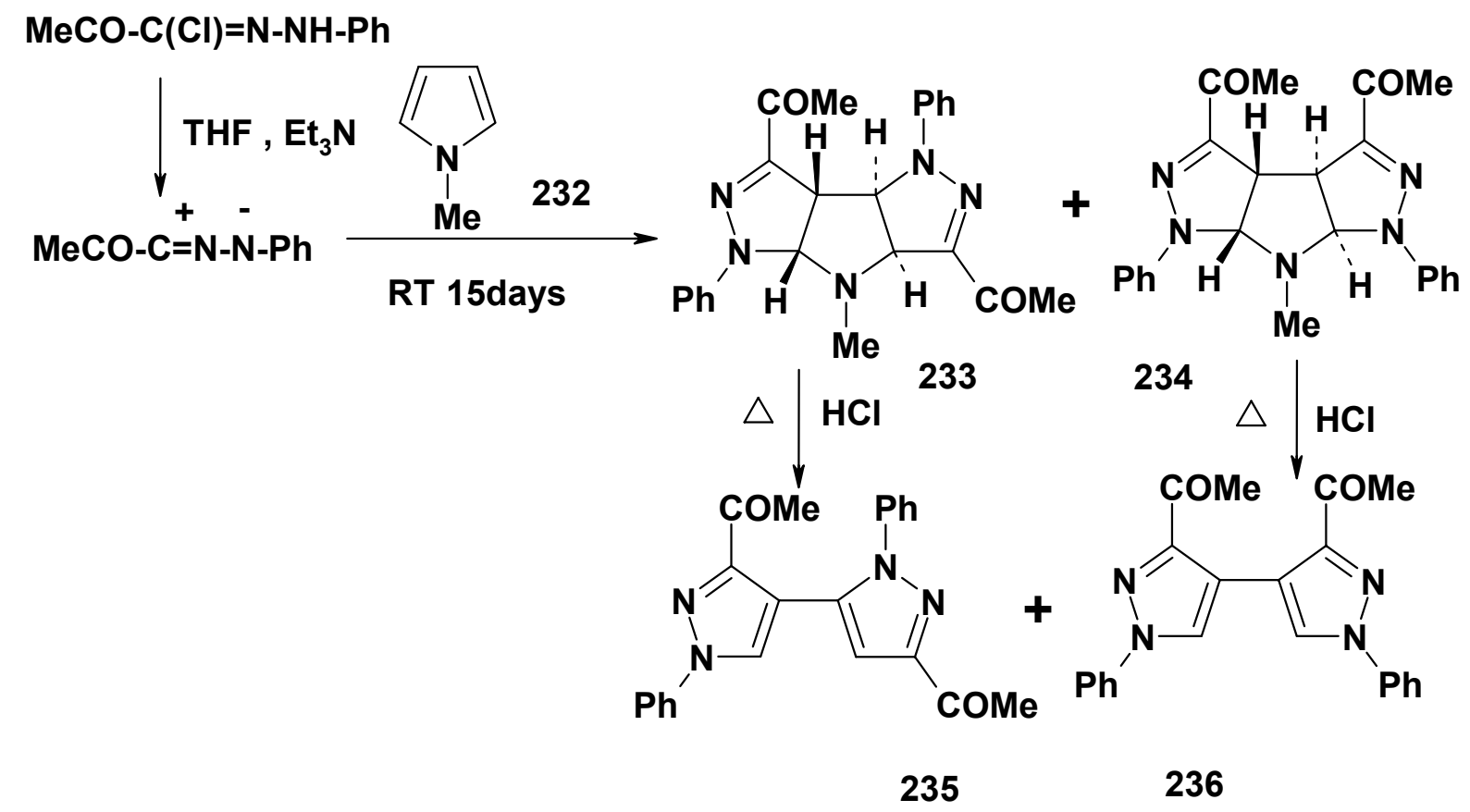

\section{Scheme 84}

Similar reaction of $C, N$-diphenylnitrilimine with 1-methyl-2-alkoxy derivatives of cyclic enamines $\mathbf{2 3 7}$ afforded the respective fused pyrazoles $\mathbf{2 3 8}$ in 70-79\% yields via cycloaddition to endo-double bond followed by elimination of alcohol molecule from the initially formed cycloadducts (Scheme 85$){ }^{90}$ 


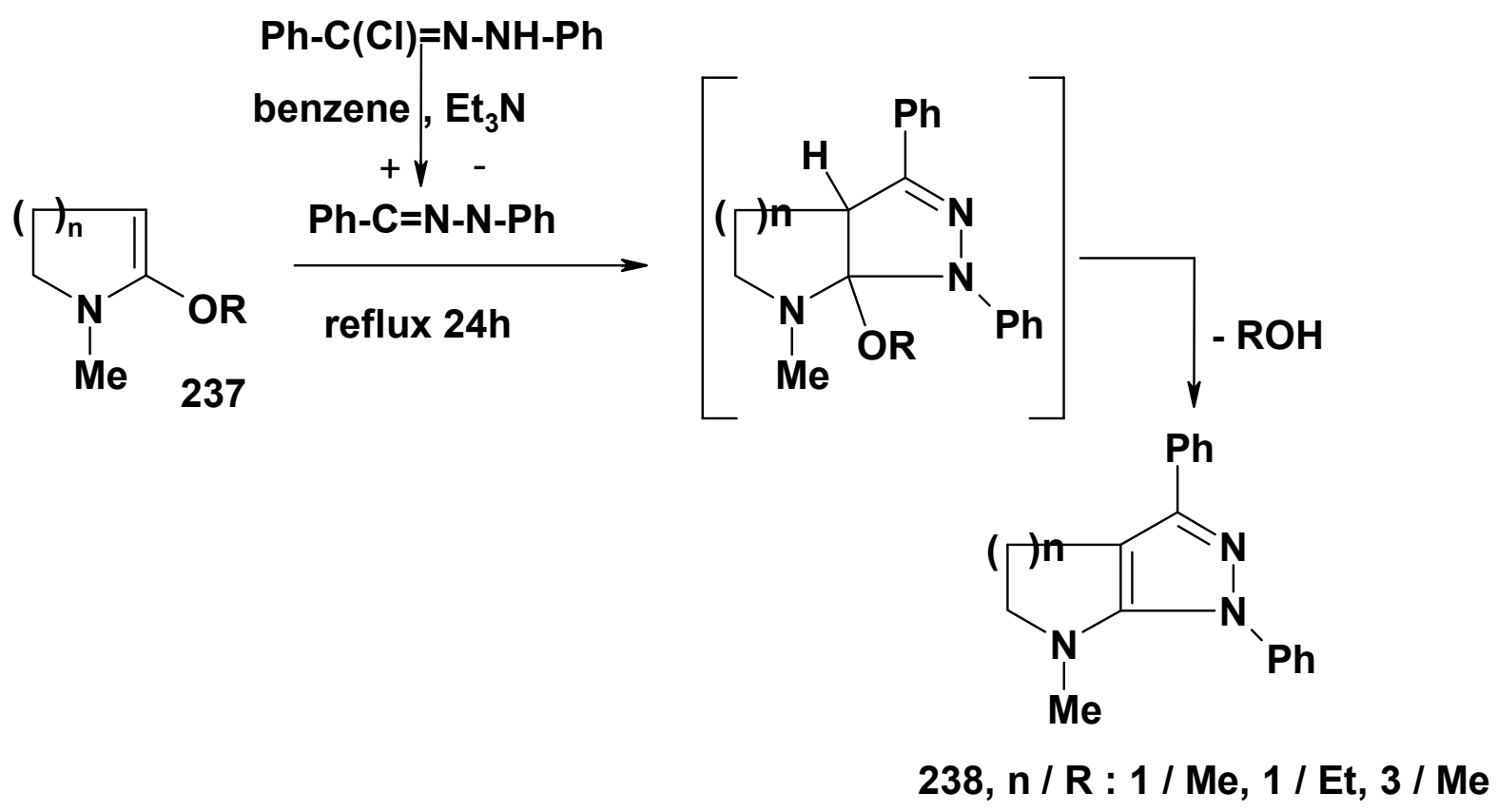

\section{Scheme 85}

1-Methyl-2-methoxycarbonylpyrrole 239 reacted with $C$-acetyl- $N$-phenylnitrilimine afforded only the bis-cycloadduct $\mathbf{2 4 0}$ in $20 \%$ yield. ${ }^{91}$ On the other hand, reaction of the same nitrilimine with 1,2-dimethylpyrrole (241) yielded four different products namely the bis-cycloadducts 242 and 243, the spirocycloadduct $\mathbf{2 4 4}$ and the acyclic bis-adduct $\mathbf{2 4 5}$ in 40, 30, 10 and 11\% yields, respectively (Scheme 86). ${ }^{91}$

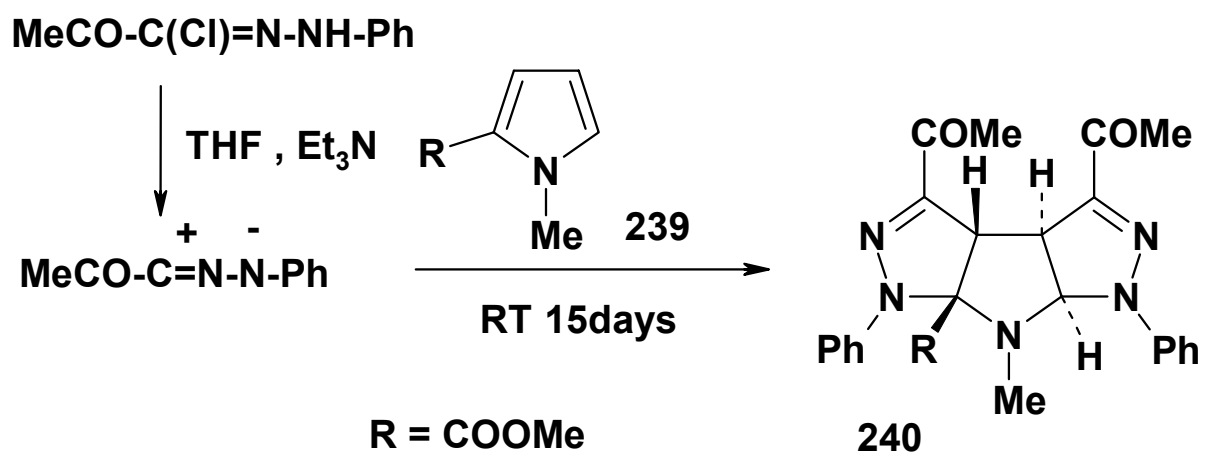


$\operatorname{MeCO}-\mathrm{C}(\mathrm{Cl})=\mathrm{N}-\mathrm{NH}-\mathrm{Ph}$
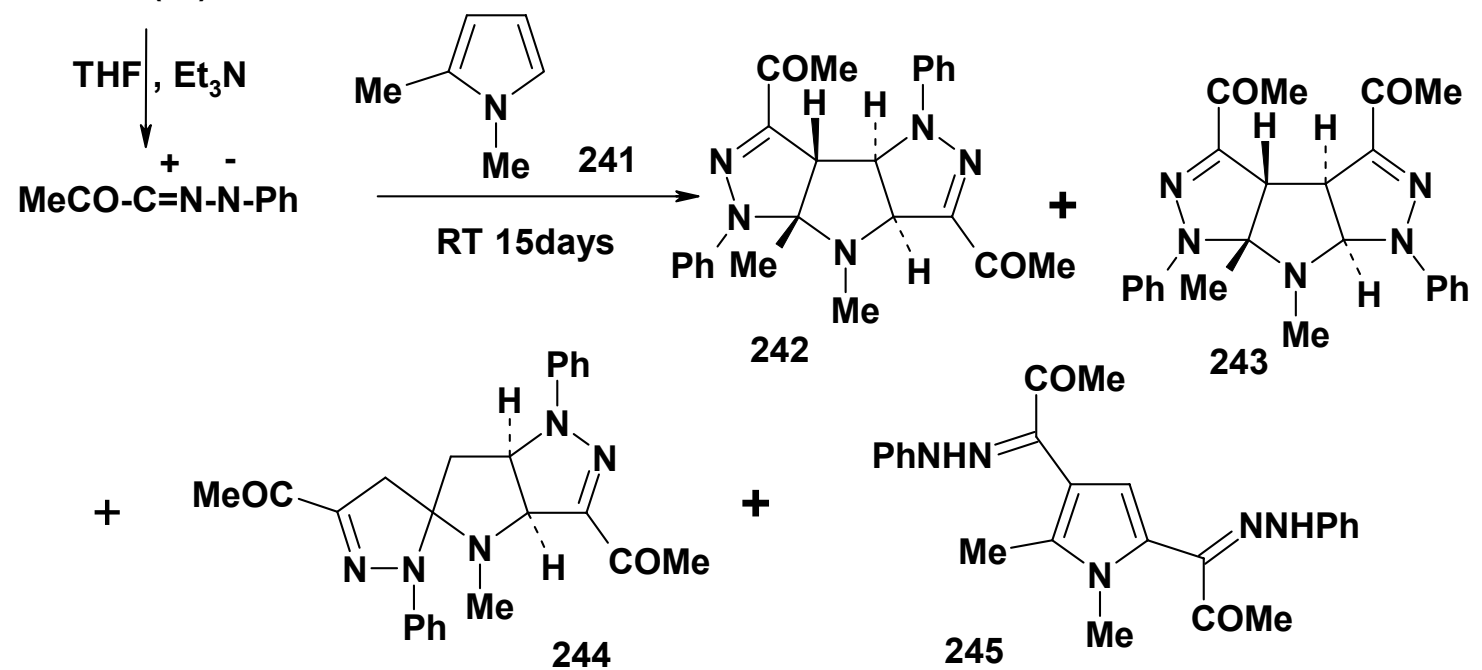

\section{Scheme 86}

Heating the products $\mathbf{2 4 2 - 2 4 4}$ at $170^{\circ} \mathrm{C}$ resulted in cleavage of the pyrazoline ring to give the bis-hydrazones 246 - 248, respectively. However, refluxing the products 242-244 in ethanol in the presence of hydrocloric acid resulted in the cleavage of the pyrrolidine ring and the formation of the bis-pyrazoles 249-251, respectively (Scheme 87). ${ }^{91}$
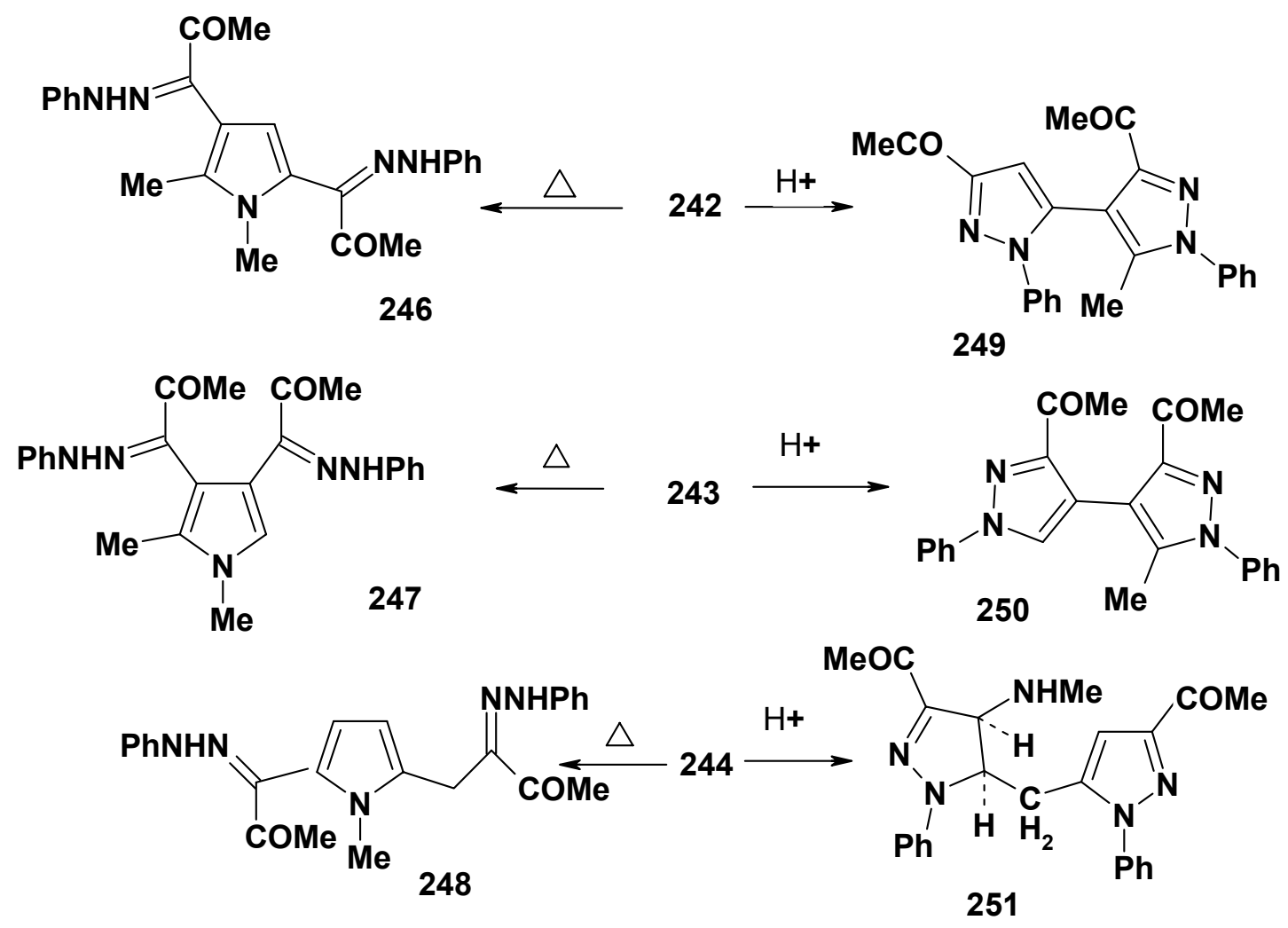

Scheme 87 
1-Methylimidazole (252) reacted with nitrilimines in a different fashion. For example, its reaction with $C$-methyloxycarbonyl- $N$-phenylnitrilimine yielded the ring opened 1:1 adduct 253 in $75 \%$ yield. Treatment of the latter with sodium hydroxide afforded the pyrazin-2-one 254 in $55 \%$ yield. ${ }^{27}$ Similar reaction of $N$-substituted benzimidazoles 255 with the same nitrilimine afforded an adduct $\mathbf{2 5 6}$ which gave, upon treatment with sodium hydroxide, the quinoxalin-2-one derivative 257 via ring expansion. Treatment of $\mathbf{2 5 7}$ with acetic acid gave $\mathbf{2 5 8}$ which underwent air oxidation to yield the azo derivative 259 as end product (Scheme 88). ${ }^{27}$
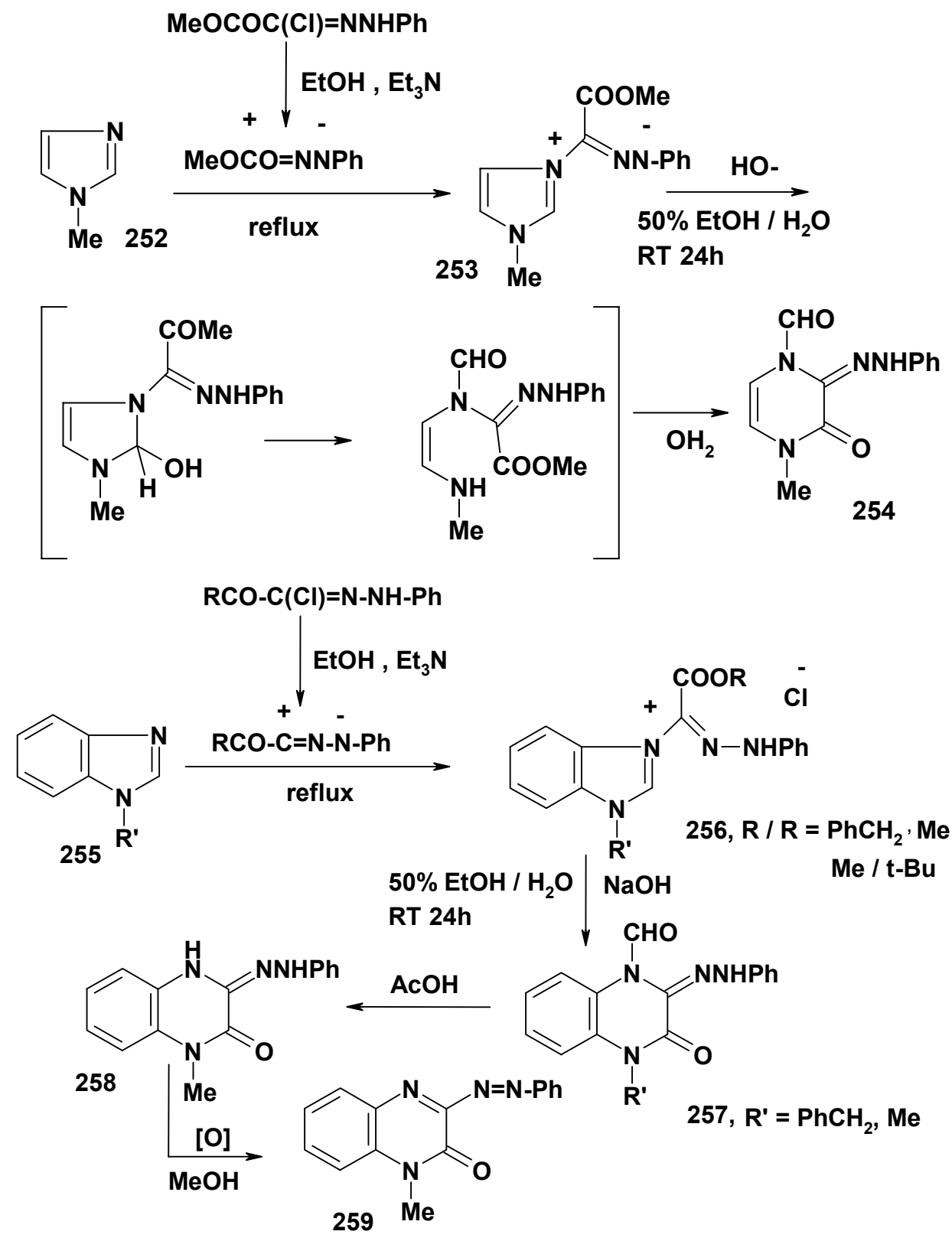

\section{Scheme 88}


Reaction of the diazepine $\mathbf{2 6 0}$ with $C$-ethoxycarbonyl- $N$-arylnitrilimines at room temperature yielded the bis-1,3-cycloadduct 261 and the adducts 262 in 10 and 65\% yields, respectively (Scheme 89). ${ }^{92}$

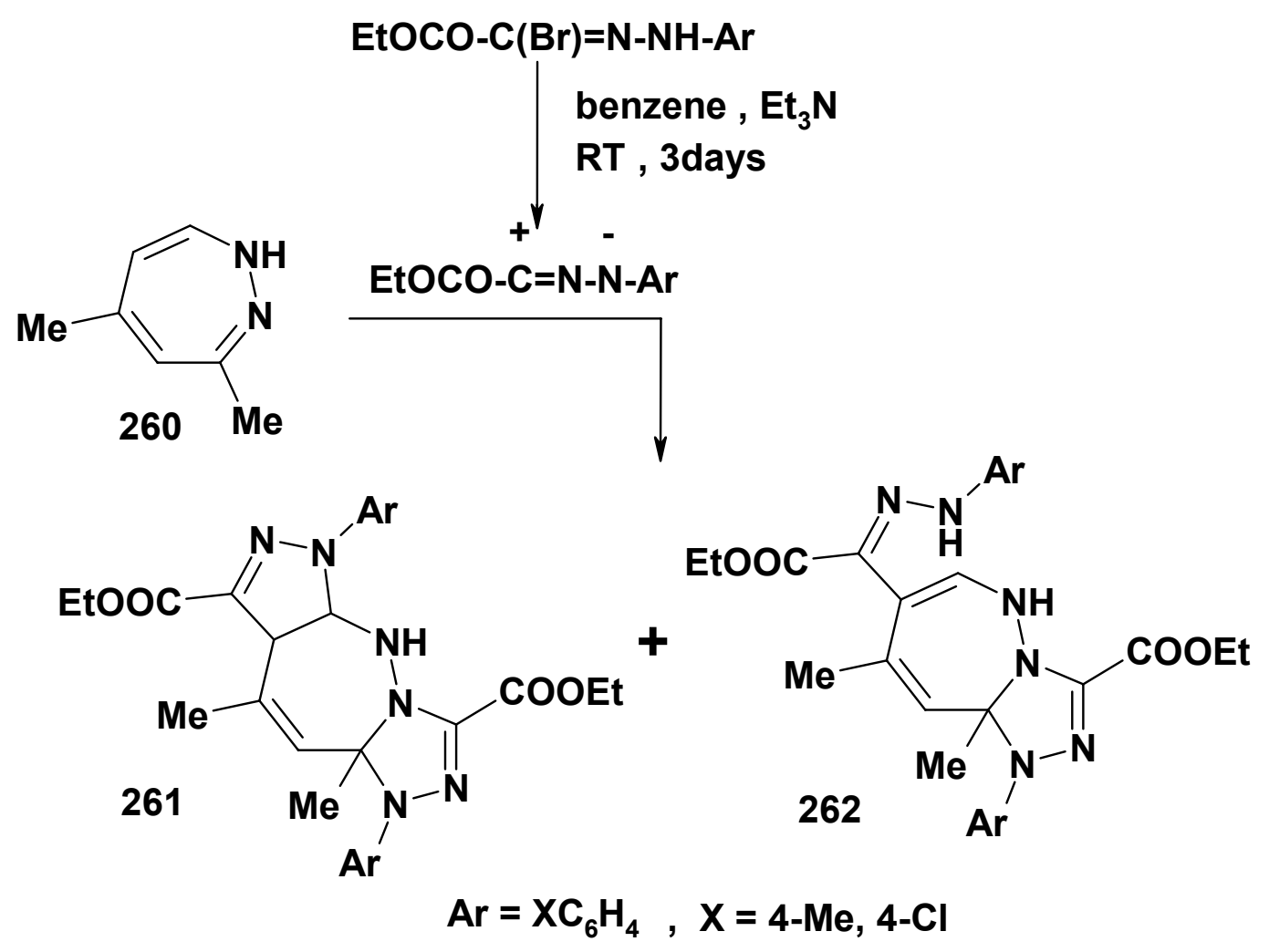

Scheme 89

Reactions of nitrilimines with indole derivatives 263 were reported to give products that depend on the type and site of the substituent(s) present. For example, unsubstituted indole reacted with $C$-acetyl- and $C$-ethoxycarbonyl- nitrilimines and gave the respective 1,3-adducts 264 in $24-30 \%$ yields (Scheme 90$){ }^{93}$

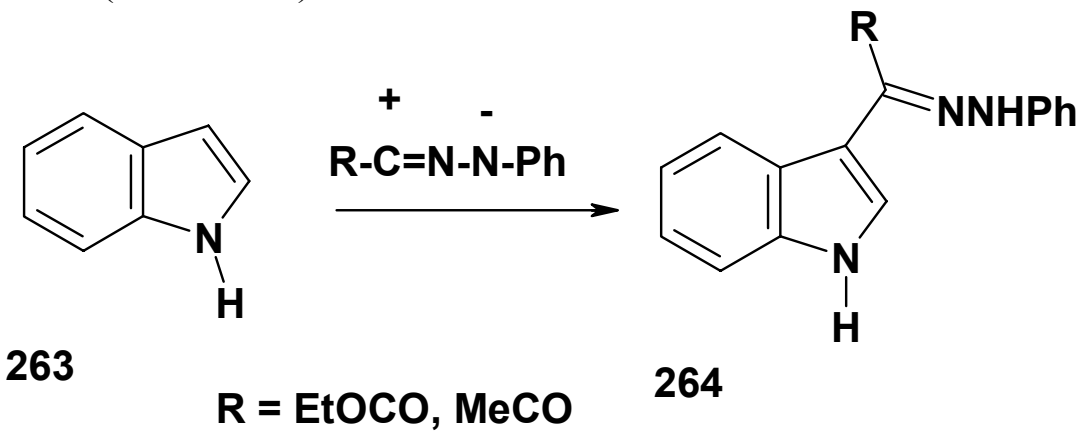

Scheme 90 
Similar reactions of 2-methyl- and 2-phenylindoles 265 with the same nitrilimines were reported to give in each case the respective 1,3-adducts 266 in 14-45\% yields (Scheme 91). ${ }^{93}$

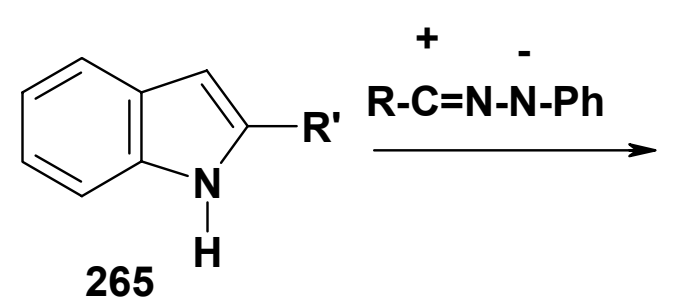

R / R' : EtOCO / Me; EtOCO / Ph; MeCO / Me; MeCO / Ph

\section{Scheme 91}

On the other hand, Ruccia et al. reported that reactions of $N$-substituted indoles 267 with nitrilimines gave a mixture of the respective 1,3-cycloadduct 268 (in 35-36\% yields) and 1,3adduct 269 (8-13\% yields) (Scheme 92). ${ }^{89,93-95}$<smiles>[R]C(=NNc1ccccc1)c1cn([R2])c2ccccc12</smiles>

\section{R / R' : EtOCO / Me; MeCO / Ph; MeCO/ PhNHN=C(COMe)}

\section{Scheme 92}

$C, N$-diarylnitrilimines reacted with each of 1-methylindole ${ }^{96}$ and 1-ethylindole ${ }^{97} \mathbf{2 6 7}$ and gave in each case only the respective 1,3-cycloadducts $\mathbf{2 6 8}$. However, a mixture of the respective cycloadducts $\mathbf{2 6 8}$ and the 1,3-adducts $\mathbf{2 6 9}$ was produced in reaction of diphenylnitrilimine with 1-methylindole (Scheme 93). ${ }^{96}$ 


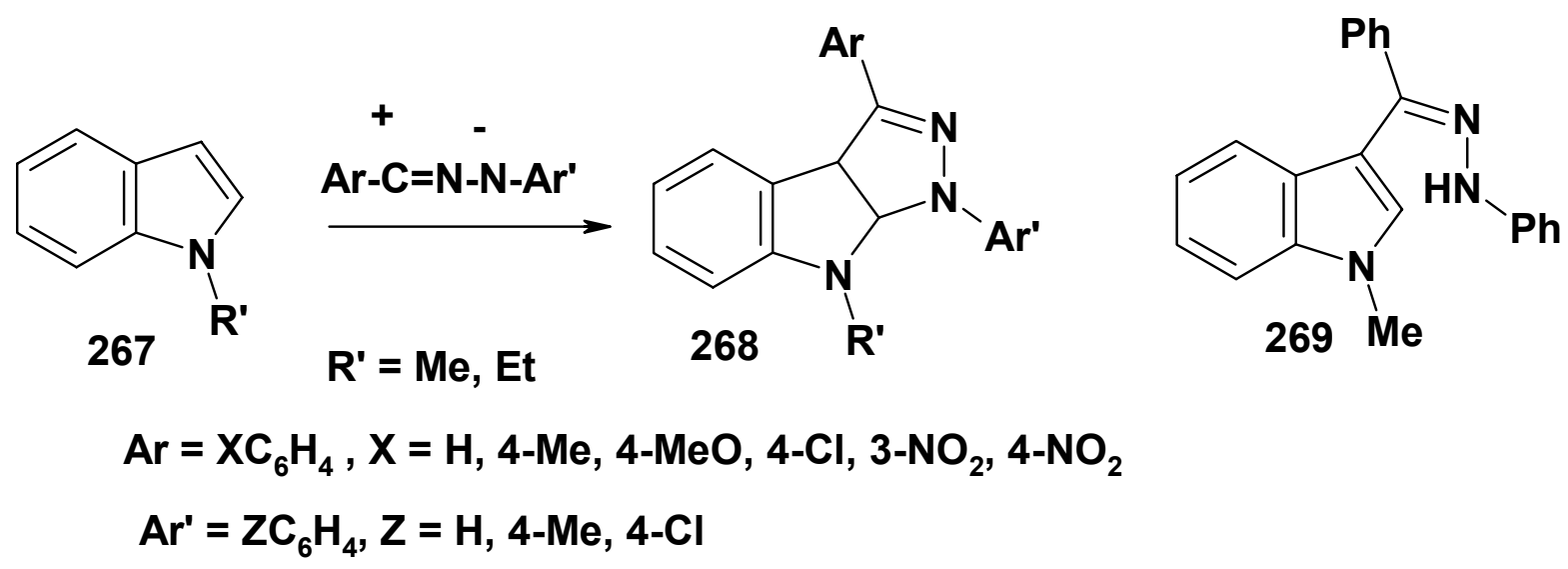

Scheme 93

Heating the latter cycloadducts $\mathbf{2 6 8}$ in acetic acid afforded 1,3-diaryl-4-(2alkylaminophenyl)pyrazoles $\mathbf{2 7 0}$ in $90-95 \%$ yields. ${ }^{96,97}$ Also, the cycloadducts $\mathbf{2 6 8}$ were oxidized with lead tetraacetate in dichloromethane and gave the respective 8 -alkylpyrazolo[3,b] indole derivatives 271 (Scheme 94 ). ${ }^{96}$

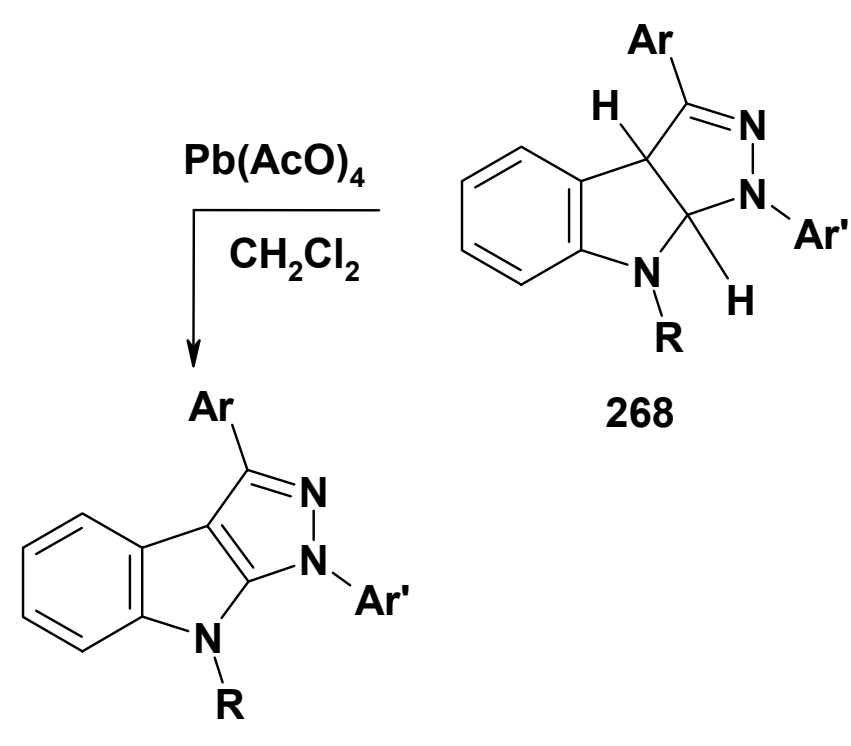

271
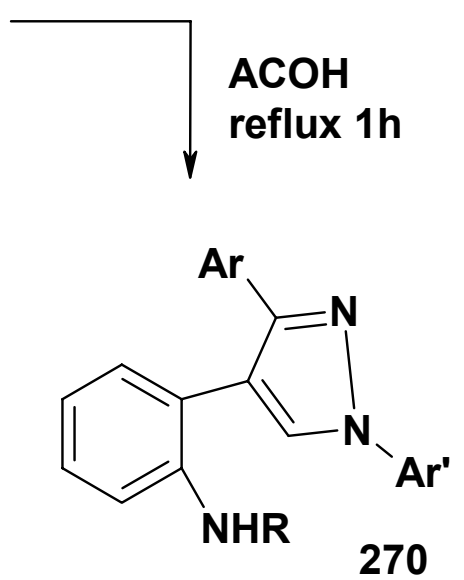

\section{Scheme 94}

Furthermore, while 1,2-dimethylindole 272 reacted with each of $C$-acetyl- and $C$ ethoxycarbonyl- $N$-phenylnitrilimine and gave the respective 1,3 -adducts $\mathbf{2 7 3}^{93}$ in $63-64 \%$ yield, reactions of 1,3-dimethylindole 274 with the same nitrilimines gave the 1,3-cycloadduct 275 in $4 \%$ yield (Scheme 95$).{ }^{93}$ 


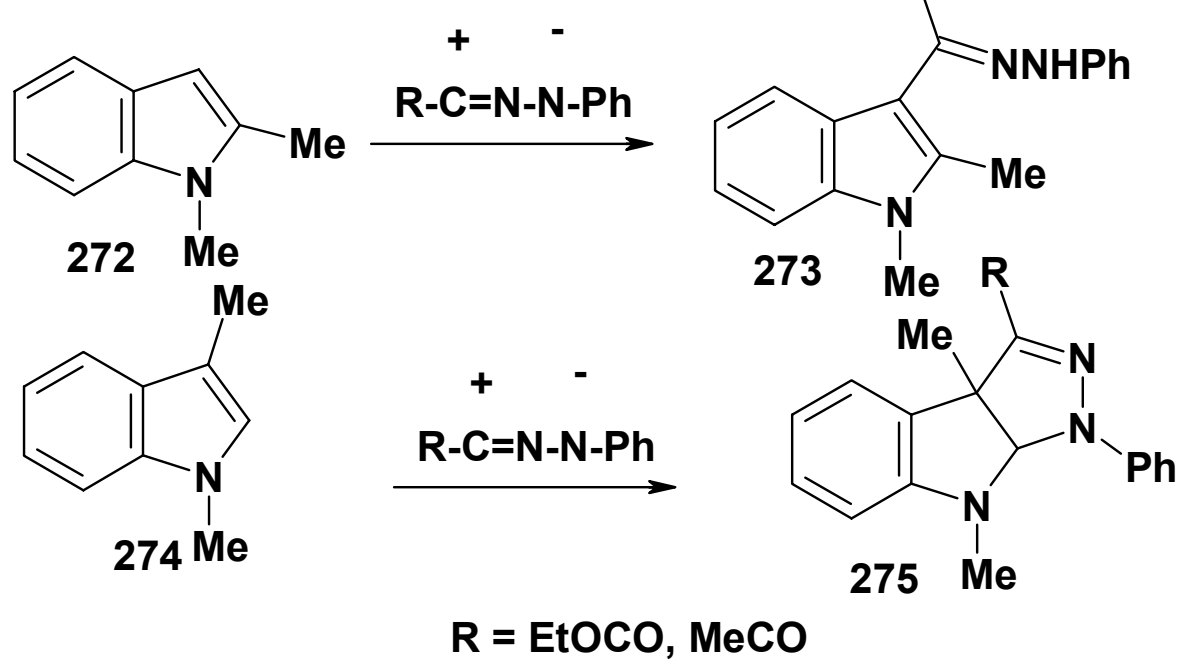

\section{Scheme 95}

Reaction of $N$-phenyl- $C$-acetylnitrilimine with 1-methyl-2-ethoxycarbonylindole 276 was reported by Ruccia et al. ${ }^{93}$ to give the cycloadduct 277 which was converted into the hydrazone derivative $\mathbf{2 7 8}$ upon heating in acetic acid (Scheme 96).

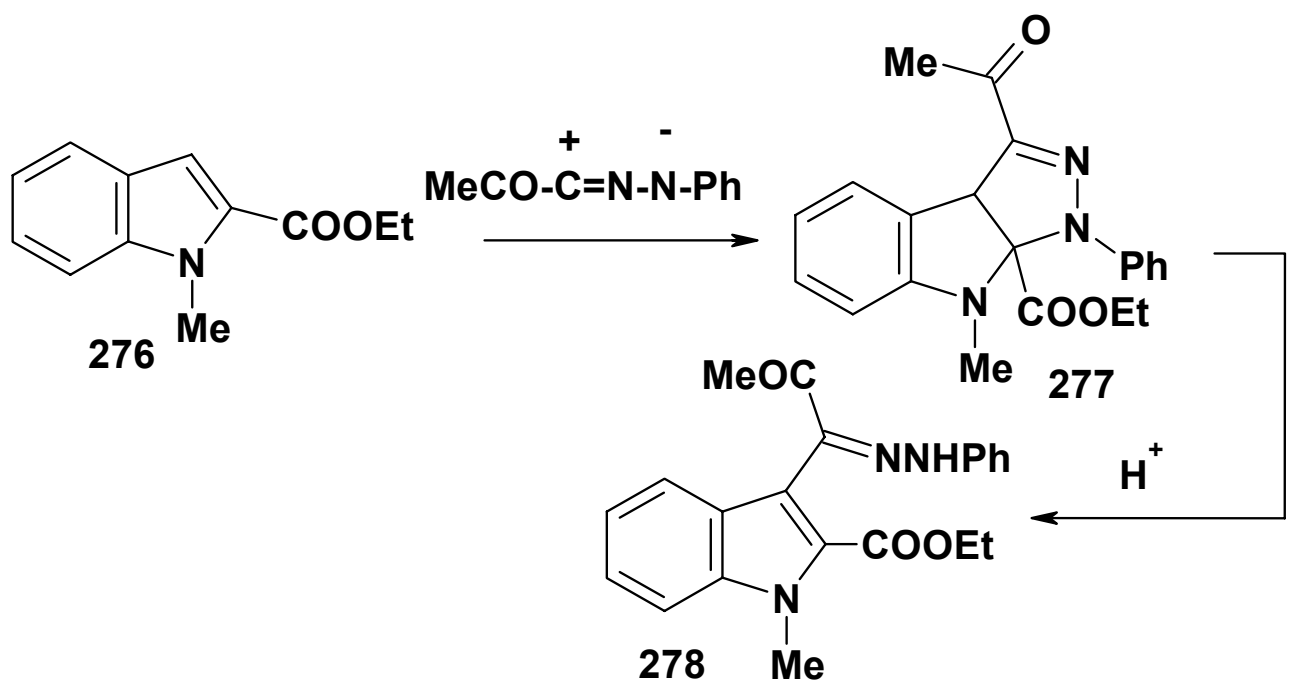

\section{Scheme 96}

However, similar reactions of diarylnitrilimines with other 1-alkyl-2-alkoxycarbonylindoles 279 in benzene were reported to follow a different regiochemical pathway to give $\mathbf{2 8 0}$. $^{97,98}$ Heating the latter products in acetic acid or in ethanol in the presence of hydrochloric acid afforded in each case a mixture of $\mathbf{2 8 1}$ and $\mathbf{2 8 2}$ (Scheme 97). ${ }^{98}$ 
<smiles>[R]OC(=O)c1cc2ccccc2n1[R]</smiles><smiles>[R]Oc1nc2ccccc2c2c1c([Al])nn2-c1ccccc1</smiles>

\section{R / R' = Et / Me; Me / Et; $\mathrm{PhCH}_{2} / \mathrm{Et}$ \\ $\mathrm{Ar}=\mathrm{Ph}, 4-\mathrm{MeC}_{6} \mathrm{H}_{4}$}

\section{Scheme 97}

Reactions of the indole derivative $\mathbf{2 8 3}$ with $C$-ethoxycarbonyl- and $C$-acetyl- $N$ phenylnitrilimines yielded in each case a mixture of the respective cycloadduct 284 in $27-60 \%$ yields and the 1,3-adducts 285 in 7-8\% yield. ${ }^{93}$ Reactions of the indole derivative 286 with Cacetyl-N-phenylnitrilimines followed the same regiochemical pathway and yielded only the cycloadduct 287 (Scheme 98). ${ }^{93}$

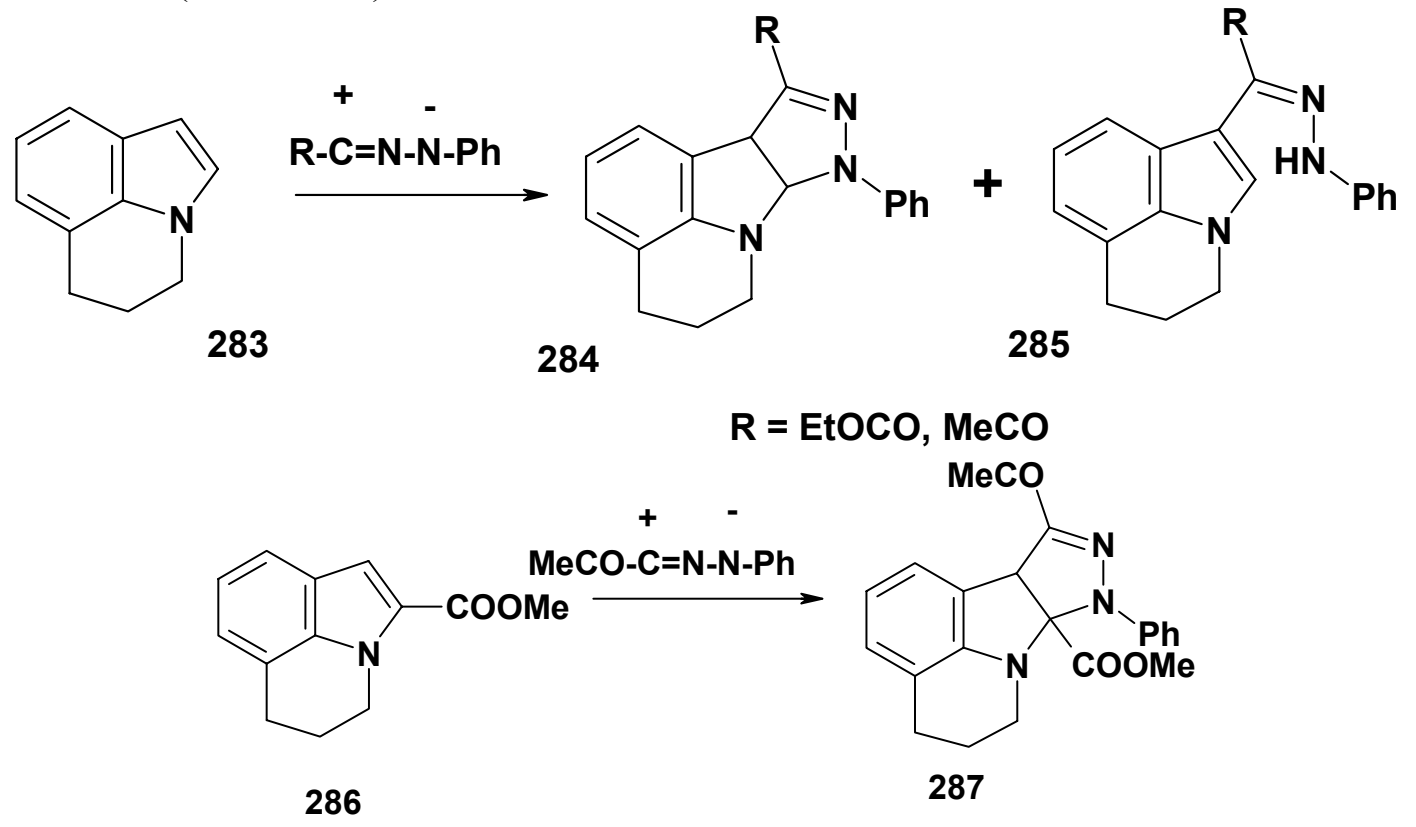

Scheme 98 
Reaction of $C, N$-diarylnitrilimine with the heterocyclic enamine $\mathbf{2 8 8}$ proceeded regio- and stereoseletively to yield the cycloadducts $\mathbf{2 8 9}$ as the sole product. Heating this product in acetic acid for $1 \mathrm{~h}$ afforded $\mathbf{2 9 0}$. Saponification of either $\mathbf{2 8 9}$ or $\mathbf{2 9 0}$ with $2 \mathrm{~N}$ methanolic $\mathrm{KOH}$ followed by acidification yielded, in both cases, the respective tricyclic derivative 291 in $58 \%$ yield (Scheme 99). ${ }^{99}$

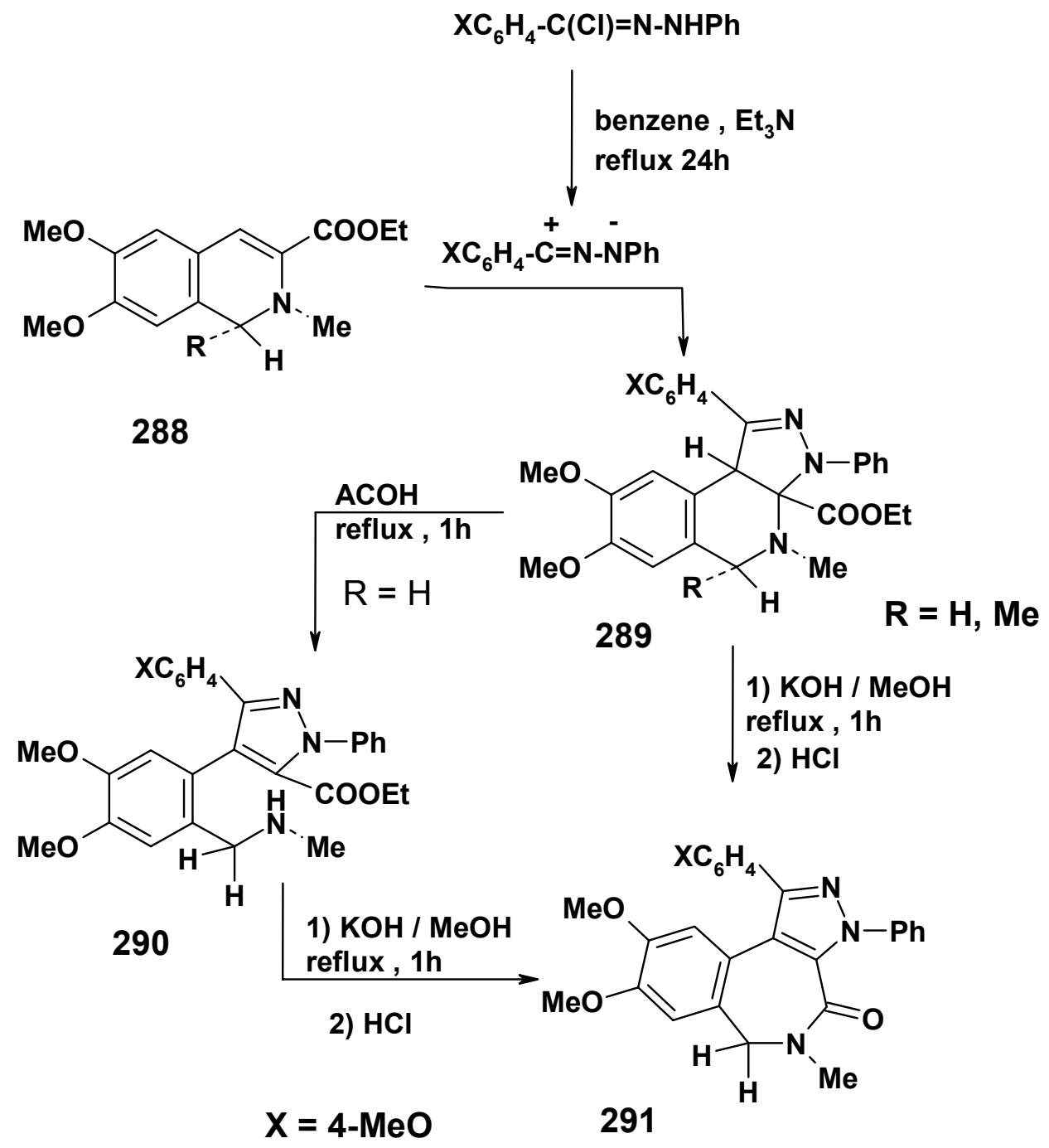

Scheme 99

Also, reaction of $C, N$-diarylnitrilimines with 2-alkyl-1-phenyl-1,2-dihydroisoquinolines (292) was reported to give mainly the cycloadducts 293 as a mixture of stereoisomers which underwent ring cleavage upon acid treatment to yield the respective pyrazole derivatives 294 (Scheme 100). ${ }^{100}$ 


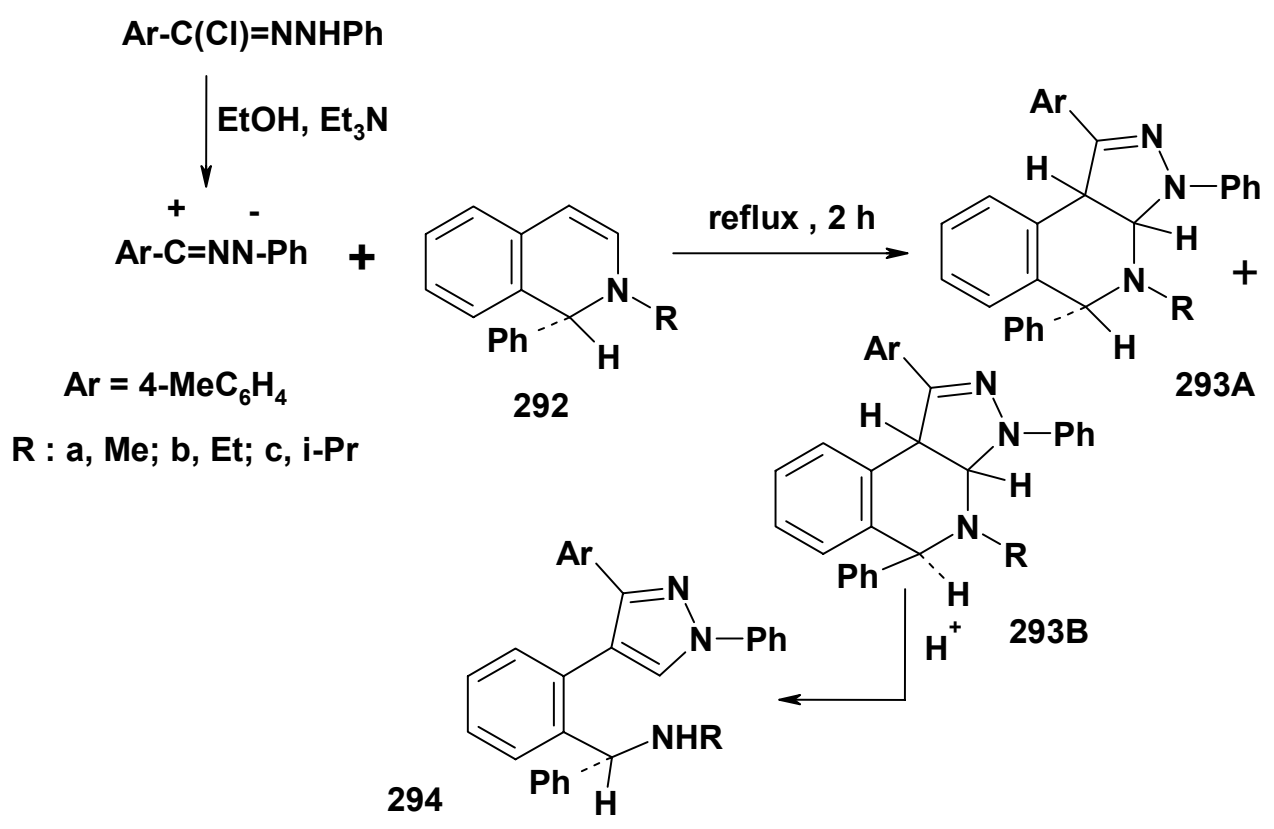

Scheme 100

\subsection{Ketene aminals}

Reactions of $C$-acyl- $N$-arylnitrilimines with the ketene aminals 295 at room temperature in dry benzene in the presence of triethylamine were reported to give the pyrazole derivatives 296 in $80-85 \%$ yield. $^{57}$ The latter products underwent deamination upon heating in chloroform or in ethanol in the presence of $\mathrm{HCl}$ to give rise the respective aminopyrazoles 297 in $85-90 \%$ yields (Scheme 101). ${ }^{57}$

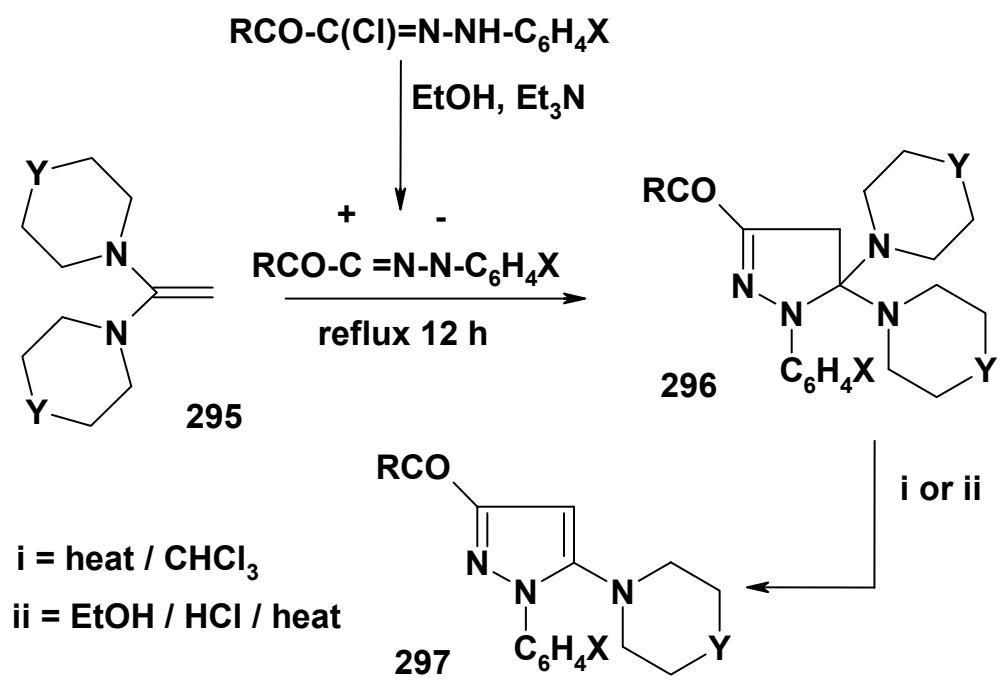

$$
\mathrm{R}=\mathrm{EtO}, \mathrm{Me} ; \quad \mathrm{X} / \mathrm{Y}: \mathrm{H} / \mathrm{O}, \mathrm{H} / \mathrm{CH} 2,4-\mathrm{MeO} / \mathrm{O}, 3-\mathrm{F}_{3} \mathrm{C} / \mathrm{O}
$$

Scheme 101 
The reaction of $\mathrm{C}, \mathrm{N}$-diarylnitrilimines with the ketenaminals 298 in $\mathrm{HCCl}_{3}$ at room temperature afforded the respective pyrazole derivative 299. ${ }^{101}$ However , similar reaction of N(2,4-dinitrophenyl)-benzenecarbohydrazonoyl bromide with 298 under the same conditions furnished only the hydrazones $\mathbf{3 0 0}$ in $75-95 \%$ yield. Heating the latter $\mathbf{3 0 0}(\mathrm{n}=0, \mathrm{R}=\mathrm{H})$ in xylene for $10 \mathrm{~h}$ gave the respective pyrazole derivative 301 in $45 \%$ yield. ${ }^{101} \mathrm{Such}$ results were considered to indicate that reaction of nitrilimines with $\mathbf{2 9 8}$ is stepwise reaction. It starts with the formation of 1,3-adduct followed by the cyclization. This was further confirmed by the finding that reaction of the ketene aminal 302 with $\mathrm{C}, \mathrm{N}$-diphenylnitrilimine and $\mathrm{N}$-(2,4-dinitrophenyl)C-phenylnitrilimine under similar conditions afforded 303 (55\% yield) and 304 (80\% yield), respectively (Scheme 102). ${ }^{101}$

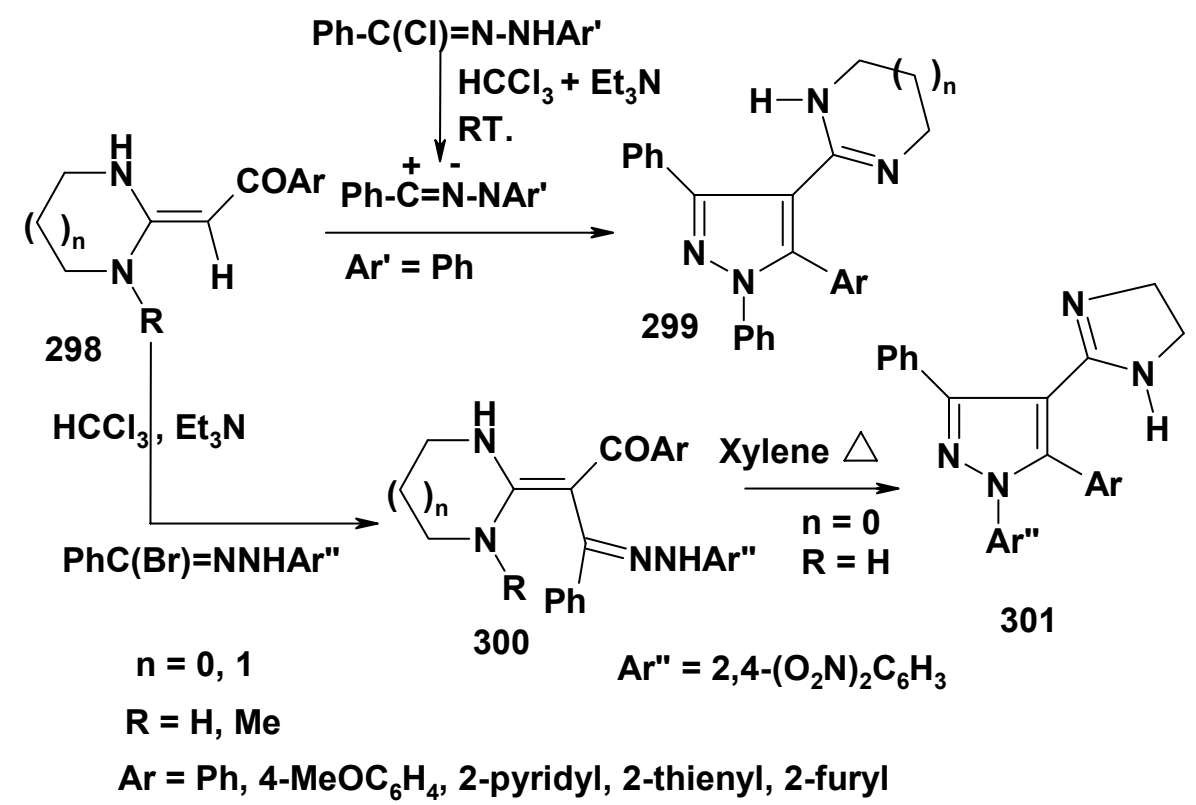

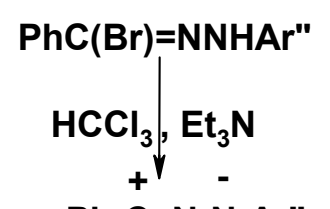

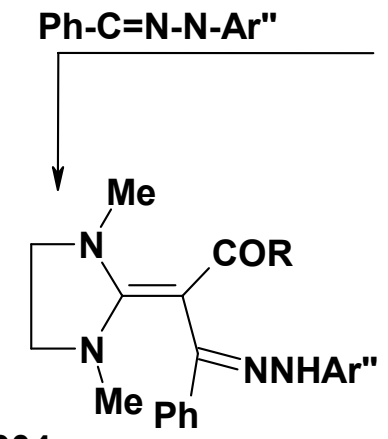

304

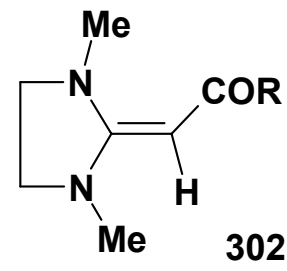

$\mathrm{Ph}-\mathrm{C}(\mathrm{Cl})=\mathrm{N}-\mathrm{NHPh}$

R = 2-Furyl

RT.
$\mathrm{HCCl}_{3}+\mathrm{Et}_{3} \mathrm{~N}$

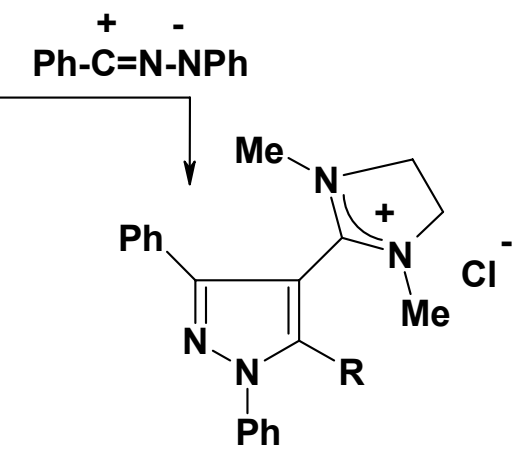

303

Scheme 102 


\section{Conclusions}

From the foregoing reports that have been covered in this review, it is obvious that the reactions of nitrilimines with both heterocyclic amines and enamines provide wide synthetic strategies for annulation and ring-transformation of various heterocycles. It is hoped that it will stimulate further research groups throughout the world to explore more the utility of such reactions in the synthesis of novel heterocycles and natural products.

\section{References}

1. Shawali, A. S.; Albar, H. A. Can. J. Chem. 1986, 64, 871.

2. Shawali, A. S.; Abdelkhalik, A. A.; Sayed, A. R. J. Chin. Chem. Soc. 2001, 48, 693.

3. Shawali, A. S.; Elwan, N. M.; Awad, A. M. J. Chem. Res. 1997, (S) 268, (M) 1870.

4. Shawali, A. S.; Parkanyi, C. J. Heterocycl. Chem. 1980, 17, 833.

5. Shawali, A. S. Heterocycles 1983, 20, 2239.

6. Shawali, A. S. Chem. Rev. 1993, 93, 2731.

7. Shawali, A. S.; Abdallah, M. A. Adv. Heterocycl. Chem. 1995, 63, 277.

8. Shawali, A. S.; Elsheikh, S. M. J. Heterocycl. Chem. 2001, 38, 541.

9. Shawali, A. S.; Mosselhi, M. A. N. J. Heterocycl. Chem. 2003, 40, 725.

10. Negri, G.; Kascheres, C.; Kascheres, A. J. J. Heterocycl. Chem. 2004, 41, 461.

11. Erian, A. W. Chem. Rev. 1993, 93, 1991.

12. Wamhoff, H. Adv. Heterocyclic Chem. 1985, 38, 357.

13. Cuccovia, A. M.; Quina, F. H.; Chaimovich, H. Tetrahedron 1982, 38, 1972.

14. Albert, A. Adv. Heterocyclic Chem. 1982, 32, 1.

15. Hosti, L.; Schenone, P.; Menozzi G. J. Heterocycl. Chem. 1980, 17, 61.

16. Taylor, E. C. and Mckillop, M. The Chemistry of Cyclic Enaminonitriles and orthoAminonitriles, Wiley, New York 1970, p. 306.

17. Blaha, K.; Cervinka, O. Adv. Org. Chem. 1963, 4, 1.

18. Elgemeie, G. H.; Elfahham, H. A.; Ghozlan, S. A. S.; Elnagdi, M. H. Bull. Chem. Soc. Jpn. 1984, 57, 1650.

19. Elfahham, H. A.; Abdel-Latif, F. F.; Mohamed, S. K. Indian J. Chem. 1990, 29B, 381.

20. Elgemeie, G. H.; Elghandour, A. H.; Elshimy H. M. J. Prakt. Chem. 1989, 331, 466.

21. Elghandour, A. H. J. Chem. Res. 1993 (S) 358, (M) 2384.

22. Elfahham, H. A.; Sadek, K. U.; Elgemeie, G. E. H. and Elnagdi, M. H., J. Chem. Soc. (Perkin Trans. 1) 1982, 2663.

23. Ibrahim, M. K. A.; Elgharib, M. S.; Farag, A. M.; Elmoghayer, A. M. J. Indian Chem. Soc. 1988, 65, 194.

24. Abdelhamid, A. O.; Hassaneen, H. M.; Shawali, A. S. and Parkanyi, C. J. Heterocycl. Chem. 1983, 20, 639 . 
25. Farag, A. M.; Shawali, A. S.; Algharib, M. S.; Dawood, K. M. Tetrahedron 1994, 50, 5091.

26. Gallos, J. K.; Corobili, E. F. Synthesis 1989, 751.

27. Croce, P. D.; Ioannisci, M. and Licandro, E. J. Chem. Soc. Perkin Trans. I 1979, 330.

28. Ibrahim, M. K. A.; Elgharib, M. S.; Farag, A. M.; Elghandour, A. H. Indian J. Chem. 1988, $27 B, 836$.

29. Graf, H.; Klebe, G. Chem. Ber. 1987, 120, 965.

30. Shawali, A. S.; Abdelkader; M. H., and Altalbawy, F. M. A. Tetrahedron, 2002, 58, 2875.

31. Shawali, A. S.; Harb, N. M. S.; Badahdah, K. O. J. Heterocycl. Chem. 1985, 22, 1397.

32. Shawali, A. S.; El-Sheikh, S. J. Heterocycl. Chem. 2003, 40, 207.

33. Shawali, A. S.; Farghaly, T. A. Tetrahedron 2004, 60, 3051.

34. El-Fahham, H. A.; El-Gemeie, G. E. H.; Ibraheim, Y. R.; Elnagdi, M. H. Liebigs Ann. Chem. 1988, 819.

35. Awadallah, A. M.; Seppelt, K.; Shorafa, H. Tetrahedron 2006, 62, 7744.

36. Shawali, A. S.; Zeid, I. F.; Abdelkader, M. H.; Elsherbini, A. A.; Altalbawy, M. A. J. Chin. Chem. Soc. 2001, 48, 65.

37. Butler, R. N.; Eithne, P.; Bhradaigh, N.; Fitzgerald, K. J. J. Chem .Res. 1993, 306.

38. Ghozlan, S. A. S.; Hafez E. A. A.; El-Bannany, A. A. A. Arch. Pharm., $(W)$ 1987, 320, 850.

39. Elnagdi, M. H.; Zayed, E. M.; Khalifa; M. A. F.; Ghozlan, S. A. Monatsch. Chem. 1981, 112, 245.

40. Ito, S.; Tanaka, Y.; Kakehi, A.; Miyazawa, H. Bull. Chem. Soc, Jpn. 1977, 50, 2969.

41. Shawali, A. S.; Elghandour, A. A.; Elsheikh, S. M. Heteroatom Chem. 2000, 11, 87.

42. Shawali, A. S.; Abdallah, M. A.; Zayed, M. M. J. Heterocycl. Chem. 2002, 39, 45.

43. Shawali, A. S.; Sayed, A. R. J. Chem. Res. 2004, 399.

44. Hassaneen, H. M.; Abdelhadi, H. A. Tetrahedron 2001, 57, 10133.

45. Mosselhi, M. A. N. Monatsch. Chem. 2002, 133, 1297.

46. Mosselhi, M. A. N.; Abdallah, M. A.; Farghaly, T. A.; Shawali, A. S. Monatsch. Chem. 2004, 135, 211.

47. Abdallah, M. A. Monatsch Chem. 2001, 132, 959.

48. Shawali, A. S.; Mosselhi, M. A. N.; Hussein, A.M. J. Chin. Chem. Soc. 2006, 53, 923.

49. Abdallah, M. A. Z. Naturforsch. 2002, 57b, 699.

50. Shawali A. S.; Elghandour A. A.; Elsheikh S. M. J. Prakt. Chem. 2000, 342, 96.

51. (a) Fusco, R.; Bianchetti, G.; Pocar, D. Gazz. Chim. Ital. 1961, 91, 1233; (b) Kuehne, M. F.; Weaver, S. J.; Franz, P. J. Org. Chem. 1964, 29, 1582.

52. Hassaneen, H. M. E.; Hassaneen, H. M.; Elnagdi, M. H. Z. Naturforsch. 2004, 59b, 1132.

53. Biere, H.; Schroder, E.; Ahrens, H.; Kapp, J. F.; Bottcher, I. European J. Med. Chem. 1982, $17,27$.

54. Oida, T.; Tanimoto, S.; Ikehira, H.; Okano, M. Bull. Chem. Soc. Jpn. 1983, 56, 1203.

55. Donohue, A. C.; Pallich, S.; McCarthy, T. D. J. Chem. Soc., Perkin Trans $12001,2817$.

56. Fliege, W.; Huisgen, R.; Kolbeck, W.; Weberndorfer, V. Chem. Ber. 1983, 116, 3438.

57. Pocar, D.;.Rossi, M.; Stradi, R. Synthesis 1976, 684. 
58. Agawa, T.; Ishikawa, M.; Komatsu, M.;Ohshiro, Y. Bull. Chem. Soc. Jpn. 1982, 55, 1679.

59. Katritzky, A. R.; Musgrave, R. P.; Breytenbach, J. C. J. Heterocycl. Chem. 1996, 33, 1637.

60. Huisgen, R.; Sustmann, R.; Wallbillich, G. Chem. Ber. 1967, 100, 1786.

61. Oida, Y.; Shimizu, T.; Hayashi, Y.; Teramura, K., Bull. Chem. Soc. Jpn. 1981, 54, 1429.

62. Al-Zaydi, K. M.; Hafez, E. A. J. Chem. Res. 1999, (S) 360, (M) 1621.

63. Al-Omran, F.; Al-Awadi; N., El-khair, A. A.; Elnagdi, M. H. Org. Prep. Proc. Int. 1997, 29, 285.

64. Dawood, K. M.; Kandeel, Z. E.; Farag, A. M., Heteroatom. Chem. 1999, 10, 417.

65. Abdelkhalik, M. M.; Elnagdi, M. H.; Agamy, S. M. Synthesis 2000, 1166.

66. Al-Shiekh, M. A.; El-Din, A. M. S.; Hafez, E. A.; Elnagdi, M. H. J. Chem. Res. 2004, 174.

67. Al-Zaydi, K. M. Molecules 2003, 8, 541.

68. Sukhova, L. N.; Ostroumov, I. G.; Bel'skii, V. K.; Maretina, I. A.; Galishev, V. A. Zh. Org. Khim. 1993, 29, 1237 (Chem. Abstr. 1994, 120, 298535j.

69. Samia, M. S.; Khalil, M. A.; Ahmed, M. A.; Raslan, M. A. Synthetic Commun. 2002, 32(2), 481.

70. Pocar, D.; Maiorana, S.; Croce, P. D. Gazz. Chim. Ital. 1968, 98, 949.

71. Ghozlan, S. A. S.; Abdelhamid, I. A.; Gaber, H. M.; Elnagdi, M. H. J. Heterocycl. Chem. 2005, 42, 1185.

72. Ibrahim, M. K.; El-Reedy, A. M.; Elgharib, M. S.; Farag, A. M. J. Indian Chem. Soc. 1987, $64,345$.

73. Ito, S.; Tanaka, Y.; Kakehi, A.; Matsuno, T. Bull. Chem. Soc. Jpn. 1978, 51, 327.

74. Wamhoff, H.; Sohair, P. Chem. Ber. 1971, 104, 3510.

75. Al-Saleh, B.; Metwally, N.H.; Hassaneen, H.M.E.; Elnagdi, M.H. Synthesis, 2006, 59.

76. Kobayashi, K.; Tanaka, K.; Uneda, T.; Maeda, K.; Morikawa, O.; Konishi, H. Synthesis 1998, 1243.

77. Palacios, F.; Pagalday, J.; Piquet, V.; Dahan, F.; Baceiredo, A.; Bertrands, G. J. Org. Chem. 1997, 62, 292.

78. Cardia, M. C.; Corda, L.; Fadda, A. M.; Maccioni, A. M.; Maccioni, E.; Plumitallo A. Il Farmaco 1998, 53, 698.

79. Cardia, M. C.; Maccioni, E.; Bonsignore, L. J. Heterocycl. Chem. 2003, 40, 309.

80. Marki, G.; Baier, H. Tetrahedron Lett. 1972, 4439.

81. Kerbal, A.; Vebrel, J.; Cerutti, E.; Laude, B. J. Chem. Soc., Chem. Commun. 1989, 632.

82. Tshiamala, K.; Kitane, S.; Vebrel, J.; Laude, S. Bull. Soc. Chem. Belg. 1986, 95, 1083.

83. Reinhoudt, D. N.; Kouwenhoven, C. G. Rec. J. Royal Netherland Chem. Soc. 1974, 93, 321.

84. Boyd, G. V.; Montiel, R. L. J. Chem. Soc. Perkin Trans. I 1980, 846.

85. Croce, P.D.; LaRosa, C.; Pocar, D. J. Chem. Res. 1983 (S) 296.

86. Groselj,U.; Svete, J.; Stanovnik, B.; Golic, G. S. Zh. Ref. Posvetovanja Slov. Kem. Dnevi 2000, 147 (Chem. Abstr., 2001, 134, 222669z).

87. Abdallah, T. A. Synth. Commun. 2002, 32, 2459.

88. Fathi, T.; Ciamala, K.; An, N. D.; Vebrel, J. Can. J. Chem. 1994, 72, 1424. 
89. Ruccia, M.; Vivona, N. Tetrahedron Lett. 1972, 4703.

90. Mohrle, H.; Dwuletzki, H. Chem. Ber. 1986, 119, 3591.

91. Ruccia, M.; Vivona, N.; Cusmano, G. J. Heterocycl. Chem. 1978, 15, 293.

92. El-Massaoudi, M.; Hasnaoui, A.; Lavergne, J. P. Synth. Commun. 1994, 24, 513.

93. Ruccia, H.; Vivona, N.; Cusmano, G.; Marino, M. L.; Piozzi F. Tetrahedron, 1973, 29, 3159.

94. Ruccia, M.; Vivona, N.; Piozzi, F.; Aversa, M. C. Gazz. Chim. Ital. 1969, 99, 588.

95. Ruccia, M.; Vivona, N.; Cusmano, G.; Marino, M. L. Gazz. Chim. Ital. 1970, 100, 358.

96. Laude, B.; Soufiaoui, M.; Arriau, J. J. Heterocycl. Chem. 1977, 14, 1183.

97. Daou, B.; Soufiaoui, M.; Carrie, R. J. Heterocycl. Chem. 1989, 26, 1485.

98. Daou, B.; Soufiaoui, M. Tetrahedron 1989, 45, 3351.

99. Moustaid, K.; Nguyen, D. A.; Laude, B.; Mercier, M. F.; Sedqui, A. Can. J. Chem. 1992, 70, 802.

100.Kitane, S.; Sebban, A.; Vebrel, J.; Laude, B. Bull. Soc. Chim. Belg. 1989, 98, 105 (Chem. Abstr., 1989, 111, 231663v).

101.Liu, B.; Wang, M. X.; Huang, Z. T. Tetrahedron Lett. 1999, 40, 7399.

\section{Biographical Sketches}

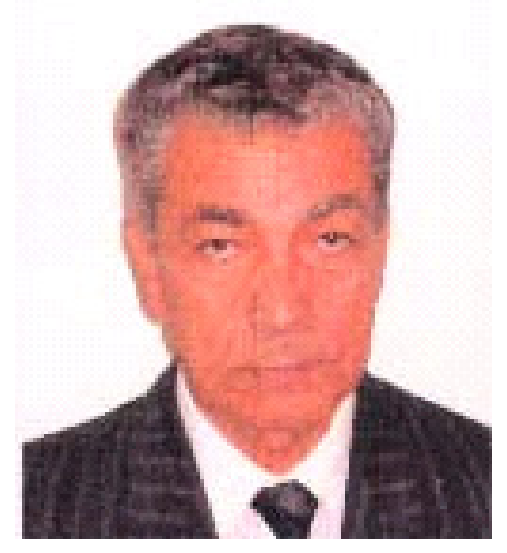

Ahmad Sami A. S. Shawali is presently Professor of Physical organic chemistry in the Chemistry Department, Faculty of Science, University of Cairo. He graduated with B.Sc. degree from the same university in 1958. He received his M.Sc. and Ph.D. degrees in 1962 and 1966, respectively, from Lowell Technological Institute, presently The University of Lowell, Lowell, Massachusetts, USA. He was awarded the degree of Doctor of Science (D.Sc.) from British Royal Chemical Society and the University of Cairo in 1995. Prof. Shawali has been the recipient of the state award for science and Egypt State Medal of Science and Arts in 1977. He holds several national and international certificates of merit for his distinguished services. He was visiting professor at the university of Texas, El Paso, Texas, USA from 1979 to 1980, University of Kuwait from 1973 to 1977 and King Abdulaziz University, Jeddah, Saudi Arabia 
from 1982 to 1988. He was appointed Vice-Dean for student affairs in 1989, then he was elected Dean of the Faculty of Science in 1991. He published 204 papers including 8 review articles in the fields of reaction mechanisms, applications of LFERs, chemistry of hydrazonoic acid derivatives, 1,3-dipolar cycloaddition and electrocyclization of nitrilimines. At present the average numbers of citations of his work by other authors are 50/year and 9/paper.

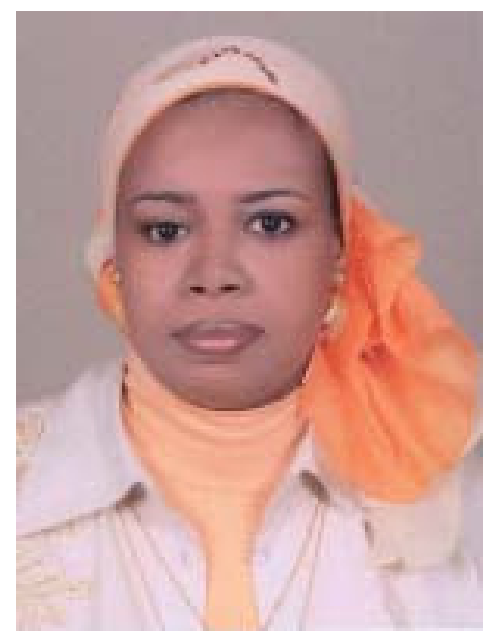

Mastoura Mohamed Edrees Abdou was born in Egypt in 1974. She was educated at Cairo University (1992-1996) and graduated with B.Sc. degree in chemistry from Faculty of Science, University of Cairo in 2001. She received her Ph.D. degree in 2004 in organic chemistry from Faculty of Science, University of Cairo, Giza, Egypt in 2004. She was appointed as Researcher in the National Organization of Drug control and Research department of Pharmaceutical Chemistry. 